\title{
Preliminary Human Factors Design Guidelines for Driver Information Systems
}




\section{FOREWORD}

The purpose of this report is to provide preliminary design guidelines for driver information systems using auditory or visual display techniques. The guidelines are based on field and lab experience with pre-competitive interface designs, as well as the human factors engineering literature.

This report will be useful to the designers of driver information systems and scientists conducting driving-related human factors research in academia, industry, or government agencies.

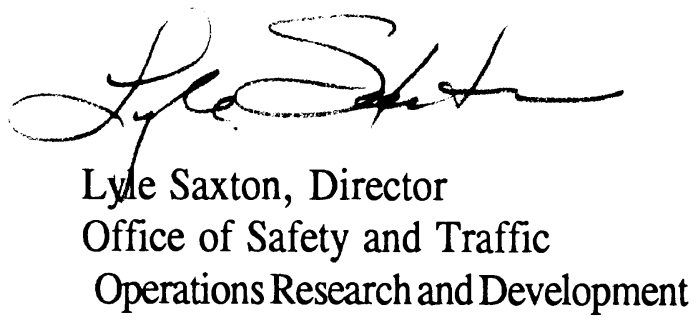

\section{NOTICE}

This document is disseminated under the sponsorship of the Department of Transportation in the interest of information exchange. The United States Government assumes no liability for its contents or use thereof. This report does not constitute a standard, specification, or regulation.

The United States Government does not endorse products or manufacturers. Trade and manufacturers' names appear in this report only because they are considered essential to the object of the document. 


\begin{tabular}{|c|c|}
\hline $\begin{array}{l}\text { 1. Report No. } \\
\text { FHWA-RD-94-087 }\end{array}$ & 3. Recipient's Catalog No. \\
\hline \multirow{2}{*}{$\begin{array}{l}\text { 4. Title and Subtitle } \\
\text { PRELIMINARY HUMAN FACTORS DESIGN GUIDELINES FOR DRIVER } \\
\text { INFORMATION SYSTEMS }\end{array}$} & $\begin{array}{l}\text { 5. Report Date } \\
\text { December } 1995\end{array}$ \\
\hline & $\begin{array}{r}\text { 6. Performing Organization Code } \\
\text { account } 303571 \\
\end{array}$ \\
\hline $\begin{array}{l}\text { 7. Author(s) } \\
\text { Paul Green, William Levison, Gretchen Paelke, and Colleen Serafin }\end{array}$ & $\begin{array}{l}\text { 8. Performing Organization Report No. } \\
\text { UMTRI-93-21 }\end{array}$ \\
\hline $\begin{array}{l}\text { 9. Performing Organization Name and Address } \\
\text { The Universitv of Michiaan }\end{array}$ & $\begin{array}{l}\text { 10. Work Unit No. (TRAIS) } \\
\text { 3B3B-2032 }\end{array}$ \\
\hline Transportation Research Institute & $\begin{array}{l}\text { 11. Contract or Grant No. } \\
\text { DTFH61-89-C-00044 }\end{array}$ \\
\hline 2901 Baxter Road, Ann Arbor, Michigan 48109-2150 & 13. Type of Report and Period Covered \\
\hline $\begin{array}{l}\text { 12. Sponsoring Agency Name and Address } \\
\text { Office of Safety and Traffic Operations R\&D }\end{array}$ & $\begin{array}{l}\text { Final Report } \\
\text { September } 1991 \text { - May } 1993\end{array}$ \\
\hline $\begin{array}{l}\text { Federal Highway Administration } \\
6300 \text { Georgetown Pike, McLean, Virginia 22101-2296 }\end{array}$ & 14. Sponsoring Agency Code \\
\hline
\end{tabular}

15. Supplementary Notes

This research was jointly funded by the Federal Highway Administration and the National Highway Traffic Safety Administration. Contracting Officer's Technical Representative (COTR): Nazemeh Sobhi, HSR-30.

16. Abstract

This document is written for the designers of IVHS-related driver information systems. It describes how to make those systems safe and easy to use for ordinary drivers. These guidelines are based on experimental work carried out as part of this project, the literature, and the authors' human factors experience.

This document includes a description of its objectives, general design principles, and guidelines for the design of manual controls, spoken input, visual displays, auditory displays, destination entry, visual displays for navigation, auditory displays for navigation, traffic information, car phones, vehicle monitoring, IVSAWS (a hazard warning system), interface integration, as well as an extensive reference section. For most guidelines, a commentary and examples of how they should be applied are provided.

These guidelines should be viewed as preliminary.

\begin{tabular}{|l|l|l|l|}
\hline $\begin{array}{l}\text { 17. Key Words } \\
\text { IVHS, human factors engineering, ergonomics, } \\
\text { navigation, driver information system, test methods. }\end{array}$ & $\begin{array}{l}\text { 18. Distribution Statement } \\
\text { No restrictions. This document is available to the public } \\
\text { through the National Technical Information Service, } \\
\text { Springfield, Virginia 22161. }\end{array}$ \\
\begin{tabular}{|l|c|c|} 
19. Secunity Classif. (of this report) \\
unclassified
\end{tabular} & $\begin{array}{l}\text { 20. Security Classif. (of this page) } \\
\text { unclassified }\end{array}$ & 111 & 21. No. of Pages \\
\end{tabular}




\section{PREFACE}

\section{PROJECT OVERVIEW}

The United States Department of Transportation (DOT), through its Intelligent VehicleHighway Systems (IVHS) program, is aiming to develop solutions to the most pressing problems of highway travel. The goal is to reduce congestion and improve traffic operations, reduce accidents, and reduce air pollution from vehicles by applying computer and communications technology to highway transportation. If these systems are to succeed in solving the Nation's transportation problems, they must be safe and easy to use, with features that enhance the experience of driving. A project was carried out to help develop IVHSrelated driver information systems for cars of the future. This project concerns the design of the driver interface, the controls and displays that the driver interacts with, as well as their presentation logic and sequencing.

The project had three objectives:

- Provide human factors guidelines for the design of in-vehicle information systems.

- Provide methods for testing the safety and ease of use of those systems.

- Develop a model that predicts driver performance in using those systems.

Although only passenger cars were considered in the study, the results apply to light trucks, minivans, and vans as well because their driver population and likely use are similar to cars. Another significant constraint was that only able-bodied drivers were considered. Disabled and impaired drivers are likely to be the focus of future DOT research.

A complete list of the driver interface project reports and other publications is included in the final overview report, 1 of 16 reports that document the project. ${ }^{[1]}$ (See also reference 2 for an overview.) To put this report in context, the project began with a literature review and focus groups examining driver reactions to advanced instrumentation. ${ }^{[3,4,5]}$ Subsequently, the extent to which various driver information systems might reduce accidents, improve traffic operations, and satisfy driver needs and wants, was analyzed. ${ }^{[6,7]}$ That analysis led to the selection of two systems for detailed examination (traffic information and car phones). Three additional systems (route guidance, road hazard warning, and vehicle monitoring) were also included.

Each of the five systems selected was examined separately in a sequence of experiments. In a typical sequence, patrons at a local driver licensing office were shown mockups of interfaces, and driver understanding of the interfaces and preferences for them was investigated. Interface alternatives were then compared in laboratory experiments involving response time, performance on driving simulators, and part-task simulations. The results for each system are described in separate reports. (See references 8 through 14.) To check the validity of those results, several on-road experiments were conducted in which performance and preference data for the various interface designs were obtained. ${ }^{[15,16]}$ 
Test methods and evaluation protocols, design guidelines, and a model to predict driver performance while using in-vehicle information systems were concurrently developed. (See references 17 through 21.)

Many of the reports from this project were originally dated May 1993, the contractual end date of the project whereby reports were to be delivered. However, the reports were actually drafted when the research was conducted, more than 2 years earlier for the literature review and feature evaluation, and a year earlier for the laboratory research and methodological evaluations. While some effort was made to reflect knowledge gained as part of this project, the contract plan did not call for rewriting reports to reflect recent findings.

\section{GUIDELINES REPORT}

This report provides suggested guidelines for the design of driver information systems for cars of the future, though the material is also applicable to retrofits. The guidelines were developed as a result of experience gained in building prototype driver information systems. The guidelines are based upon experimental work carried out as part of this project, the literature, and the authors' human factors expertise.

Specifically, the contract stated the following:

Based on the information from preceding work, develop comprehensive human factors guidelines. Guidelines shall be of three types: general, function specific, and integral.

- General guidelines are broad ergonomic design considerations which are applicable to any in-vehicle information system.

- Function specific guidelines are those human factors design considerations that are specific to the display(s), control interface and system architecture used for a particular function.

- Integral guidelines are concerned with human factors design considerations when two or more functions are used together in a partial or fully integrated information system.

In the title of the report, the word preliminary appears and the authors want to emphasize its importance. Some may be tempted to take the guidelines offered here and convert them into legal requirements. These guidelines have been reviewed by the authors, a few selected others working for the contractor and a subcontractor, the Contracting Officer's Technical Representative, and others at the Department of Transportation. The DOT reviewed only the technical quality of this report, not the adequacy of these guidelines as DOT regulations.

These guidelines are by no means complete, but represent a first attempt to develop guidance based upon "lessons learned" in the laboratory and on the highway. They should not be thought of as design requirements. Nonetheless, they should be very useful for designing real products. 


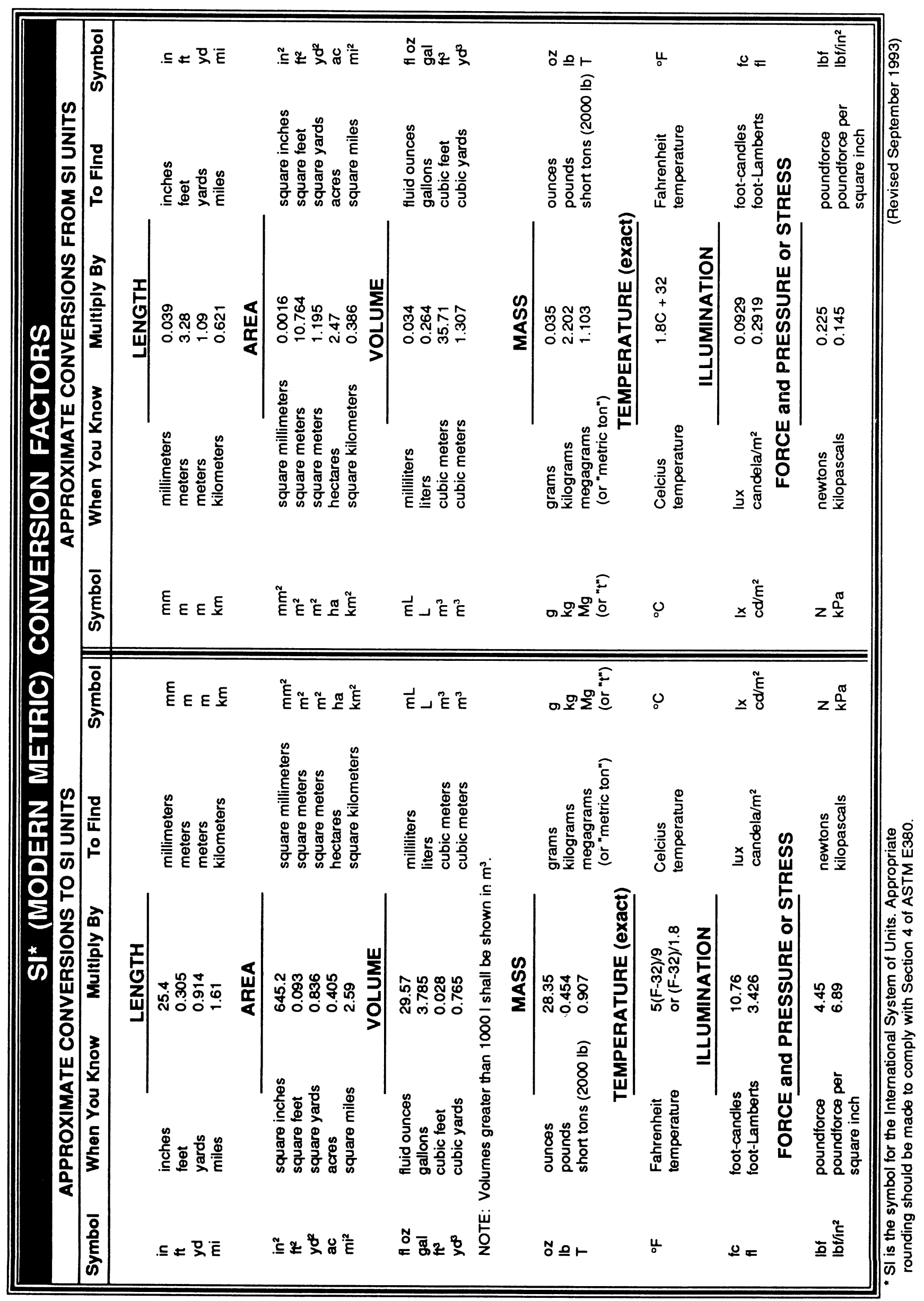


TABLE OF CONTENTS

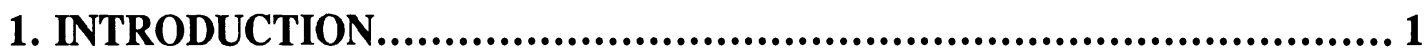

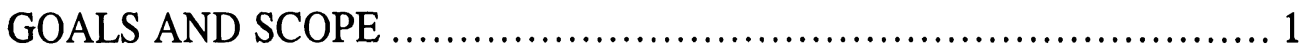

LIKELY READERS OF THESE GUIDELINES …........................ 2

APPLICATION OBJECTIVES ............................................... 2

TARGET PRODUCT USER POPULATION DEMOGRAPHICS ............. 2

APPROACH TO GUIDELINES DEVELOPMENT ............................ 3

SUMMARY OF APPROACH......................................... 7

ORGANIZATION OF THE GUIDELINES ................................ 7

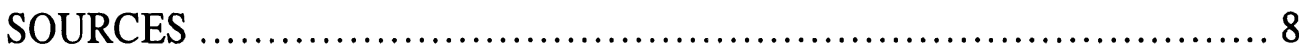

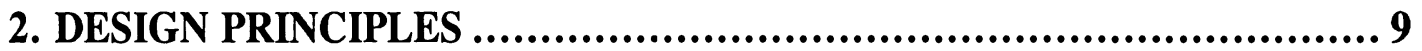

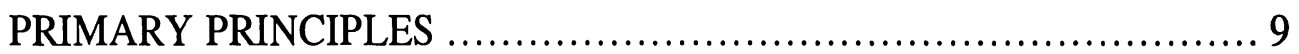

SECONDARY PRINCIPLES .............................................. 11

3. GENERAL MANUAL CONTROL GUIDELINES ............................... 13

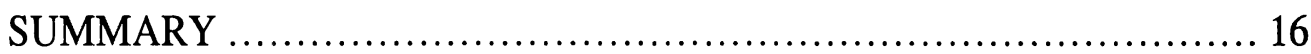

4. GENERAL SPOKEN INPUT AND DIALOG GUIDELINES .................... 17

INFORMATION NEEDS .................................................... 19

5. GENERAL GUIDELINES FOR VISUAL DISPLAYS ......................... 21

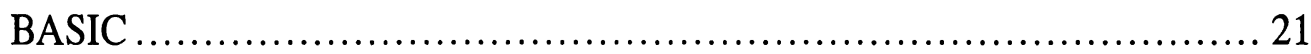

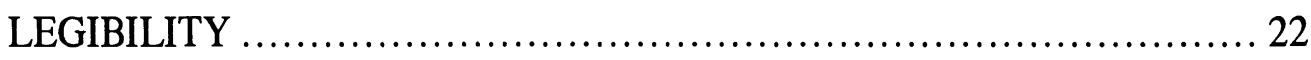

UNDERSTANDABILITY .......................................................... 26

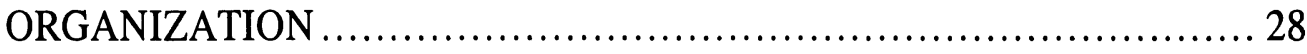

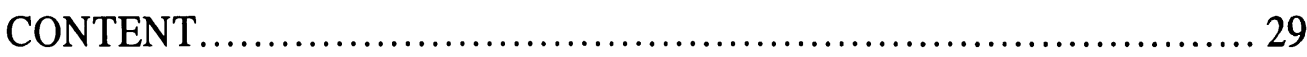

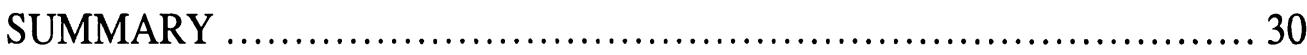

6. GENERAL GUIDELINES FOR AUDITORY DISPLAYS ....................... 31

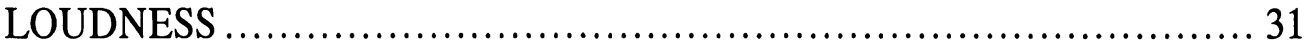

DISCRIMINABILITY OF WARNING SOUNDS ........................ 32

SYNTHETIC VERSUS RECORDED SPEECH ........................... 34

7. NAVIGATION GUIDELINES - VISUAL DISPLAYS …........................ 37

PRESENTATION MODALITY ................................................ 37

TURN DISPLAY OVERALL FORMAT …............................... 37

TURN DISPLAY CONTENT …....................................... 40

LABELING OF DETAILS ................................................. 44

DISPLAY ORIENTATION AND PLACEMENT ......................... 47

8. NAVIGATION GUIDELINES - AUDITORY OUTPUT ...........................49 
TABLE OF CONTENTS (continued)

9. NAVIGATION INPUT GUIDELINES .......................................53

10. TRAFFIC INFORMATION GUIDELINES...............................59

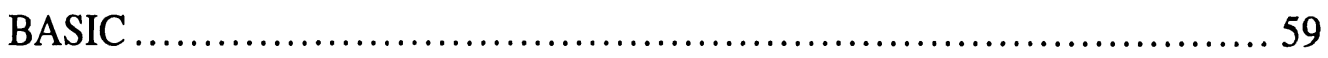

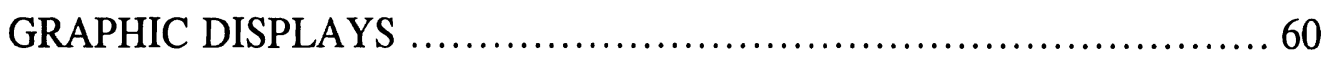

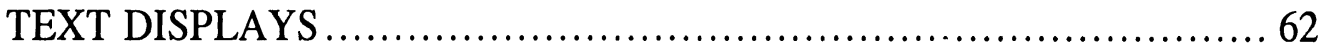

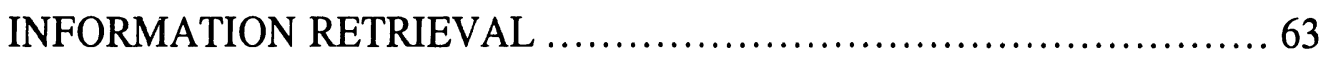

11. CAR PHONE GUIDELINES..............................................65 65

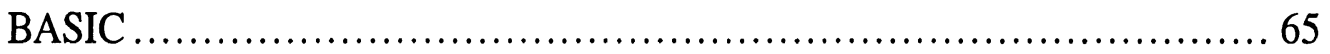

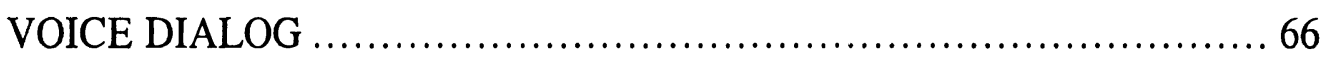

MANUAL DIALING AND HANDSET DESIGN ......................... 67

12. VEHICLE MONITORING GUIDELINES..................................69

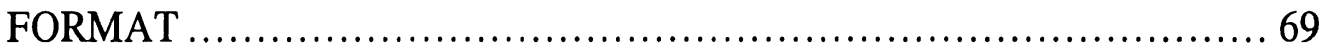

PRIMARY WARNINGS .................................................. 70

ADDITIONAL WARNINGS ............................................ 72

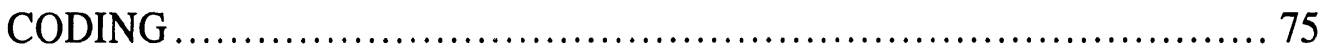

EXAMPLE IMPLEMENTATION ................................... 77

13. IVSAWS GUIDELINES..................................................... 81

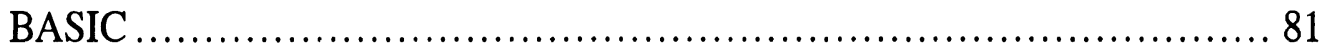

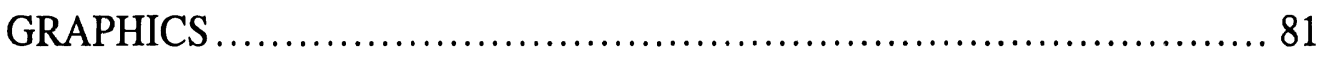

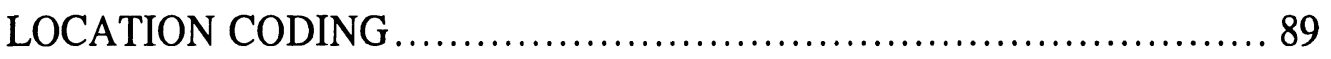

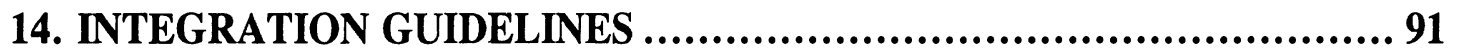

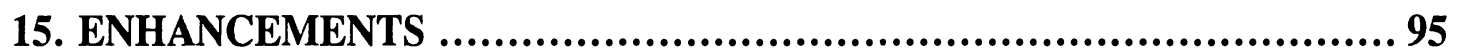

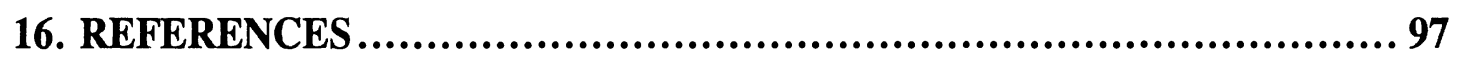




\section{LIST OF FIGURES}

1. Organization of the design guidelines. ........................................ 8

2. Text reading performance versus visual angle. ................................. 23

3. Reading time versus digit size................................................ 24

4. Example displays used in the project interface. ................................ 38

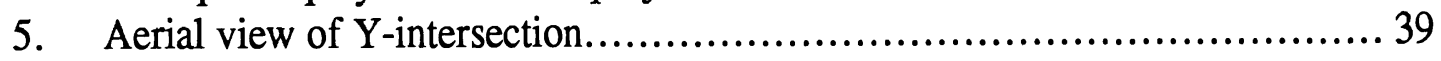

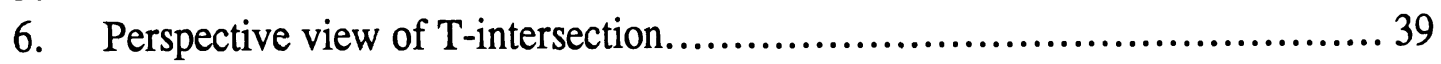

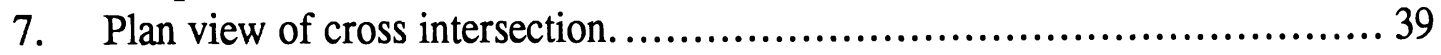

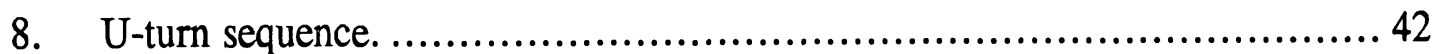

9. Examples of countdown bars. ................................................... 43

10. Example of map showing lane details......................................... 44

11. Columbia Avenue fork as an example of a complex intersection. ............... 48

12. Example Qwerty keyboard........................................................ 54

13. Example phone keypad entry device. ........................................... 55

14. Example doublepress keyboard. ............................................... 55

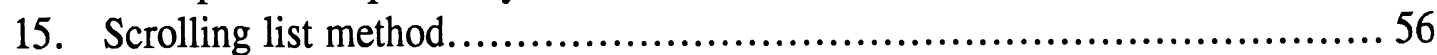

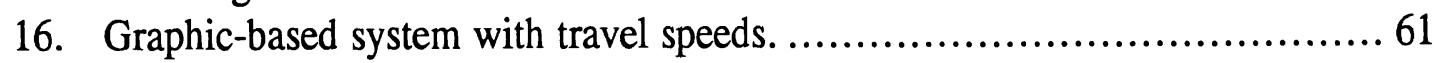

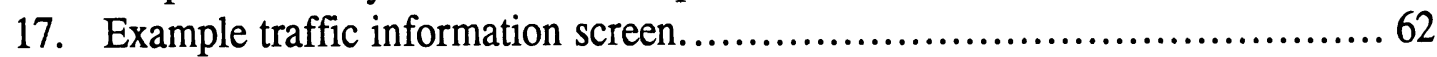

18. Touch screen map of Detroit highways used for selection. .......................6 63

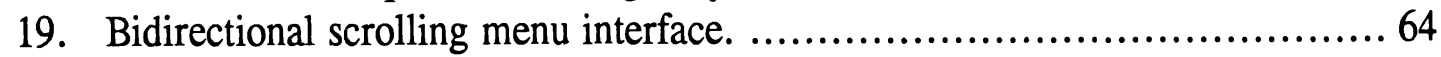

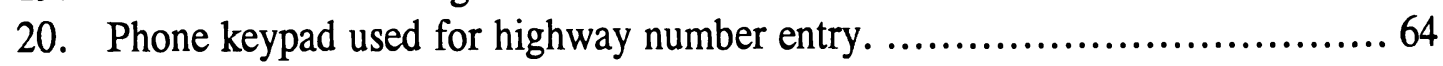

21. Text and symbol for engine temperature warning...............................6 69

22. Trunk and door opening warning messages. ................................... 73

23. Example of a two-panel warning. .............................................. 82

24. Recommended in-vehicle warnings for traffic control devices (new and out of order) ....................................................................... 83

25. Recommended in-vehicle warnings for road construction........................ 84

26. Recommended in-vehicle warnings for miscellaneous hazards (train at crossing, curve speed limit, and accident ahead) ............................... 85

27. Recommended warnings for moving emergency vehicles...................... 86

28. Recommended warnings for stopped emergency vehicles........................ 87

29. Recommended warnings for vehicles that make frequent stops. .................8 87

30. Recommended warnings for vehicles that are slow moving. ..................... 88

31. Recommended warnings for other atypical vehicles (school bus, tow truck,

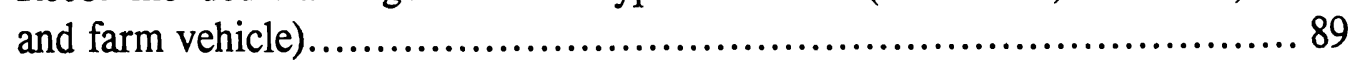

32. Location codes not recommended for a hazard ahead. .......................... 90

33. Example of a hierarchical menu employing multiple buttons..................... 92

34. Example of a hierarchical menu employing a single multiposition switch....... 92 


\section{LIST OF TABLES}

1. Summary of device recommendations for GIDS applications. .................. 4

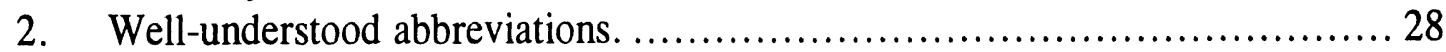

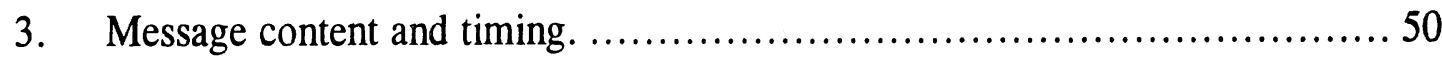

4. Driver tasks and vehicle motion. ............................................. 53

5. Recommended warning messages......................................... 70

6. Warning messages for unscheduled maintenance problems requiring immediate attention that are understood by drivers. ............................ 72

7. Warning messages for critical status problems, which drivers are expected to correct. .................................................................. 72

8. Warning messages for unscheduled maintenance problems, which drivers are expected to correct. ....................................................... 73

9. Warning messages for scheduled maintenance problems, which drivers are

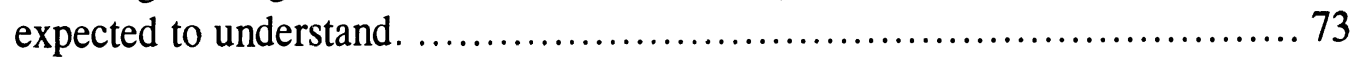

10. Warning messages for driver information. .................................. 74

11. Warning messages for unscheduled maintenance problems, which drivers are not expected to understand. .............................................. 74

12. Warning messages for unscheduled maintenance problems, which the drivers are expected to understand.................................................. 75

13. Primary warning message color codes......................................... 76

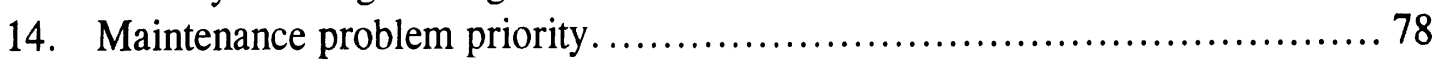

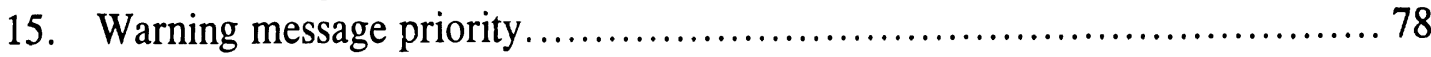




\section{INTRODUCTION}

\section{GOALS AND SCOPE}

The purpose of this report is to provide design guidelines for driver information systems in future vehicles implemented as part of the Intelligent Vehicle-Highway Systems (IVHS) program. These guidelines have neither the authority of a set of design requirements nor the completeness of a handbook. For that information readers are referred to Military Standard 1472D and standard textbooks on the topic of human factors engineering such as Sanders and McCormick. ${ }^{[22,23]}$ For several topics, such as controls, only general guidelines are included in this set. Specific guidelines, such as those for control spacing and shape coding, appear in the referenced documents. Those topics were not investigated in this research project but are important to interface design. It was considered unwise to include specific recommendations untested in the automotive context in this set of guidelines. However, the recommendations in the Military Standard are accepted human factors practice and should be examined carefully.

The guidelines are based on field and lab experience with pre-competitive interface designs, as well as the human factors engineering literature. The guidelines contained in this document do not consider conventional controls (turn signal, shift lever, etc.) and displays (speedometer, tachometer, fuel gauge, etc.). It should be noted that the design of those traditionally nonIVHS interfaces could affect the design of IVHS interfaces (because of location conflicts and operational consistency). Other systems, such as climate control and radio/CD player, may actually be integrated into IVHS interfaces. Such larger scale considerations are beyond the scope of this contract. In contrast, vehicle monitoring, a conventional system with enhanced functionality due to IVHS, is considered.

Because these guidelines are being written for the U.S. Department of Transportation, they are intended for vehicles sold in the United States. In general, these guidelines will be applicable to other nations, but some modifications may be required. For example, based on the first author's observations and comments from other travelers, traffic circles are quite common in Europe but are rarely found in most of the United States. This document does not provide any recommendations for turn displays depicting traffic circles. In Japan, China, Korea, and other Asian countries, people rely primarily on landmarks with street names for local navigation, not on street addresses. Further, in the United States, streets often form a rectangular grid, while outside the United States, the network is sometimes less grid-like. Finally, map labels in the United States are in English (and only in English). In other countries, other languages (or multiple languages) may be required, and non-Roman characters may be used.

It also should be noted that the intent of these guidelines is to provide a compact, usable set of references for designers in the field. Due, in part, to the newness of both the technology and the applications being considered for IVHS, much more detail and explanation is included in this document than had ever been envisioned. As the technologies and programs mature, and additional research is performed based on the needs highlighted by this and other preliminary 
studies, there will be pressure to produce an expanded set of guidelines. However, a shorter, more succinct version of design guidelines is preferred and should be developed.

\section{LIKELY READERS OF THESE GUIDELINES}

Traditionally, vehicle instrumentation has been developed by industrial designers working with engineers. For IVHS-related systems, it is likely that engineers working with computer programmers will take the lead. For the foreseeable future, many of the engineers will have had minimal exposure to human factors engineering. In some cases, there may be userinterface designers on the design team; but it is assumed for the purpose of this document that they are not present. Accordingly, this document does not assume that the reader has much knowledge of the human interface design literature. This document is intended to fill gaps in IVHS designer knowledge. It is assumed, however, that the reader is familiar with automotive engineering and associated terms. Accordingly, automotive terms such as "buck" (vehicle body mockup), "mimic" (car outline graphic), "header" (the interior section of the roof near the windshield), "pod" (an extension of the instrument panel near the steering wheel on which controls are located), and "eye brow" (the arch of the instrument panel near the steering wheel) are used without explanation, as well as other engineering terms such as "harmonic."

\section{APPLICATION OBJECTIVES}

The intent of this document is to help engineers develop interfaces for a wide range of product users as described in the next section. It is intended that those products will be safe and easy to use - they will not cause accidents or distract people from driving-and that information can be obtained quickly and without error. These products should be at least as usable and useful as existing in-vehicle information systems. Finally, they should require no learning. A typical driver, without instruction and without referring to a manual, should be able to use them correctly the first time.

\section{TARGET PRODUCT USER POPULATION DEMOGRAPHICS}

It is beyond the scope of this project to engage in a detailed discussion of the expected product user population. Of the systems covered in this report, aspects of advanced vehicle monitoring systems appear in a few production models (mostly luxury vehicles) and car phones are being marketed for all types of drivers. Navigation and traffic information systems are initially targeted for luxury vehicles and the rental market.

In the first study in this research project, the Brand Consulting Group recruited 46 drivers (in Los Angeles and New York) to participate in focus groups on advanced driver information systems. $^{[3,4]}$ Only drivers of late model cars with high-technology information systems (car phones, trip computers, head-up displays (HUD's), etc.) were recruited to participate. Consequently, participants tended to have moderately high incomes (median of $\$ 50,000$ to $\$ 75,000$ ) and to be professionals (architect, dentist, engineer, etc.) who drove expensive cars (Corvette, Saab 9000, Lincoln Town Car, Nissan Maxima). While this is characteristic of 
initial purchasers of these systems, advanced driver information systems will eventually be used by almost all licensed drivers, and must be designed accordingly. To avoid diffusing the effort, and because they are a small segment of the market with special needs, disabled and impaired drivers were not considered in this report.

\section{APPROACH TO GUIDELINES DEVELOPMENT}

Since the definition of this project, two guideline-like documents for application to IVHS have been released. One of those two, the draft guidelines written by ICE Ergonomics, are extremely general and, for the most part, have little content that is specific to vehicles. ${ }^{[24]}$

Leiser and Carr have edited a report analyzing input-output devices. It contains sections on tone output devices, speech output devices, visual displays, speech recognition devices, keyboards, touch screens, and conventional controls. ${ }^{[25]}$ This report was written as part of the Generic Intelligent Driver Support project. While this report is more substantive than the ICE guidelines and contains useful human engineering design guidelines, it is not specific enough for most applications. One important exception is its summary of device recommendations, which appears in table 1 of this document.

Considerable thought was given as to what characterizes good guidelines. In developing this set, the following recommendations were kept in mind.

\section{Good guidelines are based on design experience.}

When this project was proposed, it was thought that the guidelines would be created in a topdown manner. The authors would look at guidelines in the literature (for example, the Military Standard, guidelines for human-computer interactions, SAE documents, and other automotive design guidelines), create from them a superset of guidelines, and then modify the superset based on experimental work. However, this was not the approach followed and it would have been a mistake to do so. This approach would have generated a huge and unwieldy set of guidelines, only some of which would have been useful.

The approach followed was to begin to design real interfaces. When a question arose, the interface developers relied on good human factors practice, their expertise, the literature, and comments from colleagues who have tested real systems to make a decision. For questions the interface developers could not answer, experiments were often conducted. When issues arose, the issue and the decision were recorded, though the recording process was not rigorous. This approach led to a succinct set of core guidelines that were actually used in design. The choice of approach was the most important decision made in the formulation of these design guidelines. While there is no direct evidence comparing design-based and literature reviewbased guideline development, the first author's experience leaves no doubt in his mind of the superiority of the design-based approach. 
Table 1. Summary of device recommendations for GIDS applications. ${ }^{[25]}$

\begin{tabular}{|c|c|c|c|}
\hline & Tone Output & Speech Output & Visual Displays \\
\hline General & $\begin{array}{l}\text { - Limited number of } \\
\text { meanings possible. } \\
\text { - Low visual demand. } \\
\text { - Too many tones } \\
\text { distracting: Limit to } \\
\text { safety-critical information. } \\
\text { - Combine with more } \\
\text { explicit displays. } \\
\text { - Single tones can also } \\
\text { be used for input feedback } \\
\text { and announcing new info. }\end{array}$ & $\begin{array}{l}\text { - Wide range of info. can be } \\
\text { output. } \\
\text { - Low visual demand. } \\
\text { - "Natural": low training/skill demand. } \\
\text { - Poor for visual/spatial info. } \\
\text { - Slow presentation: complex info. can't } \\
\text { be scanned. } \\
\text { - Best for short, simple messages. } \\
\text { - Distracting if overused. }\end{array}$ & $\begin{array}{l}\text { - Unlimited range of quantitative } \\
\text { and qualitative info. possible. } \\
\text { - Can be scanned. } \\
\text { - Distracting if too much/too } \\
\text { complex info. Only minimal info. } \\
\text { should be presented while driving. } \\
\text { - Can emulate conventional displays. } \\
\text { - In-vehicle or head-up displays } \\
\text { possible. }\end{array}$ \\
\hline $\begin{array}{l}\text { Navigation (Traffic } \\
\text { Information and } \\
\text { Route Guidance) }\end{array}$ & $\begin{array}{l}\text { Not useful (Except to } \\
\text { announce info. from other } \\
\text { displays). }\end{array}$ & $\begin{array}{l}\text { - Can provide simple } \\
\text { instructions when needed } \\
\text { (e.g., "Turn left here"). } \\
\text { - Not useful for complex series } \\
\text { of directions. } \\
\text { - Can complement graphical map } \\
\text { displays. }\end{array}$ & $\begin{array}{l}\text { - Road maps, etc. when } \\
\text { stationary. } \\
\text { - Simpler info. (e.g. } \\
\text { direction arrows, signs) } \\
\text { while driving. }\end{array}$ \\
\hline Obstacle Detection & $\begin{array}{l}\text { Attention getting for safety } \\
\text { critical situation. }\end{array}$ & $\begin{array}{l}\text { - Attention getting for safety } \\
\text { critical situation. } \\
\text { - Short, informative messages } \\
\text { allow quick and appropriate } \\
\text { response. }\end{array}$ & $\begin{array}{l}\text { - May be distracting at a time } \\
\text { when vision is especially } \\
\text { important. } \\
\text { - Less attention-getting/ } \\
\text { salient than auditory } \\
\text { signals. } \\
\end{array}$ \\
\hline Lane Control & $\begin{array}{l}\text { Not useful (Except to } \\
\text { announce info. from other } \\
\text { displays). }\end{array}$ & $\begin{array}{l}\text { Can give informative advice without } \\
\text { distracting from primary driving task. }\end{array}$ & $\begin{array}{l}\text { May be useful for simple } \\
\text { instructions, if situation is not critical } \\
\text { (see Collision Avoidance). }\end{array}$ \\
\hline Telephone & $\begin{array}{l}\text { Several standard tones are } \\
\text { already used. }\end{array}$ & $\begin{array}{l}\text { - Call handling info. (alternative } \\
\text { to tones). } \\
\text { - Suggested use to give "busy" } \\
\text { message to out-of-vehicle party when } \\
\text { driver's attention is needed for difficult } \\
\text { driving situations. } \\
\end{array}$ & $\begin{array}{l}\text { - Feedback of number dialed. } \\
\text { - Display of calling party's number. } \\
\text { - Directory functions (e.g., menu of } \\
\text { names/numbers). }\end{array}$ \\
\hline Stereo & $\begin{array}{l}\text { Not useful (Except for } \\
\text { feedback from controls. }\end{array}$ & $\begin{array}{l}\text { Not useful while stereo playing. May be } \\
\text { useful during tuning/control. }\end{array}$ & Status indications. \\
\hline $\begin{array}{l}\text { Intelligent Gas } \\
\text { Pedal }\end{array}$ & $\begin{array}{l}\text { Not useful. Continuous tone } \\
\text { feedback would be } \\
\text { distracting. }\end{array}$ & $\begin{array}{l}\text { Not useful (except possibly to inform } \\
\text { driver of the reason for change in pedal } \\
\text { setting). }\end{array}$ & Not useful. \\
\hline $\begin{array}{l}\text { Cruise Control } \\
\text { (Distance Keeping) }\end{array}$ & $\begin{array}{l}\text { Should only be used for } \\
\text { safety-critical distance } \\
\text { keeping (see Collision } \\
\text { Avoidance). }\end{array}$ & $\begin{array}{l}\text { - Attention getting for safety critical } \\
\text { situation. } \\
\text { - Short, informative messages allow } \\
\text { quick and appropriate response. } \\
\end{array}$ & $\begin{array}{l}\text { May be useful for simple } \\
\text { instructions, if situation is not critical } \\
\text { (see Collision Avoidance). }\end{array}$ \\
\hline Collision Avoidance & $\begin{array}{l}\text { Attention getting for safety } \\
\text { critical situation. }\end{array}$ & $\begin{array}{l}\text { - Attention getting for safety critical } \\
\text { situation. } \\
\text { - Short, informative messages allow } \\
\text { quick and appropriate response. }\end{array}$ & $\begin{array}{l}\text { - May be distracting at a time when } \\
\text { vision is especially important. } \\
\text { - Less attention-getting/salient than } \\
\text { auditory signals. }\end{array}$ \\
\hline $\begin{array}{l}\text { Car Status } \\
\text { (Warnings, } \\
\text { Maintenance) }\end{array}$ & $\begin{array}{l}\text { Can draw attention to safety } \\
\text { critical warnings (e.g., brake } \\
\text { circuit failure). Should be } \\
\text { combined with more explicit } \\
\text { displays. }\end{array}$ & $\begin{array}{l}\text { - Short explanatory warnings while } \\
\text { driving. } \\
\text { - Less useful for detailed maintenance } \\
\text { info. }\end{array}$ & $\begin{array}{l}\text { - Short, explanatory warnings while } \\
\text { driving. } \\
\text { - More detailed status/ } \\
\text { maintenance/diagnostic info. when } \\
\text { stationary. }\end{array}$ \\
\hline $\begin{array}{l}\text { Trip Information } \\
\text { (Mileage, Average } \\
\text { Speed, etc.) }\end{array}$ & Not useful. & $\begin{array}{l}\text { Could present Trip Info, but has no } \\
\text { advantages over visual presentation. }\end{array}$ & $\begin{array}{l}\text { Can potentially provide a greater } \\
\text { range of info. than conventional } \\
\text { displays. }\end{array}$ \\
\hline
\end{tabular}


Table 1. Summary of device recommendations for GIDS applications (continued).

[25]

\begin{tabular}{|c|c|c|c|c|}
\hline & Speech Recognition & Keyboards & Touchscreens & Conventional Controls \\
\hline General & $\begin{array}{l}\text { - Allows hands- } \\
\text { free control } \\
\text { while driving. } \\
\text { - Unreliable } \\
\text { performance at } \\
\text { present. Do not } \\
\text { use for critical } \\
\text { inputs. } \\
\text { - Speaker dependent } \\
\text { and independent } \\
\text { devices available. }\end{array}$ & $\begin{array}{l}\text { - The most efficient } \\
\text { device for text/digit } \\
\text { input. } \\
\text { - High visual/manual } \\
\text { load: Use must not be } \\
\text { required or encouraged } \\
\text { while driving. } \\
\text { - Standard layouts } \\
\text { for text and digits. } \\
\text { - Combination with } \\
\text { visual displays allows } \\
\text { command and menu- } \\
\text { based dialogues. }\end{array}$ & $\begin{array}{l}\text { - Many functions can be } \\
\text { controlled from a small } \\
\text { area. } \\
\text { - Potentially reduces } \\
\text { proliferation of } \\
\text { conventional controls. } \\
\text { - Uniquely suited to } \\
\text { deictic (pointing) input } \\
\text { in vehicles. } \\
\text { - Natural for menu } \\
\text { selection. } \\
\text { - Best suited to occasional, } \\
\text { low resolution pointing. }\end{array}$ & $\begin{array}{l}\text { - Wide range of controls } \\
\text { available. } \\
\text { - Several standard controls } \\
\text { already used. } \\
\text { - Proliferation in controls would } \\
\text { result in an unusable } \\
\text { dashboard. } \\
\text { - Critical functions should be } \\
\text { prioritized. } \\
\text { - Control-function mapping } \\
\text { should be based on } \\
\text { ergonomic principles. }\end{array}$ \\
\hline $\begin{array}{l}\text { Navigation } \\
\text { (Traffic } \\
\text { Information } \\
\text { and Route } \\
\text { Guidance) }\end{array}$ & $\begin{array}{l}\text { Specification of destina- } \\
\text { tions. Speaker indepen- } \\
\text { dent for recognition of } \\
\text { all possible geographical } \\
\text { locations (large No. of } \\
\text { templates). Speaker } \\
\text { dependent possible for } \\
\text { subset of common } \\
\text { destinations (e.g., } \\
\text { "home", "gas station"). }\end{array}$ & $\begin{array}{l}\text { Destination can be typed } \\
\text { in when stationary. }\end{array}$ & $\begin{array}{l}\text { Can be used to specify } \\
\text { locations without having to } \\
\text { input a name. }\end{array}$ & $\begin{array}{l}\text { Device activation, mode } \\
\text { selection. }\end{array}$ \\
\hline $\begin{array}{l}\text { Obstacle } \\
\text { Detection }\end{array}$ & Not useful. & Not useful. & Not useful. & Not recommended. \\
\hline Lane Control & Not useful. & Not useful. & Not useful. & $\begin{array}{l}\text { Device activation, mode } \\
\text { selection. }\end{array}$ \\
\hline Telephone & $\begin{array}{l}\text { Allows hands-free } \\
\text { dialing, either by digit } \\
\text { recognition or from } \\
\text { directory (e.g., "Call } \\
\text { Jones"). }\end{array}$ & $\begin{array}{l}\text { - Standard keyboard } \\
\text { already in use. } \\
\text { Directory/code } \\
\text { set-up for speed } \\
\text { dialing. }\end{array}$ & $\begin{array}{l}\text { - Can emulate conven- } \\
\text { tional keypad. Auditory } \\
\text { feedback essential. } \\
\text { - Speed dialing by } \\
\text { directory menu } \\
\text { selection. } \\
\end{array}$ & $\begin{array}{l}\text { Device activation, mode } \\
\text { selection. }\end{array}$ \\
\hline Stereo & $\begin{array}{l}\text { Only useful if stereo is } \\
\text { not on, due to audio } \\
\text { interference. }\end{array}$ & $\begin{array}{l}\text { Can be used for radio } \\
\text { frequency input, but not } \\
\text { recommended while } \\
\text { driving. }\end{array}$ & $\begin{array}{l}\text { - Can emulate } \\
\text { conventional controls. } \\
\text { - Tuning by dragging } \\
\text { along or pointing at a } \\
\text { scale. } \\
\end{array}$ & $\begin{array}{l}\text { Several controls currently used, } \\
\text { e.g., on/off, mode selection, } \\
\text { tuning. }\end{array}$ \\
\hline $\begin{array}{l}\text { Intelligent } \\
\text { Gas Pedal }\end{array}$ & Not useful. & Not useful. & Not useful. & Not useful. \\
\hline $\begin{array}{l}\text { Cruise } \\
\text { Control } \\
\text { (Distance } \\
\text { Keeping) } \\
\end{array}$ & Not useful. & Not useful. & Not useful. & $\begin{array}{l}\text { Device activation, mode } \\
\text { selection. }\end{array}$ \\
\hline $\begin{array}{l}\text { Collision } \\
\text { Avoidance }\end{array}$ & Not useful. & Not useful. & Not useful. & Not useful. \\
\hline $\begin{array}{l}\text { Car Status } \\
\text { (Warnings, } \\
\text { Maintenance) }\end{array}$ & $\begin{array}{l}\text { May be useful to request } \\
\text { status info. (e.g., "Fuel } \\
\text { Level"). }\end{array}$ & $\begin{array}{l}\text { May be useful to } \\
\text { request specific } \\
\text { status info. } \\
\text { - Maintenance/ } \\
\text { diagnostic dialogues. } \\
\text { - Not recommended } \\
\text { when driving. } \\
\end{array}$ & $\begin{array}{l}\text { - May be useful to } \\
\text { request specific } \\
\text { status info. } \\
\text { - Interaction with } \\
\text { mimic diagrams. }\end{array}$ & $\begin{array}{l}\text { Device activation, mode } \\
\text { selection. }\end{array}$ \\
\hline $\begin{array}{l}\text { Trip } \\
\text { Information } \\
\text { (Mileage, } \\
\text { Average } \\
\text { Speed, etc.) }\end{array}$ & $\begin{array}{l}\text { May be useful to request } \\
\text { specific trip info. }\end{array}$ & $\begin{array}{l}\text { May be useful to request } \\
\text { specific trip info., but not } \\
\text { recommended when } \\
\text { driving. }\end{array}$ & $\begin{array}{l}\text { May be useful to request } \\
\text { specific status info. }\end{array}$ & $\begin{array}{l}\text { Device activation, mode } \\
\text { selection. }\end{array}$ \\
\hline
\end{tabular}




\section{Good guidelines are short.}

In developing a set of guidelines there is a tradeoff between comprehensiveness and the ease of finding critical information. The Macintosh human interface guidelines, which are 144 pages (including indexes) are usable, but a bit long. ${ }^{[26]}$ On the other hand, the Smith and Mosier human-computer interfaces guidelines are so long (478 pages) that one needs a Hypertext program to find information in them, even though they are well indexed. ${ }^{[27]}$ Providing more information is not better if it interferes with retrieving desired information. This is the key point of the "minimal manual" research. ${ }^{[28]}$ Furthermore, exhaustiveness and nonselectivity tend to make all guidelines equally important, so that attention is diverted from primary to secondary issues. Accordingly, the guidelines included in the set were not intended to be exhaustive.

\section{Good guidelines include examples.}

This is a strength of both Smith and Mosier, and Macintosh guidelines. ${ }^{[27,26]}$ Sometimes it is easier to provide an example of what to do than to say how to do it.

\section{Good guidelines are specific and often quantitative.}

If a guideline simply states that something should be "easy to use," it is unlikely to be achieved because, in tradeoffs, hard specifications always "win" over soft specifications. Design specifications that are given as numbers have impact (cost, weight, etc.). The best example is Military Standard $1472 \mathrm{D}$, which is liberally referenced here. ${ }^{[22]}$ That standard gives numbers or equations for computing character size, switch spacing, switch actuation forces and the like. For many human factors questions, however, numeric answers do not exist, and decisions must be made based on principles (such as "be consistent").

\section{Good guidelines are extendible.}

Again, the Apple guidelines are a good example. As the Macintosh computer line has evolved, additional guidelines (e.g., for color) have been added to the set. However, the basic principles of operation have remained unchanged. However, extendibility is difficult to achieve when the range of possibilities is unknown.

\section{Good guidelines refer to the literature.}

Both the Smith and Mosier, and Human Factors Society VDT guidelines have this quality. ${ }^{[27,29]}$ It is very useful to be able to examine the evidence upon which a guideline is based to verify where it is applicable. However, some restraint must be applied in documenting the rationale of a guideline. Excess explanation can make it difficult to abstract the engineering recommendations from the research presented.

The guidelines presented here rely primarily upon the research conducted under this contract. In several cases, guidelines are linked to literature by citing references in groups, rather than 
individually, to enhance readability. Specific page numbers for reports produced under this contract have not been cited because the reports are being revised, so the page numbers would be incorrect.

\section{Good guidelines should be well indexed.}

The number and types of document organizers required depends upon the document length, with longer documents needing more organizers. For this document, a table of contents is provided. Should the document expand, additional structures may be necessary. An excellent example of how indexes can be used effectively is the Smith and Mosier guidelines.

\section{Good guidelines use a well-understood vocabulary.}

In the suggested guidelines that follow, common automotive industry vocabulary (understood by the intended readers of this document, engineers) is used to avoid the need for a glossary.

\section{SUMMARY OF APPROACH}

The tenets of the approach here, (1) develop guidelines from design experience, and (2) keep guidelines short, were reinforced by a previous effort to develop guidelines for warning graphics. ${ }^{[30]}$ The first point-useful and usable guidelines emerge from design experience-is a very important one.

\section{ORGANIZATION OF THE GUIDELINES}

The project contract required the development of information covering three topics: general issues (broad ergonomic principles that apply to any information system); specific issues (concerning the implementation of specific functions); and integration issues (that deal with combining subsystems). Matters relating to general and specific guidelines were given the most attention, reflecting the contract effort. Because the interfaces examined were not highly integrated, integration issues were secondary. To maximize usefulness, information has been grouped into three classes of increasing specificity: principles, general guidelines, and systemspecific guidelines. Principles apply to all information systems and to both input and output. General guidelines are modality-specific advice (e.g., visual displays). System-specific guidelines concern particular interfaces (e.g., traffic information) and in some cases modalitysystem combinations (auditory displays for navigation). Figure 1 shows how the guidelines are organized. The design principles (section 2) are contained in a separate section. Following from them are the general guidelines which consist of two sections on input ( 3 and 4 , for manual and voice controls, respectively), two sections on output ( 5 and 6 , for visual and auditory displays), and a short section on integration. The bulk of the report contains systemspecific guidelines, each of which is in a separate section except for navigation. The guidelines for navigation are extensive and comprise three sections $(7,8$, and 9).

Partitioning the guidelines in this manner avoids overloading the designer with too much information. For example, to design a traffic information system that used manual controls 
and visual displays, a designer would need only to refer to the design principles (section 2), the general guidelines for manual controls (section 3), the general guidelines on visual displays (section 5), and the specific guidelines on traffic information systems (section 10). To facilitate finding desired information, designers may want to create a guidelines subset for each project. In this example that subset would be 24 pages $(=4+4+10+6)$, a relatively manageable amount.

To facilitate reference to specific guidelines, each section is numbered and the guidelines within each section are numbered. Within each section, guidelines are ordered so that the more general and important guidelines come first.

The specific focus of this report is on methods of presenting information and receiving input from drivers. While experiments to test the safety and ease of use of driver interfaces are critical, assessment is covered in other reports. ${ }^{[18,19]}$

The guidelines that follow should be viewed as a first attempt to assemble an evolving collection of knowledge. As experience is gained in using these guidelines, and associated research is completed, changes in the organization and content of these guidelines are likely. Nonetheless, these guidelines represent a reasonable first approximation of what engineers should do to design safe and easy-to-use driver interfaces.

\section{SOURCES}

The sources for the guidelines in this report are driving information and performance human factors documents, non-driving human factors documents which are related to driving human performance and information issues, and the authors' human factors experience. Those guidelines which are related to specific documents in the literature are followed by reference numbers associated with items in the reference section. Those guidelines which are not followed by reference numbers are based on the authors' human factors experience.

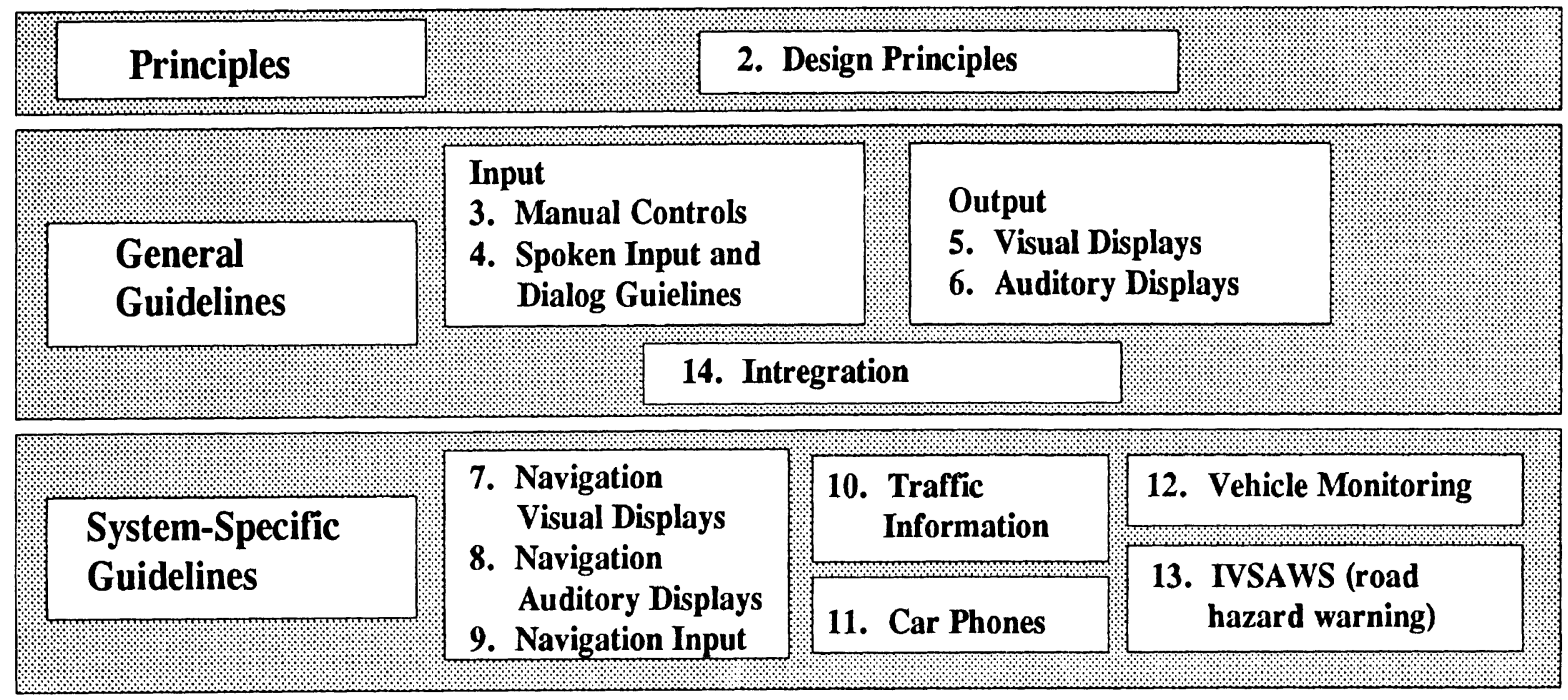

Figure 1. Organization of the design guidelines. 


\section{DESIGN PRINCIPLES}

The principles listed in this section may seem vague to some readers. They certainly are not quantitative and are much more indefinite than the general and specific guidelines in other sections. However, for many design decisions, specific research data (for example, comparing two map formats) or calculations do not exist. Many decisions made in this project were based on "good engineering judgment" and "accepted human factors practice," which have stood the test of time and experience, and in this report these tenets are referred to as design principles. Again, it should be stressed that the research performed for this project allowed the verbalization of these principles. The research was not performed with a conscious application of these principles but rather included an after-the-fact examination of what was found to be successful in design. Often, design principles can be more useful and certainly more cost effective than innumerable analyses of every nuance of a design question. Principles similar to those in this section appear in the Macintosh Human Interface Guidelines and the IBM Common User Access Guidelines, two widely cited sets of documents. ${ }^{[26,31,32]}$

The guidelines contained in this section (principles) were written with a specific focus on IVHS-related driver interfaces. To help maintain that focus, topics that were not examined in this research project, topics that are described in great detail in the human factors literature, and topics for which the information is voluminous (such as control selection and spacing), are not covered in detail here. For these human engineering guidelines, the appropriate principle is noted and the reader is referred to specific references for additional details should they be desired. In cases where exception is taken with the literature, or more stringent requirements are needed (e.g., for text size), those details are provided in this report. If an IVHS driver interfaces handbook is produced, it may be appropriate to include those additional details in all cases, rather than rely on reader familiarity with the subject literature.

For the principles that follow (and for the guidelines in other sections), a commentary on each of them is provided. The intent is to provide additional explanation, relevant observations, sources of further information, and in some cases, example implementations.

\section{PRIMARY PRINCIPLES}

\section{Principle 2.1 - Be Consistent}

Of the guidelines suggested, this one is probably most commonly cited, yet most difficult to define. Consistency refers to consistency of input, consistency of output, and compatibility of input and output with each other. For example, for input (controls), consistency means that the same sequence of actions is used for entering information in various subsystems or in parts of a task sequence. To give a specific example, if selections from a business listing menu are formatted in a "yellow pages" fashion, where items are listed alphabetically, then a similar format should be used for choices in the destination entry system. Keying in the alphabetic first letter of the function name in one instance and entering an assigned, arbitrary alphabetic designator for another selection (where entries were identified as a, b, c, d, etc.) in another would be inconsistent. Input consistency is also reflected in how commonly an entry 
terminator is used to end an input sequence. (For example, does the driver always hit the "return" key to enter a sequence?) The consistency of input sequences can be evaluated using cognitive complexity theory, though validation in the context of driving is lacking. ${ }^{[33,34]}$ Input consistency can also be structural. On screens, common functions such as "help," "next screen," and "back one screen" should always be located in the same place so people do not have to search for them. Also, with regard to controls, switches with similar responses (such as turning a function on) should have similar actuation motions. Consistency of input reduces the potential for human error.

Output consistency often takes the form of using the same words and phrase structure to communicate the particular message. For example, do not use "press help for more information" in one part of the system and "if you don't know what to do, press the help key" in another part of the system. Similarly, "Oops, you should have turned left at the previous street" sometimes and "Error, missed left turn for previous street" in other cases would be inconsistent. The use of standard message lists can reduce the likelihood of message inconsistency and resulting error.

When selection screens are used, the same basic structure should be used for particular functions. For example, if the user is given a menu of choices, the format should not be a horizontal list across the top on one screen, a vertical list in the middle on a second, and a list across the bottom on a third.

Control labels should also be consistent. If scrolling keys are provided, they should not be identified with up and down arrows on one screen, and the words "up" and "down" on another. Similarly, where text is abbreviated, the same abbreviations should be used everywhere. (For example, for "help," do not use " $\mathrm{H}$ " in one place, "Hlp" in a second place, " and "hel" in a third place.)

\section{Principle 2.2 - Controls and displays should function the way people expect them to function.}

One could argue that conforming to expectations is a form of consistency. Here, consistency is between the driver's concept of how something functions, or should function, and how it actually does function. In its simplest form, this involves the agreement between control and display actions and likely methods of operation. (Move a control up, to the right, and forward for "on" or "increase.") There is considerable literature on this aspect of expectation (controldisplay compatibility) and readers interested in additional information should consult a standard human factors textbook (e.g., Sanders and McCormick) or Military Standard 1472D for specific recommendations. ${ }^{[23,22]}$ Compatibility may take other forms, such as people expecting maps to be oriented with north at the top when planning a route. 


\section{Principle 2.3 - Arrange controls and displays so they follow the flow of reading: left to right, and top to bottom.}

This principle applies to English and European language-based cultures (and products) for whom these guidelines have initially been formulated. It is not clear whether this principle (sequence of use) applies to countries where the native language is read differently. (Hebrew is read right to left; several Asian languages can be read top to bottom.)

As an example application, if an alphanumeric keyboard is provided and the keys are to be arranged alphabetically, this principle dictates how the keys should be arranged.

\section{Principle 2.4 - Minimize what the user has to remember.}

Drivers may need to remember instructions from (1) a system on how to carry out a task, (2) directions to a destination, or (3) items retrieved while using one system feature that need to be entered elsewhere. For example, suppose a vehicle information system provided a yellow pages business listing function. Forcing the driver to memorize the phone number, step through the interface to the destination entry function, and then key in the phone number of the destination from memory would violate this principle. Short-term and long-term memory

loads are quantifiable using human performance models and cognitive complexity theory. ${ }^{[35]}$

Principle 2.5 - Operations that occur most often or have the greatest impact on driving safety should be the easiest to perform.

For example, drivers will set the destination each time they use the route guidance system but should rarely need to recalibrate the system. Hence, it is more important that the more frequent destination setting task be easier to do than the recalibration task.

Principle 2.6 - Controls, displays, and information elements that are used together should be near each other.

This principle has many implications for individual information elements. In the case of local maps, the names of the city and State shown should appear together, and street names should appear near the streets to which they refer. The current location indicator (car icon), current street address, and compass form another group. Using the same font and color can reinforce the connection between grouped elements.

\section{SECONDARY PRINCIPLES}

Principle 2.7 - Use metaphors and conceptual models to simplify operation.

This guideline has proven useful in human-computer interaction, but may have more limited use in IVHS. Most graphical user interfaces rely upon the desktop metaphor. Information is stored in file folders, which can hold files and other folders. Folders are opened to retrieve their contents. Information is discarded by moving it to the trash. Hence, users determine 
what they should do on an electronic desktop (their computer) by identifying an analogous action in the nonelectronic world.

The most common in-vehicle metaphor is likely to be that of a paper map. Other objects likely to serve as metaphors are the home phone for a car phone and a telephone book for yellow pages functions.

\section{Principle 2.8 - Provide support for expert and novice users of interfaces.}

In computer systems, support of experts usually takes the form of keyboard shortcuts and advanced functions. Automotive examples of this are difficult to find. In the case of a navigation system, a novice might enter the destinations manually. An expert will have preprogrammed them. Most likely this principle will arise when issues relating to help functions and calibration need to be considered. The point is to leave room to accommodate the skills of advanced drivers. Eventually, all drivers who survive to old age become experts, often accumulating several hundred thousand hours of driving experience.

\section{Principle 2.9 - Keep the user in control.}

The driver needs to determine when use of the interface can occur. If the driver must respond immediately to a system request, driving performance could suffer. As an example, if a driver enters an inquiry to find out about upcoming traffic and pauses in mid-entry, the interface should not return to an initial state after a second or so of no input, forcing the driver to reenter the sequence from the beginning. In summary, the system should serve the driver, not the other way around. 


\section{GENERAL MANUAL CONTROL GUIDELINES}

This section covers hand-operated controls-buttons, slide switches, knobs, etc. This includes both real switches and images of them drawn on a computer display. For a review of the literature on automotive controls, readers should consult Turner and Green. ${ }^{[36]}$ Voice-activated controls are discussed in a subsequent chapter. The commentaries for controls tend to be briefer than those for displays because the emphasis of this project was on displays.

\section{Guideline 3.1 - Limit the need for manual user input while driving.}

When drivers are operating controls, other than the steering wheel and foot pedals, they are not devoting full attention to driving. In some cases, it is possible to anticipate what drivers might want, and present it automatically. For example, some believe drivers want a trip overview when they start a trip or when turns are a great distance away, but need arrow displays when they are close to a turn. A navigation system could show a map display as long as the car is in park, then switch to an arrow display once the car is taken out of park. Also, if a turn is many miles away, a simplified map display might appear. Operations that are complex, such as entering destinations, should either be performed predrive or when the car is stopped. (Recommendations for navigation tasks appear in the specific guidelines for that system.) At the present time, validated equations do not exist to estimate if a task is too complex to perform while driving.

As an example, this guideline also suggests that touch screen cathode ray tubes (CRT's) with deep multilevel menus are not advisable, especially if common functions (e.g., operating the climate control) are buried there. Following that guideline, for the driver information system assembled as part of this project, all information was either immediately available to the driver or required minimal manual selection for retrieval. Where retrieval was required, there were few problems. ${ }^{[10]}$

\section{Guideline 3.2 - Controls used most frequently or for critical functions should be close to the predominate position of the hands.}

The intent of this guideline is for the driver to refrain from excessive motion to perform some action, so as to minimize movement times and errors. In driving, it is generally assumed the hands are in the 10 and $2 o^{\prime}$ clock positions on the steering wheel, though they may be elsewhere. Key controls could be mounted on the steering wheel, on pods or on the eye brow of the instrument panel, locations close to common locations of the hands, and easy to reach from the steering wheel hand position. While this guideline is important to allow efficient operations, placing too many controls too close to the driver can have disadvantages. The intent of this guideline is not to suggest that all controls should be on the steering wheel or on stalk controls. The first author has observed that steering wheel controls can be difficult for older drivers to see because of the short focal distance, though the need to read them will depend on frequency of use. (As an aside, except for the horn, a critical control, steering wheel-mounted controls are rarely used when the car is turning, and hence operating problems 
due wheel rotation are unlikely.) For stalk controls there can be problems with inadvertent operation and labeling (because of the limited surface area). ${ }^{[36]}$

\section{Guideline 3.3 - Put controls within easy reach.}

Reach envelopes for drivers are specified in SAE J287. ${ }^{\text {[37] }}$ Other relevant information appears in SAE J1138. ${ }^{[38]}$ These reach envelopes, in most standards, represent how far drivers can reach, not how far they want to reach. Hallen gives data on driver reach preferences, which typically are 4 to 8 in $(10$ to $20 \mathrm{~cm}$ ) less than maximum envelopes in the standards and recommended practices. ${ }^{[39]}$ Hallen's data are recommended over published practices.

For controls not to be used while driving, it may be desired to put them outside the normal reach envelope to avoid inadvertent operation. It is for this reason that the inside hood release is often located underneath the instrument panel.

\section{Guideline 3.4 - Provide flexibility in terms of the sequence of actions.}

If multiple pieces of information are required, for example, a city and a street address for a destination entry system, it may be desirable for the driver to enter either one first. This guideline is intended to avoid limiting the driver's capability to obtain or provide information. It should complement, rather than replace, the desire for consistency as stated in principle 1.

\section{Guideline 3.5 - Be forgiving of user errors.}

Making mistakes is a part of being human. Some errors will occur even for interfaces that are extremely easy to use. To facilitate task completion, errors should be easily corrected. For example, a user who keys in the wrong character in a sequence (e.g., an address), should be able to delete the last character and not be forced to reenter the string. Similarly, in menu selection, users should be able to back up one level rather than be forced to return to the top level to start again.

\section{Guideline 3.6 - Make errors difficult.}

In contrast to the previous guideline, here the focus is on eliminating errors rather than on correcting them. In brief, if the location of a control (such as the gear shift lever) is too close to the motion path of the hand for other operations, the driver might inadvertently bump (and actuate) a control, causing an unintended result (for example, turning off the headlights at night).

In the case of IVHS interfaces, the critical item might be system resets. If a reset must occur and a touch screen was used, two different locations on the screen should be touched in succession to avoid inadvertent reset due to finger bounce.

One way to minimize control actuation errors is to separate controls so multiple controls are not touched at the same time. In the case of groups of push buttons, raised ridges between 
them or individually recessing buttons reduces opportunities for this type of error. For spacing recommendations, readers should consult Military Standard 1472D. ${ }^{[22]}$

\section{Guideline 3.7 - Select the appropriate type of control for each task.}

There is a considerable body of literature on types of controls and when to use each (e.g., buttons and rocker switches for two state selection, slide switches and knobs when there are three or more states). To keep the focus of these guidelines on IVHS-specific issues, general task-specific guidelines for controls are cited by reference. In particular, readers should consult the Military Standard or Sanders and McCormick for further information, though almost any human factors textbook for an engineering audience should have the desired information. ${ }^{[22,23]}$

One of the more commonly observed design errors is the use of push buttons for every secondary function. If levels are being set (for example, display brightness), knobs or slide switches are usually more appropriate than up and down buttons.

\section{Guideline 3.8 - Select the appropriate forces and switch movements to control operation and provide feedback.}

This topic is also covered in great detail in the human factors literature, especially in the Military Standard and will not be reviewed here. ${ }^{[22]}$ For the most part, that literature concerns single task performance, not timesharing as in the case of driving.

It has been noted that there are problems with the design of push buttons for many interfaces. Often the switch travels are too short (for touch screens it is almost zero), and actuation feedback is poor. If forces are low, inadvertent operation is more likely. If switch travels are excessively large, drivers may be mislead to thinking they have operated a function when that is not true. Therefore, for IVHS applications, further research needs to be done to document optimal touch forces and feedback while driving. The prototypes developed during this research project brought to light the lack of guidance available to designers, and the importance of this parameter for effective operation.

\section{Guideline 3.9 - Use color coding to group controls and represent their function.}

Use of color coding to group controls is a 'vell-accepted human factors guideline. However, there are no accepted automotive-specific color-system or color-function associations. Until automobile-specific research is conducted, designers should follow the standard color coding conventions described elsewhere as these have been studied for other situations of operators interfacing with advanced technology. ${ }^{[23]}$

\section{Guideline 3.10 - Shape code controls to represent their function.}

Shape can be used to provide a driver with tactile cues indicating a control's purpose. For example, a switch for the windshield wiper could be shaped like a blade, while a headlamp 
switch might be rounded to represent a headlamp. Currently, there are no specific recommendations for which shapes to use for automotive controls. Research could be conducted to address this issue.

\section{SUMMARY}

There are hundreds of guidelines for controls available in the literature, but these 10 are the ones that were most prominently identified by this project. Manual controls guidelines are in many cases taken from valuable work examining human interactions with controls in military applications, especially aircraft. Pilots are usually young, male, and highly trained, which is not commonly the case for drivers. Accordingly, additional research specific to driving should be instigated. 


\section{GENERAL SPOKEN INPUT AND DIALOG GUIDELINES}

This section concerns recorded or computer-generated speech presented by the vehicle to the driver, voice commands uttered by the driver to the car, and the general structure of the interaction. Route guidance was the only system for speech that was examined in this project, and hence experience with speech input/output was limited. However, since speech may be an important element of future IVHS interfaces, it was believed to be necessary to include some guidelines in this document.

The first five guidelines are abstracted from a recent literature review of the management of errors in spoken language system dialogs. ${ }^{[40]}$ One of the most significant conclusions of that review is that systems employing terse phraseology, simple one-word commands such as "next," "back," or "select," seem to be more efficient and acceptable than those that use conversational-style dialogues. (See references 41 through 45.) Also considered in the development of the first eight guidelines was the research of Frankish and Noyes and Schwab, Ball, and Lively. ${ }^{[46,47]}$

Guideline 4.1 - Design structured dialogs that are easy for the driver to learn and remember.

Guideline 4.2 - Design dialogs that enable users to speak brief commands.

Do not attempt to mimic a conversational style of dialog. For example, the driver should say "Radio on," not "Please turn on the radio for me."

Guideline 4.3 - Present tersely, consistently phrased output in forms such as verbnoun, noun-verb, or object-action so that users can more readily adapt to the system.

For example, drivers would say "temperature-78 degrees," "fan-high" and not "78 degrees should be the temperature. Adjust the fan speed to high."

Guideline 4.4 - Provide non-threatening responses and help/error messages that contain the vocabulary and phrases that the user can understand.

For example, in response to a driver's query about vehicle status, say "The air bag electronics module is not working properly, so the air bag may not function. Please contact your dealer for assistance." Do not say, "Fatal error 553AB40 hex in unit SRS subunit 47 logged. Checkout execution terminated. Repair requires tech cert level 7.5."

Guideline 4.5 - Present explicit feedback indicating when the system is or is not in a state where it can accept speech input.

For example say, "One moment please. Wait for the beep, then begin speaking." 
Guideline 4.6 - When dialogs present prompts or messages, design the interface so that users can interrupt these dialogs.

Just as many banks have phone bill-paying services, where account numbers, pin numbers, and type of transaction needs to be entered, it is envisioned that cars may require input on destination, type of driving desired (highway or rural), and time constraints to arrive at destination. A driver who knows that these entries will be requested should not need to wait to hear the dialog explaining the options prior to entering the data for each interaction. So upon hearing "route type" a knowledgeable driver should be able to respond immediately instead of waiting to hear "enter 1 for fastest, 2 for fewest turns, 3 for shortest, 4 for fewest tolls, 5 for most scenic."

Guideline 4.7 - Provide explicit confirmation of all commands by the user.

Depending upon the command, confirmation may be accomplished either while users are entering responses or when commands are completed. Confirmation may be as simple as causing the requested action to happen, such as moving a map from an instrument panel display to a head-up display (HUD) on command. It is important that the driver knows that the input was received by the system. For example, where immediate action will not be noticeable to the driver, such as set cruise control, some confirming indication should be provided. Research on appropriate confirmations, or "talk-backs, " will be an important part of advanced driver-information systems.

Guideline 4.8 - Provide different types of feedback for data and for commands.

The feedback for an "enter address" command from the user might be voice output from the system (e.g., "say address and street") while the response to the data ("123 Maple Street") might be to repeat back what the user said.

\section{Guideline 4.9 - Feedback should be context sensitive.}

To confirm to the driver that the desired action was accomplished, feedback should be unambiguous. If a driver was asked to enter longitude and latitude into a navigation system and the dialog used was "enter number" as the command for both, and "number entered" as the feedback for both, the user would never know if he or she successfully entered the longitude to proceed to enter the latitude. If the same form of feedback is used for multiple actions, the driver may not be sure the correct command or data was provided. As a further example, if a driver commanding "cruise - on" is met with the feedback of "cruise," and then upon subsequently commanding "cruise - set" again hears the confirming word "cruise," confusion may ensue. In this example, a better confirmation might be stating what has been accomplished. 
Guideline 4.10 - Speech inputs to the vehicle should be acoustically distinguishable.

Since it is intended for a voice unit to recognize an utterance, more errors are likely if the inputs sound alike. If the driver is asked to enter a word by spelling it, the letters b, c, d, e, $\mathrm{p}, \mathrm{t}$, and $\mathrm{z}$ will all sound alike. Also "increase" and "decrease" might also be confused.

Guideline 4.11 - Command names should be semantically discriminable.

Drivers are likely to make more mistakes if several commands for distinct actions have similar meanings. For example, drivers tend not to understand the difference between the seek and scan functions of a radio. See Black and Moran for research on semantic confusions. ${ }^{[48]}$

\section{Guideline 4.12 - Automatic speech recognition devices should allow for regional differences in pronunciation.}

In Boston, drivers might refer to the "radio tuna" (radio tuner). In the south, drivers might refer to a "low tar pressure" (low tire pressure). Successful speech recognition devices will need to accommodate this range of pronunciations.

\section{INFORMATION NEEDS}

The guidelines presented above should be used in the design of systems using spoken interfaces to technologies. Since spoken input and dialog are not commonly used by most driver populations, additional research should be performed to carefully understand the capabilities and limitations of persons simultaneously performing the driving task and verbally interacting with car systems. 



\section{GENERAL GUIDELINES FOR VISUAL DISPLAYS}

This section contains guidelines pertaining to the design of IVHS displays of all types. System-specific guidance appears in other sections (navigation, traffic information, car phones, vehicle monitoring, IVSAWS) as do numerous examples. The general visual display guidelines address five topics: basic issues, legibility, understandability, organization, and content. Much of the research concerning legibility and understandability was based on hardcopy, not electronic presentation. Displays of matched luminance, color, resolution, and glare will result in identical user performance, regardless of the technology used to produce the image.

\section{BASIC}

\section{Guideline 5.1 - Limit the amount of information presented to the driver.}

Minimizing material to be read will help keep the driver's eyes on the road. People cannot or should not read entire paragraphs of text while they drive. Limits on the number of words acceptable to the driver without compromising the performance of the primary driving task will depend on driver workload. Those limits have not yet been defined.

Beyond the content of particular messages, of concern is whether or not the information should be presented at all. Providing more information means there is more for the driver to read. Because display space is limited, this may lead to reducing the size of graphics and text to provide room for the added information, making existing displays less legible. A classic example comes from some early research on speedometers. ${ }^{[49]}$ Drivers took the least amount of time to read a numeric speedometer, longer to read an analog speedometer, and the most time when both were present, because of the clutter. Similarly, Streeter, Vitello, and Wonsiewicz found that drivers' navigation performance when using a map and auditory guidance was worse than when using auditory guidance alone, because they had to deal with multiple information sources (two sensory modalities). ${ }^{[50]}$

\section{Guideline 5.2 - Place commonly used displays, or those that are critical, close to the line of sight.}

Generally, head movements are necessary to look at an object more than 30 degrees from the current point of regard, though the closer an object is to the line of sight, the more likely it is to be seen. ${ }^{[2]}$ Time spent making head and eye movements, and time looking at in-vehicle displays, is time not spent looking at the road.

There may be a temptation, as technology advances, to put all driver information on a head-up display. While this technology has promising applications, there are important issues to be examined as the HUD can obscure the road scene or distract the driver from paying attention to important objects in the scene (pedestrians, other vehicles, etc.). To take full advantage of 
the HUD, drivers should not have to look elsewhere to determine how to use associated controls.

Because a navigation display may be frequently used, placing it low in the center console is not desired. Placing the information on a HUD or near the top of the center console is appropriate. ${ }^{[15]}$ Therefore, when designing the location of displays, attempt to minimize head movements by placing commonly used and highly critical displays close to the line of sight, keeping in mind the need for the driver to focus primarily on the "out-the-window" visual information required for the driving task itself.

\section{LEGIBILITY}

\section{Guideline 5.3 - Text should be 0.25 in high $(6.4 \mathrm{~mm})$ or larger (assuming a viewing distance of 28 in $(711 \mathrm{~mm})$ ).}

Typically, when a visual display interface is designed, the first step is to select the size and type of display, a decision often based on package and cost constraints. The second step is to set the required character size. This decision may be the most important human factors decision made because character size determines if information can be read and how long it will take to read the information. The selection of character size determines how much information can be presented and has implications for information format. For these reasons, considerable commentary is provided here to support the recommended size.

Drivers must be able to read displays quickly to limit eyes-off-the-road time. There is considerable literature on the legibility of displays. ${ }^{[51]}$ One of the most general expressions for determining required character height is the Bond Rule, which states that the visual angle of a character (its height divided by the viewing distance) should be at least 0.007 radians. ${ }^{[52]}$ For small visual angles, the sine, tangent, and angle in radians are all the same to three significant figures. Hence, at the standard panel viewing distance (28 in or $700 \mathrm{~mm}$ ), characters should be $4.9 \mathrm{~mm}$ (0.196 in) high (0.007 times 28). However, displays mounted on the center console can be at a slightly greater distance, requiring a larger character size. For this research project, where displays were on top of or near the top of the center console, characters were approximately 0.26 in $(6.6 \mathrm{~mm})$ high, though there were some cases where characters were 0.2 in $(5.1 \mathrm{~mm})$ high. Older drivers, the segment of the population most likely to have problems reading displays, experienced no legibility problems in this project.

The Bond Rule data was collected by having subjects (college students, presumably young adults) walk to a target and record the distance at which the target could be read. Letter heights ranged from 1 to $55 \mathrm{~mm}$, with most under $10 \mathrm{~mm}$, typical of what might appear in vehicles. Figure 2 shows the cumulative probability distribution function. While larger characters are more likely to be legible, one might reach a point of diminishing returns. In the case of the Bond Rule data, 8 of the 2007 observations required visual angles larger than .007 radians. 
Providing text that meets a minimum legibility for requirements for laboratory conditions is generally too small for easy and rapid reading while operating in the driving environment. When text is near threshold size, reading times can be long. For example, Boreczky, Green, Bos, and Kerst report the data shown in figure 3 concerning the time required to read numeric speedometers. ${ }^{[53]}$ The smallest size tested, about $5 \mathrm{~mm}$, is almost identical to the minimum required size from the Bond Rule (4.98 $\mathrm{mm}$ or $0.196 \mathrm{in}$ ). However, increasing the size to 9 $\mathrm{mm}$ decreased reading time by 15 to 20 percent, and increasing size further to 12 and $16 \mathrm{~mm}$ resulted in further, though diminishing, gains. It is not proposed that all characters should be $12 \mathrm{~mm}$ (about $0.47 \mathrm{in}$ ) or larger, however. It should be noted that for important displays, 0.25 in $(6.4 \mathrm{~mm})$ could be too small if the display is to be read quickly.

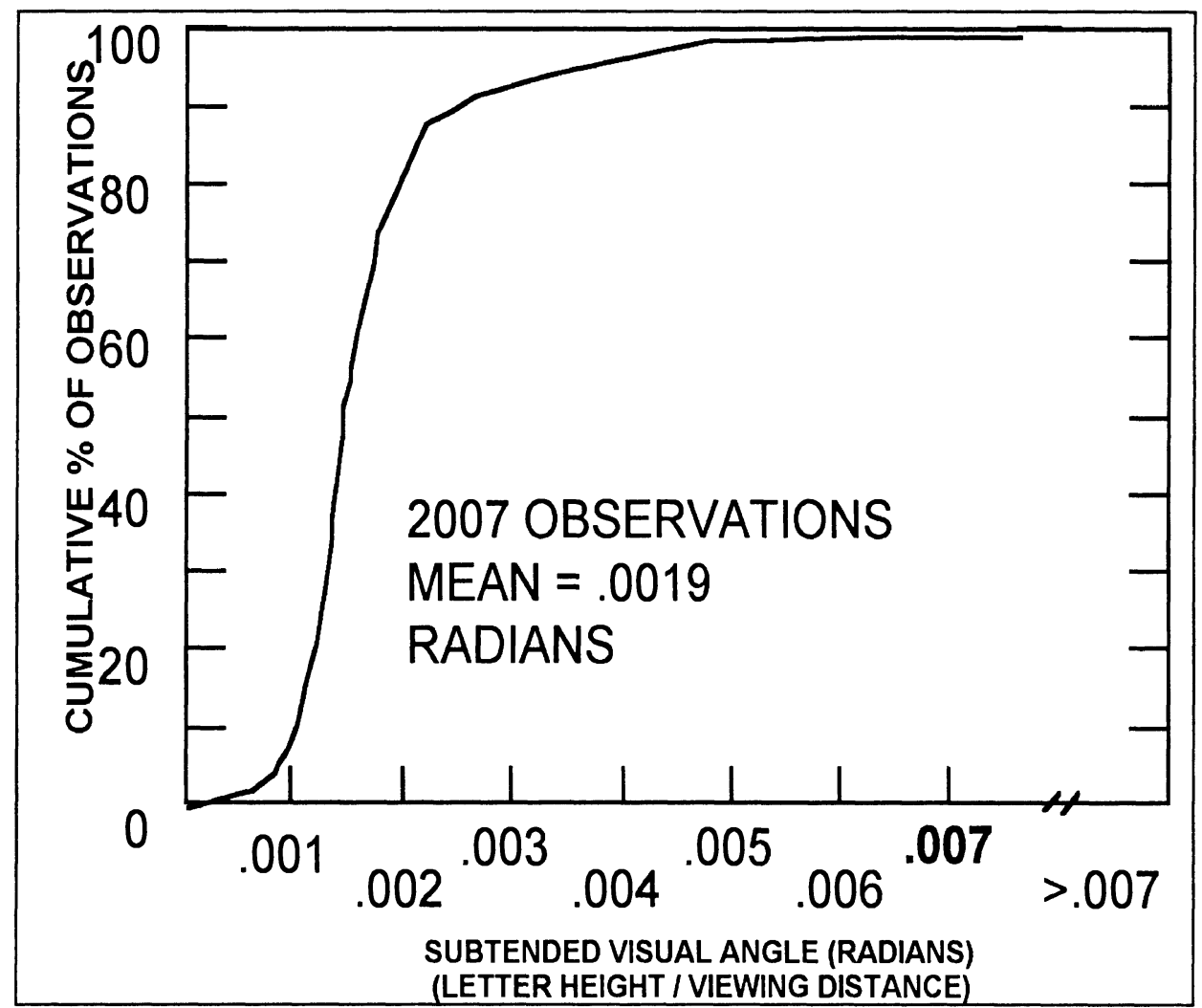

Figure 2. Text reading performance versus visual angle.

\section{Guideline 5.4 - Use a plain typeface to maximize legibility.}

The human factors literature shows that differences among modern typefaces have less impact on legibility than physical characteristics such as size or contrast. ${ }^{[54]}$ Nevertheless, plain typefaces (Geneva, Helvetica) are more legible than ornate ones (such as London). ${ }^{[51]}$ Following that recommendation in this project, most typefaces were Helvetica, though there were times that Geneva was used where it improved appearance. No problems were noted with character confusions made by participants. Where in-vehicle displays (e.g., navigation) are compared with external displays (e.g., highway signs), it is desirable that the typefaces be similar. 


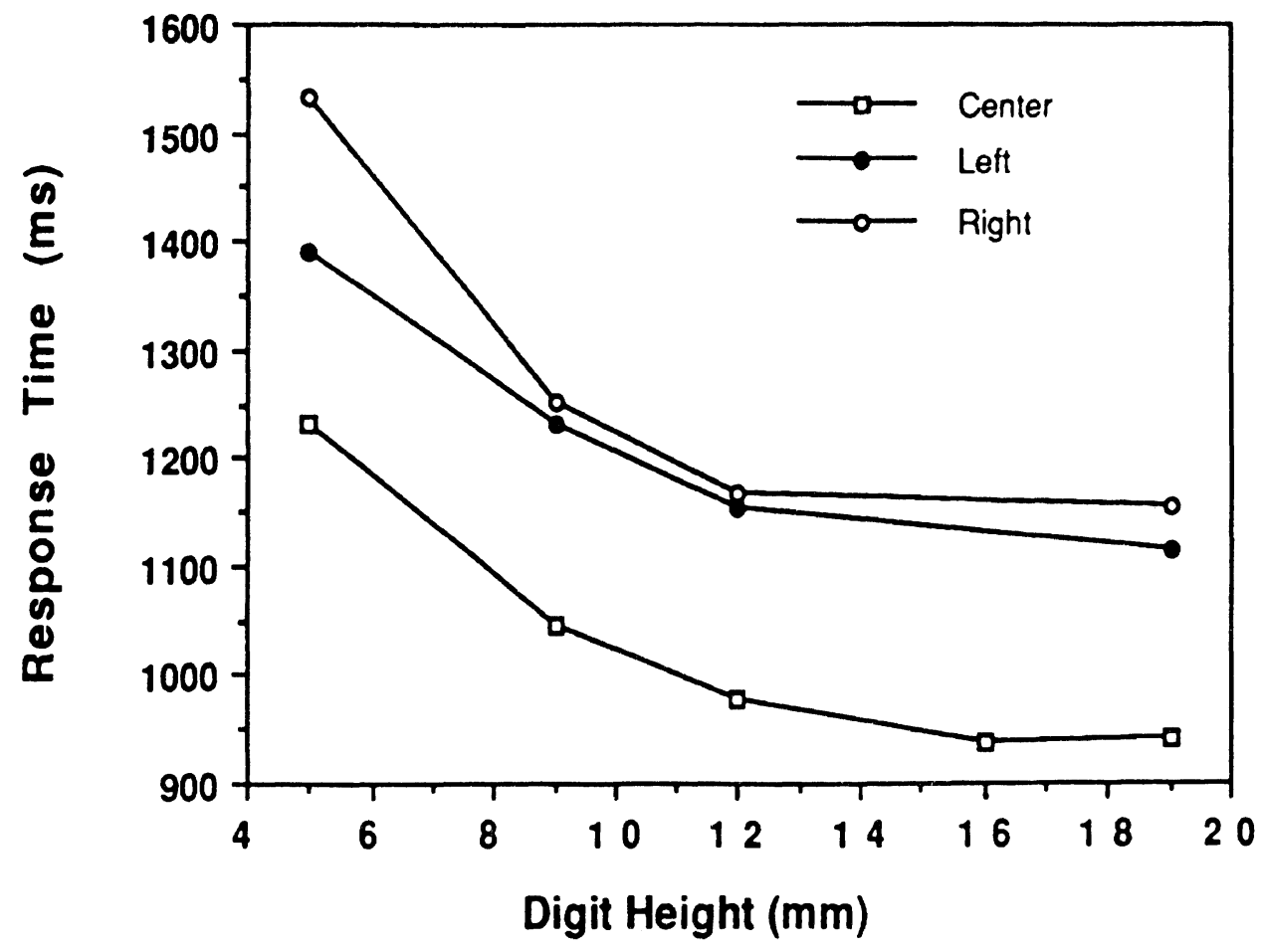

Figure 3. Reading time versus digit size. ${ }^{[53]}$

Guideline 5.5 - Use mixed case instead of all capital letters for messages in excess of two to three words.

"Right lane closed for next five miles" is easier to read than "RIGHT LANE CLOSED FOR NEXT FIVE MILES." However, short messages are often text that must be compatible with messages on signs, some of which are all upper case. Thus, departures from the guideline may be necessary for in-vehicle messages to be consistent with signs outside the vehicle. For this project most displays used mixed case. One exception in this project were the IVSAWS warnings, whose design was completed before this guideline was established.

Guideline 5.6 - All lines and gaps between lines should be at least $0.6 \mathrm{~mm}(0.025$ in) wide.

What people can discriminate is determined by critical details. For characters, these are the strokewidth of the character and the gaps between character parts (such as the opening in the letter $c$, which distinguishes it from the letter o). For design purposes, it is generally assumed that the standard instrument panel viewing distance is $71 \mathrm{~cm}$ (28 in), though the actual distance varies slightly with the location of the display (e.g., speedometer cluster versus center console), driver anthropometry, and seat position. For plain fonts, such as Helvetica, the height to strokewidth ratio is about 10:1, depending upon the weight of the particular typeface (light versus medium versus bold). Therefore, to be readily discriminated, the minimum line width, and gaps between lines or other graphic elements, all critical details, should be $1 / 10$ the minimum height of characters recommended in previous guidelines $(0.6 \mathrm{~mm}, 0.025 \mathrm{in})$. For this project line widths for minor borders around graphic elements were approximately that 
size. For emphasis, line widths for major borders were between 0.75 and $1.0 \mathrm{~mm}$, with widths closer to $1.0 \mathrm{~mm}$ being more appropriate.

\section{Guideline 5.7- In general, use light characters on a dark background.}

In computing, design follows the WYSIWYG (What You See Is What You Get) principle. For office work, the output is paper (dark characters on a light background), and screens are designed to match that output. In cars, the guiding principle is to minimize glare. Since there are more pixels for the background than the text (foreground), using a dark background will minimize the luminous output, and consequently minimize glare from the display. In the literature this is referred to as negative contrast. The route guidance, vehicle monitoring, and IVSAWS interfaces designed for this project all followed this guideline. However, the traffic information system used a light background so the shields for various roads would stand out from the background. The phone display, developed before this guideline was written, used dark characters on a light background, mainly for experimental convenience.

Guideline 5.8 - Provide adequate display luminance and contrast.

Human engineering recommendations for luminance and contrast are contained in the Military Standard. ${ }^{[22]}$ Readers are referred to that source for details. The most difficult display conditions occur during the daytime when the sun is low in the sky. Convertibles and sun roofs also present unique display conditions, increasing ambient illumination and providing opportunities for glare. Finally, in setting recommended display levels, it is important to realize that many drivers wear sunglasses; yet most lighting recommendations ignore that consideration. ${ }^{[55,56]}$ Sunglasses may reduce the light reaching a driver's eyes by an order of magnitude. This is most important for identifying desired output from low reflectance, emissive displays.

In this project, emissive LCD displays designed for in-vehicle use presented information to drivers in the on-the-road experiments. These displays were chosen because they were on hand at the time. There were some problems with display washout in bright sunlight. Luminance readings were not reported.

\section{Guideline 5.9 - Use discriminable colors.}

Procedures for calculating discriminability are given in Silverstein. ${ }^{[57]}$ The supporting evidence appears in Silverstein and Merrifield. ${ }^{\text {[58] }}$

At the beginning of this project, there was no complete scheme for color coding because it was uncertain what information needed to be presented and how many colors would be needed. Initially, color selection was made based on image appearance on color CRT's in an office. Later, since LCD's do not render colors identically to CRT's, designer "by eye" judgments were made to match the CRT-generated colors and provide adequate color disciminability. 


\section{UNDERSTANDABILITY}

\section{Guideline 5.10 - Use layman's terms and understandable graphics.}

This guideline will be applied most commonly to the design of vehicle monitoring systems. The purpose of a message is to convince drivers that there is a problem, and to give it the desired priority, something drivers cannot do if they do not understand the problem. Green, as well as Williams, Hoekstra, and Green have shown that there are many car functions about which drivers know little. ${ }^{[59,13]}$ For example, the warning "emissions sensor malfunction" would be more meaningful than "electrical fault in unit 4540, no current at power up." Some in the United States. automotive industry have preferred the technical term SRS or Supplemental Restraint System in warnings instead of the common term, "air bag." Many drivers may not know what an SRS is, so messages about them may be poorly understood.

In some cases, one can go too far in following user recommendations. For example, Landauer, Galotti, and Hartwell found that when left free to name commands for text editing, people picked names that were common and not discriminable, and often did so in an inconsistent manner. ${ }^{[60]}$ For example, they favored "space" as the command to insert a blank, "change" as the command to insert a character, and "add" to insert a line. That does not say that user input should be ignored. User input is critical. However, a simple contextindependent tally of user preferences will not always lead to the best design.

\section{Guideline 5.11 - Use international symbols to supplement words.}

Neither symbols nor words are universally preferred or result in better performance. ${ }^{[61]}$ If symbols are used, they should be drawn from those in the International Standards Organization (ISO) standard, Federal Motor Vehicle Safety Standard 101, and the Manual on Uniform Traffic Control Devices. ${ }^{[62,63,64]}$ In brief, the comparison is usually not one of symbols versus words, but symbols versus abbreviations. The rule of thumb is that a symbol for some function can be seen at double the distance (or be half the size) of an alternative text label given similar lighting conditions. However, there are many circumstances when the meaning of the symbol is obscure, hence the message will not be understood. Because it is the most commonly used technical language, English tends to be used to create messages and abbreviations. However, there are customer acceptance problems with using them in vehicles intended for the international market.

Further, providing both symbols and words may not be desired in some situations because presenting both may clutter the display.

Specific symbols for IVSAWS warnings, developed as a part of this research project, appear in section 13, the section devoted to IVSAWS. 


\section{Guideline 5.12 - When creating abbreviations, use consistent rules so that people can reconstruct them.}

Commonly accepted rules are vowel deletion (either with or without a length limit) and truncation (using the first few characters of a word). In vowel deletion schemes, the vowel is not deleted if it is the first character of a word. At times, there might be slight advantages to the use of truncation. (See Ehrenreich for a review of the literature.) In this research, it was not necessary to construct an extensive set of new abbreviations. ${ }^{[65]}$ Abbreviations were required only for the phone and route guidance functions. For the phone, a mixture of truncation and vowel deletion rules yielded the best performance. (See section 11, car phone guidelines, for details.)

\section{Guideline 5.13 - Use commonly used abbreviations only.}

This is a recommendation from the Manual on Uniform Traffic Control Devices. ${ }^{[64] ~ " A v e " ~}$ and "RR" are given as examples of common abbreviations. In this project, abbreviations used inside the car were consistent with those appearing outside the car (on road signs). In the route guidance system those abbreviations included street identifiers (Ave., Blvd., Dr., Pl., Rd., St.) and for the cardinal directions (N, S, E, W). Abbreviations for States were consistent with those employed by the U.S. Postal Service (e.g., MI for Michigan).

Data for abbreviations (table 2) are also given by Huchingson and Dudek. ${ }^{[66]}$ To create abbreviations, drivers were shown a long list of highway-related terms and asked to generate an abbreviation for each. From those data, a list of the most common responses to each term was created. A second set of drivers was shown the stereotype abbreviations and asked for the original word. The percent agreement between the original word and the reported responses appear in table 2 .

In a second part of the project, participants were shown additional abbreviations, along with a second abbreviation that was likely to appear with it [e.g., "Prep to Stop, Ahd Fog" (Prepare to stop, fog ahead)]. In that case an additional 47 words were added to Huchingson and Dudek's "to be considered" list, because they met the 85 percent correct threshold. The authors of these guidelines are less confident that those terms should be utilized because response time, an important measure in driving, was not examined.

Some caution should be exercised in using the results from this work, as commonality (emphasized by this guideline) and consistency in generation (emphasized by the guideline 5.12) will at times be in conflict. The literature shows that an important factor is the adoption of a consistent manner for generating abbreviations. ${ }^{[67]}$ By knowing the method used to create an abbreviation, people can apply the rules in reverse order to reconstruct the original term from the abbreviation. If some terms use vowel deletion, some use truncation, and others use additional protocols, the driver's task becomes quite difficult. Hence, in selecting abbreviations, both the comprehension of individual terms and the effects on understandability of the entire set caused by departing from consistent rules (something not examined by Huchingson and Dudek), must be considered. ${ }^{[62]}$ 
Table 2. Well-understood abbreviations.

$\begin{array}{lllc}\text { Word } & \text { Abbreviation } & \text { Strategy } & \text { \% Agreement } \\ \text { Freeway } & \text { Frwy } & \text { vowel deletion } & 100 \\ \text { Highway } & \text { Hwy } & \text { vowel deletion } & 100 \\ \text { Left } & \text { Lft } & \text { vowel deletion } & 100 \\ \text { Parking } & \text { Pking } & \text { last syllable } & 100 \\ \text { Service } & \text { Serv } & \text { truncation } & 100 \\ \text { Traffic } & \text { Traf } & \text { truncation } & 100 \\ \text { Warning } & \text { Warn } & \text { truncation } & 100 \\ & & & \\ \text { Boulevard } & \text { Blvd } & \text { vowel deletion } & 96 \\ \text { Speed } & \text { Spd } & \text { vowel deletion } & 96 \\ & & & \\ \text { Center } & \text { Cntr } & \text { vowel deletion } & 92 \\ \text { Entrance } & \text { Ent } & \text { truncation } & 92 \\ \text { Freeway } & \text { Fwy } & \text { vowel deletion } & 92 \\ \text { Information } & \text { Info } & \text { truncation } & 92 \\ \text { Normal } & \text { Norm } & \text { truncation } & 92 \\ \text { Shoulder } & \text { Shldr } & \text { vowel deletion } & 92 \\ & & & 88 \\ \text { Emergency } & \text { Emer } & \text { truncation } & 88 \\ \text { Expressway } & \text { Expwy } & \text { vowel deletion } & 88 \\ \text { Maintenance } & \text { Maint } & \text { truncation } & 88 \\ \text { Travelers } & \text { Trvlrs } & \text { vowel deletion } & 88 \\ \text { Road } & \text { Rd } & \text { vowel deletion } & 88 \\ \text { Slippery } & \text { Slip } & \text { truncation } & 88 \\ & & & \end{array}$

Given the general understanding of abbreviations formed using the truncation rule and other data presented above, the authors believe "Park" is an acceptable alternative abbreviation for Parking, "L" for Left, "Cen" for Center, and "Trav" for Travelers.

\section{ORGANIZATION}

Guideline 5.14 - In general, left justify free text in fields and right justify numbers when they are alone.

For additional information on field formats see Galitz. ${ }^{[68]}$ For other information on text screen format see Tullis. ${ }^{[69]}$ In this project, the primary application of this guideline was to traffic information displays (section 10). 
Guideline 5.15 - Use perceptual groupings to separate and aggregate elements on text displays.

Boxing related items, giving them a common color background, and using the same color text are ways to group display elements. In pilot studies associated with the traffic information system, black text on white was interpreted as more important than black text on gray. ${ }^{[10]}$ Lines were also used to group items related to the lane blockage location and to group information regarding the lanes blocked. (See the traffic information chapter for examples.) While not examined empirically, it was apparent from early design reviews that grouping made traffic information displays easier to comprehend.

Guideline 5.16 - Use natural hierarchies to indicate priority and importance.

It is generally accepted that information at the top and to the left in a window is perceived to be more important. For display windows, titles often appear centered at the top. Centering should only be used for the most important item in a display window.

\section{CONTENT}

Guideline 5.17 - Information on in-vehicle displays about roads should agree with road signs drivers are likely to see at the same time.

If an exit is referred to on a highway sign by number, then the primary item displayed in the vehicle should be the exit number. For example, in the route guidance system prototyped, it displayed "I-275 North" on the first line and "Flint" on the second line, the same words and format as the associated road sign. The importance of this guideline has been emphasized by the TravTek interface designers.

Guideline 5.18 - On screens giving information about roads (especially traffic information text screens, but also in navigation displays), identify both the highway to which the information refers, and the direction. Where numbered roads have names, both pieces of information should be given (e.g., Lodge Freeway - M-10 North).

Commuters are often more familiar with road names than route numbers, whereas route numbers are more useful to those unfamiliar with an area.

Guideline 5.19 - On text screens, identify location ("from," "to," etc.) using formats with which people are familiar, including exit names, numbers, and mile markers (e.g., Plymouth Road, Exit 41). 
Guideline 5.20 - The update rate for distance displays must be set based on the driver's task.

As noted later, distances should be displayed to the nearest tenth of a mile (equivalent to 1.6 $\mathrm{km}$ ), and the distance element of a display should be updated so that it is accurate. In terms of map elements, they should be oriented so the driver does not notice an inconsistency when comparing the scene ahead with a navigation display, traffic information display, or an odometer. The update of that information depends on the speed of the map matching algorithm and the update rate of the GPS signal (if a GPS sensor is provided).

\section{SUMMARY}

These general display guidelines were quite useful in designing the driver information system prototyped as part of this project. Specific applications of these display guidelines are shown throughout this report in the sections addressing particular functions: navigation visual displays in section 7, traffic information displays in section 10, car phone displays in section 11, and IVSAWS displays in section 13. Those examples have not been repeated here to keep the guidelines compact. 


\section{GENERAL GUIDELINES FOR AUDITORY DISPLAYS}

As technology makes use of voice command and computer-synthesized audible feedback more affordable, the appropriate use of auditory displays needs examination for the driving context. The information presented here is drawn primarily from design experience related to the navigation displays for this study, and also includes experience gained from other research projects. Accordingly, the guidelines in this section are more limited than those presented in other sections. As was noted elsewhere, the only auditory displays designed as part of this project were those for navigation, and that interface is covered in a separate section.

\section{LOUDNESS}

\section{Background on Interior Noise in Motor Vehicles}

Before auditory displays are designed, noise levels to be overcome should be measured at the driver's ears for the specific or similar vehicle. Sources of interior noise include road and tire interaction, air flow over the vehicle, engine, drivetrain, exhaust, climate control systems, entertainment systems, phones, accessories, passenger conversation, and noise from such outside sources as other traffic and sirens.

Data obtained from six 1970 to 1974 model year motor vehicles appears in Potter, Fidell, Myles, and Keast. ${ }^{[70]}$ Noise was measured for: (1) steady $88 \mathrm{~km} / \mathrm{h}(55 \mathrm{mi} / \mathrm{h})$ on the open road, (2) steady $48 \mathrm{~km} / \mathrm{h}(30 \mathrm{mi} / \mathrm{h}$ ) on the open road, and (3) varying speeds in an urban environment combined with: (1) all windows shut, (2) only the driver's window open, (3) only the front-seat passenger's window open, and (4) for urban driving only, all windows open. The radio, when on, was set for rock-and-roll music. Typical cruising noise levels range from 62 to 83 decibels on the A spectral weighting scale (dBA) with an energy mean of $74 \mathrm{dBA}$ at the driver's ears.

Interior noise was influenced by the state of the windows (a change of around $2 \mathrm{~dB}$ at $30 \mathrm{mi} / \mathrm{h}$ $(48 \mathrm{~km} / \mathrm{h}), 5 \mathrm{~dB}$ at $50 \mathrm{mi} / \mathrm{h}(80 \mathrm{~km} / \mathrm{h})$ ), use of snow or studded tires (increase of up to $8 \mathrm{~dB}$ ), road surface roughness (up to approximately $10 \mathrm{~dB}$ ), wet roads (up to $3 \mathrm{~dB}$ increase), and use of the radio. Interference from the radio occurs mostly at frequencies between 250 and 4000 hertz $(\mathrm{Hz})$ and can increase the ambient noise level on the order of $20 \mathrm{~dB}$.

Aerodynamic and road/tire noise increases at a rate of about $12 \mathrm{~dB}$ per doubling of vehicle speed. Engine/drivetrain noise increases at a rate of approximately $6 \mathrm{~dB}$ per doubling of speed.

Given the progress made since 1974 in reducing interior noise levels, and the use of air conditioning (which encourages driving with the windows closed), the numbers reported represent a pessimistic case for modern passenger cars. Whatever the current validity of these results, interior noise levels are highly design-specific, and the acoustic environment should be 
determined on a case-by-case basis. In the case of the test vehicle used for this project (driven with the windows closed), sound levels were not recorded.

Guideline 6.1 -Auditory tones should be about $15 \mathrm{~dB}$ above the masked threshold, but no more than $115 \mathrm{~dB}$ absolute level.

The $15 \mathrm{~dB}$ level reflects a compromise of the recommendations found in studies investigating the use of warning sounds in aircraft cockpits. Berson, citing results of Federal Aviation Administration (FAA) and DOT studies, concludes that the best performance for nonspeech sound recognition occurs when intensity level is $8+/-3 \mathrm{~dB}$ above masked threshold. ${ }^{[71]} \mathrm{He}$ believes that amplitudes over $15 \mathrm{~dB}$ for nonspeech sound produces startle.

Boff and Lincoln citing the work of Boucek, Veitengrubber, and Smith, recommend an amplitude of $15 \mathrm{~dB}$ above masked threshold. ${ }^{[72,73]}$ Patterson, as reported by Doll and Folds, recommends that warning sounds be between 15 and $25 \mathrm{~dB}$ above masked threshold. ${ }^{[74,75]}$

Tone intensity is a serious concern. Too low an intensity, relative to background noise, impairs intelligibility, whereas too high a sound level produces a startle reaction and is generally unacceptable. There is considerable agreement, therefore, that ambient sound levels should be tracked, and that the intensity of the auditory message should be adjusted accordingly, to be a specified amount above masked threshold. It is suggested that the signal level be such that the signal imbedded in noise can be detected correctly 75 percent of the time in a two-alternative forced-choice situation. Formulae for computing masked threshold as a function of signal and noise characteristics are given by Sorkin. ${ }^{[76]}$

For sounds presented in prototypes in this project, loudness levels were set by adjusting the volume control on the system amplifier as necessary. The levels were not recorded. Providing the ability to adjust intensity levels to suit individual differences is an alternative to tracking background sound levels that vary as speed varies.

\section{DISCRIMINABILITY OF WARNING SOUNDS}

Note: Because they are drawn from a common set of sources and interrelated, the commentary on guidelines 2 through 9 follows guideline 9 .

Guideline 6.2 - Limit the number of different warning tones to three or four.

Guideline 6.3 - To create distinguishable sounds, vary two or more of the following parameters: (1) spectral content, (2) pulse duration, (3) pulse shape, and (4) temporal pattern.

Guideline 6.4 - The sound should be composed of 10 or more harmonically spaced components, at least 4 of which are prominent and in the range of 100 to 4000 Hz. 
Guideline 6.5 - Most of the energy of lower-priority warning signals should be in the first $\mathbf{5}$ harmonics, whereas higher-priority signals should have relatively more energy in harmonics 6 through 10.

Guideline 6.6 - Urgency can be emphasized by incorporating a small number of additional, nonharmonically related, components or by introducing rapid glides in the fundamental frequency.

Guideline 6.7 - The duration of a signal burst should be between 100 and 150 ms.

Guideline 6.8 - Pulse shaping should be done by providing onsets of no greater that $1 \mathrm{~dB}$ that are linear or concave down. Offsets should match onsets.

Guideline 6.9 - Varying the temporal pattern (i.e., the timing and amplitude) of successive tone bursts substantially aids discriminability.

Patterson provides the detailed rationale for guidelines 2 through $9 .{ }^{[74]}$ There is some disagreement as to how many different sounds are useful. Berson suggests that, for aircraft cockpits, there should be no more than three distinct warning sounds. ${ }^{[71]}$ They should differ along more than one dimension and be selected to reflect the level of urgency. Doll and Folds quote Military Standard $1472 \mathrm{C}$ as suggesting that no more than four signals be used when absolute discrimination is required. ${ }^{[75]}$ On the other hand, Patterson and Milroy found that subjects could remember the meaning of eight or nine sounds. ${ }^{[77]}$ The authors have suggested the more conservative limit of three or four sounds to account for high workload situations when the driver's ability to remember the meaning of sounds may be diminished.

According to Sorkin, Patterson suggests that a signal burst should continue for a minimum of $100 \mathrm{~ms}$ to ensure detectability, but less than $150 \mathrm{~ms}$ to allow low signal on/off ratio and thereby maximize coding flexibility. ${ }^{[76,74]}$ In addition, short signals are less likely to interrupt ongoing speech communication.

The same source also claims that while fast onset rates attract attention to the sound, very fast rates may be associated with catastrophic events and may produce a startle reflex that manifests itself in unwanted response behavior. Onsets on the order of $10 \mathrm{~dB}$ produce this effect. Provided the final magnitude of the signal is less than $90 \mathrm{~dB}$, onsets of $1 \mathrm{~dB}$ or less tend to avoid the startle response.

As reported by Sorkin and Patterson and Milroy, signals having the same repetition rate were sometimes confused, even when they had the different spectral content. ${ }^{[76,77]}$ Varying the temporal pattern reduced confusion and improved performance. 


\section{SYNTHETIC VERSUS RECORDED SPEECH}

Guideline 6.10 - Use nonspeech auditory messages (sounds) only for the purposes of alerting-either as a self-contained message, or as a method of alerting the driver to an in-vehicle visual message or to a spoken message that follows.

Guideline 6.11 - Other auditory messages, including complex warnings, should be speech.

A speech format is superior to a nonspeech format when a complex message is presented via the auditory channel. ${ }^{[78]}$ Voice warnings are more flexible and informative than sounds; they provide better diagnostics, and they better assist the user in taking corrective action. ${ }^{[79]}$ Speech may also be more effective in high workload situations, when the meaning of a nonspeech sound is more likely to be forgotten. ${ }^{[80]}$

For example, one would not want to use one tone to warn of low oil pressure, another different tone for low tire pressure, and a third for high engine temperature, and expect the operator to know the system needing attention based on the tone. The connection between a particular tone sequence and its meaning is likely to be weak, especially for tones rarely heard. Spoken warnings would be much more informative for this example.

In this project, auditory route guidance used speech. Constructing an instantly understood tone language to communicate turn directions, distances, and street names would have been impossible.

Guideline 6.12 - Computer-generated, on line speech is recommended for situations that require substantial flexibility in generating spoken messages.

Guideline 6.13 - Where the choice of messages is relatively limited and known ahead of time, recorded human speech is preferred.

This recommendation is based on the opinion that, at present, synthetic speech is generally less intelligible and less preferred by listeners than recorded human speech. Synthetic speech is therefore recommended only when the required flexibility of response renders pre-recorded speech infeasible.

The literature is not definitive on this issue, however. Bucher, Karl, and Voorhees report that synthesized speech is distinct from human speech, and thus stands out. ${ }^{[81]}$ This characteristic would be useful in allowing the driver to distinguish readily between automated speech and human speech coming from the radio or other sources. On the other hand, synthetic speech places more processing demands on the driver. Bucher also reports that more training is required to adapt to the "accent" of synthesized speech to get the same performance as with human speech. 
Simpson obtained mixed results in a study that compared the pilot's response to callouts provided by a synthetic-speech generator or by speech from the pilot not flying. ${ }^{[82]}$ Synthetic speech was found to be more reliable than human speech for making certain callouts, but less reliable for others. Intelligibility was higher for speech generated by the pilot not flying. Pilots preferred synthetic speech for instrument or abnormal conditions, but expressed no preference for noninstrument (visual) flight conditions.

In this project, speech for the auditory route guidance system was constructed in real time using pre-recorded words and phrases. ${ }^{[15]}$ They included alerting phrases ("approaching," "at the," "in"), distances ("0 point 9 miles"), ordinal values ("next," "second"), verbs ("turn," "bear," "enter"), directions ("left" ), landmarks ("traffic light," "stop sign"), and numerous road names ("I-94 East," "Huron River Drive," etc.) Typical messages included "At the second stop sign, at Clarence Street, turn left" and "Approaching I-275 North, enter on the right." For additional details see section 8 of the guidelines. 



\section{NAVIGATION GUIDELINES - VISUAL DISPLAYS}

Guidelines for this topic are divided into five subsections: presentation modality, turn display format (arrows vs. maps, etc.), turn display content (which information elements are required), labeling of details, and display orientation and placement.

\section{PRESENTATION MODALITY}

Guideline 7.1 - If the information is limited to a few chunks (noun-verb pairs or prepositional phrases), there may be value in providing both auditory and visual navigation information.

The literature relevant to this guideline is not clear cut. While providing multiple sources of information gives drivers options, it also provides drivers with more information to process and could overload them. The benefits of dual modality presentation are very implementationdependent. In Streeter, Vitello, and Wonsiewicz, providing visual and auditory guidance degraded performance more than auditory guidance alone. ${ }^{[4]}$ In TravTek, rental drivers preferred having the visual display and the voice guidance operate concurrently. ${ }^{[83]}$ Bauer has reported that ALI-SCOUT drivers make the transition from using the visual display to using voice guidance once they became familiar with the interface. ${ }^{[84]}$ This may be due, in part, to the limited amount of visual information on the ALI-SCOUT display. In the research conducted as a part of this project, drivers were able to navigate quite well using either completely visual or completely auditory display interfaces. ${ }^{[15]}$ A dual modality navigation system was not evaluated. The authors give more weight to the TravTek and ALI-SCOUT results because these represent data from on-road use of real systems, not evidence from prototypes or experimental simulations.

\section{TURN DISPLAY OVERALL FORMAT}

Guideline 7.2 - For route guidance using a visual display, provide turn indications using either simple arrow displays or simple maps.

The literature suggests that drivers experience difficulty in reading detailed maps while driving. (See references 2, 85, 86, 87, 88, and 89.) Turn displays should present the intersection ahead and the direction of the turn, and the distance to it. The Walker, et al. research indicates that showing only a turn arrow can result in reasonable performance. ${ }^{[87,88,89]}$ One potential format for informing drivers when to turn is shown in figure 4. This design shows the next major intersection (and its name, distance, and landmark), the next turn (and its distance in miles surrounded by a box), the current location (along with the town and State) at the bottom of the screen, and the heading. 

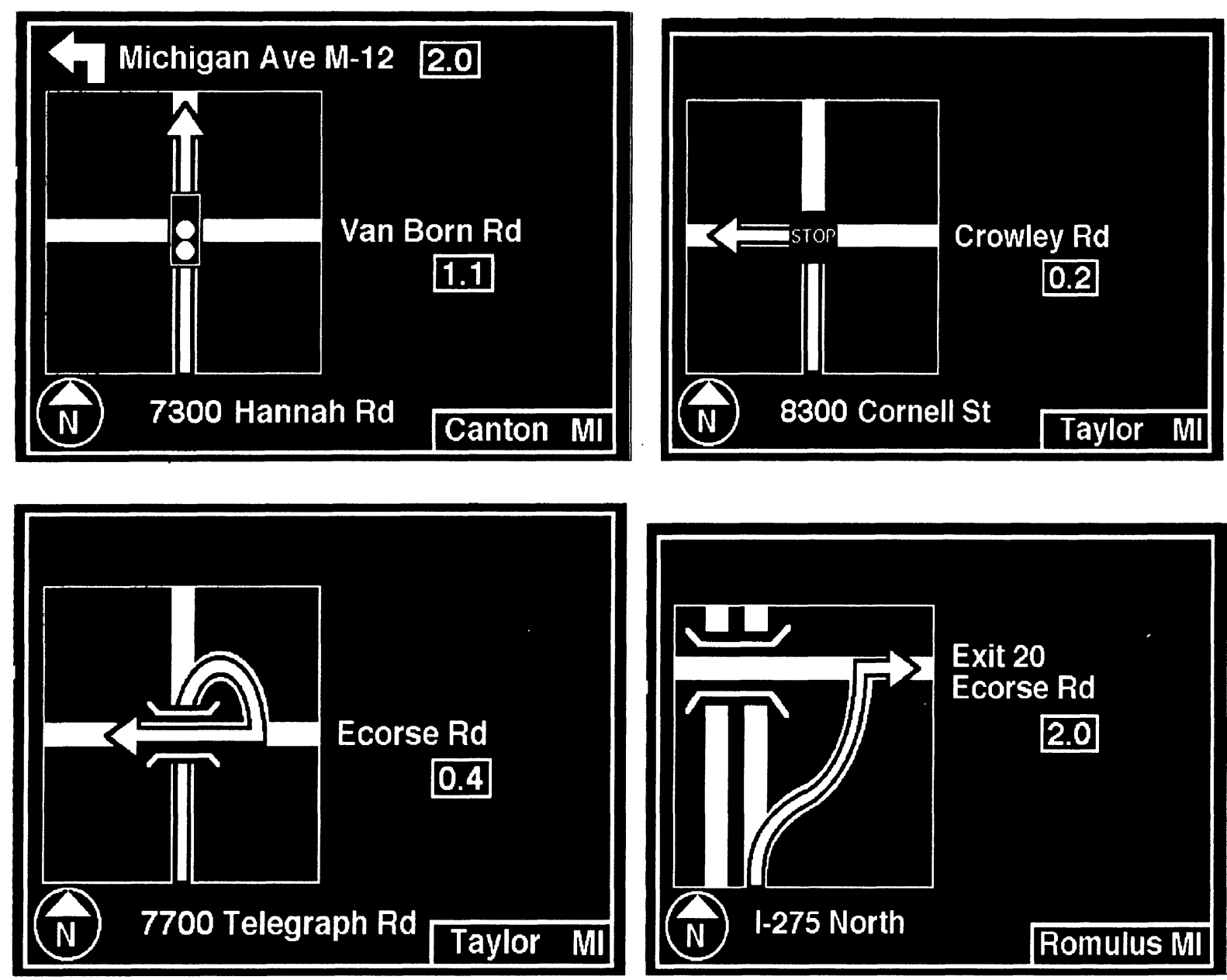

Figure 4. Example displays used in the project interface.

There may be merit in providing turn information as text (right, left), an implementation used in early versions of the Experimental Route Guidance System (ERGS). ${ }^{[90]}$ An untested implementation of this approach is shown below.

Detroit Metro Airport to Ann Arbor:

I-94w 30 miles to US-23 interchange

US-23n 5 miles to Plymouth Rd.

Turn L on Plymouth Rd.

Guideline 7.3 - Views of intersections should be plan (directly overhead) or aerial (as from a low flying airplane), but not perspective (from the driver's eye view).

Response times and errors in making decisions about intersections were examined by Green and Williams, and Williams and Green. ${ }^{[8,9]}$ Figures 5, 6, and 7 show some examples.

Differences between aerial and plan views were small. Response times and errors for both were significantly lower than those for perspective displays. Perspective displays were least preferred. 


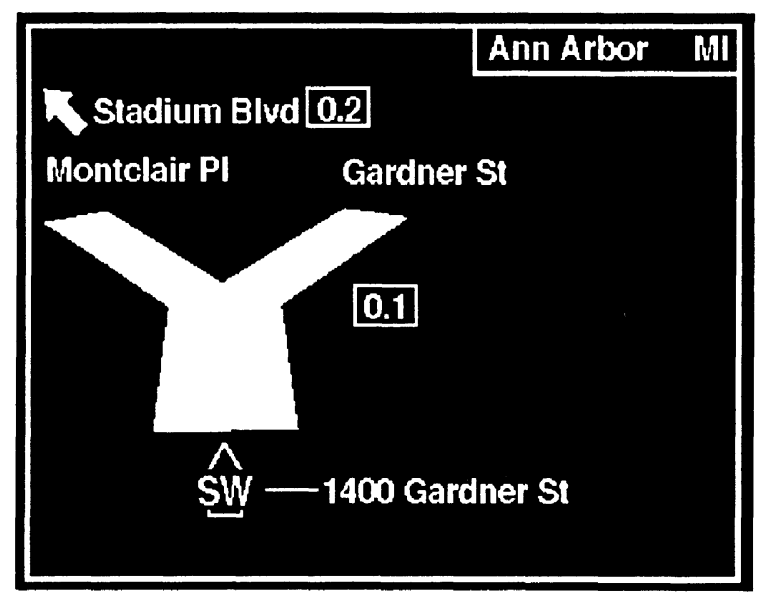

Figure 5. Aerial view of $\mathrm{Y}$-intersection.

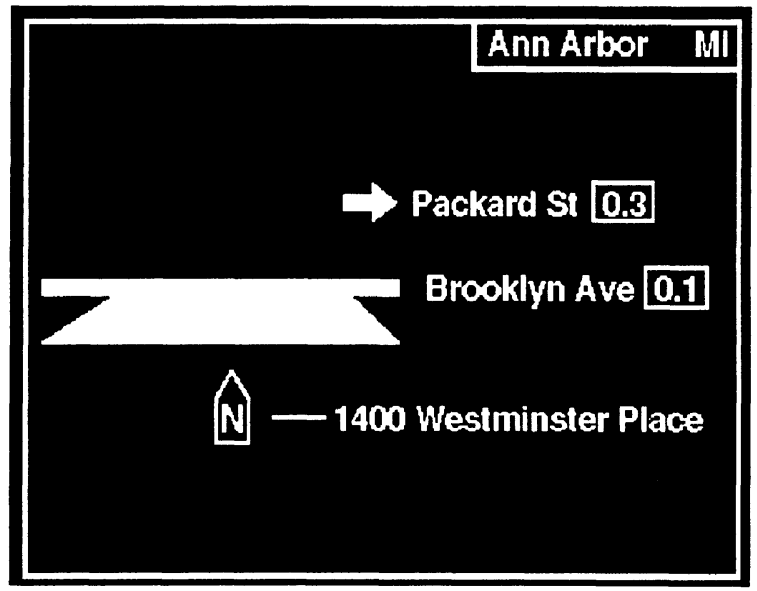

Figure 6. Perspective view of T-intersection.

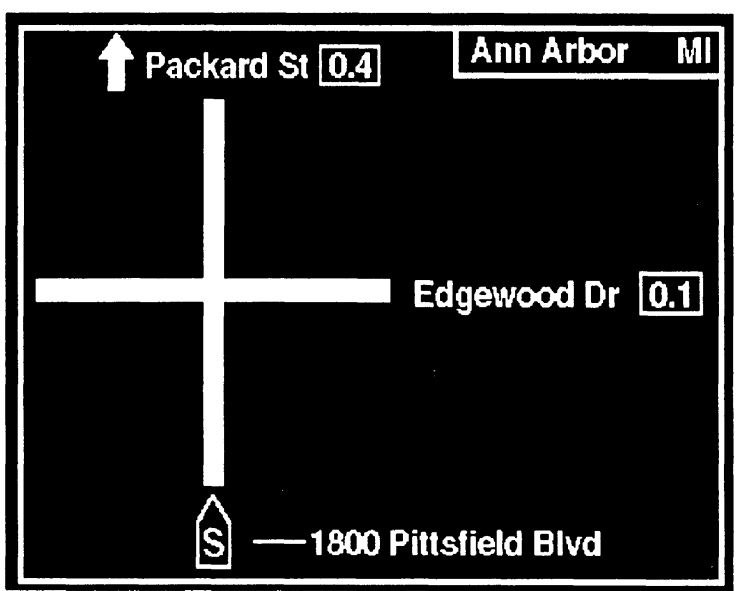

Figure 7. Plan view of cross intersection. 
Guideline 7.4 - Roads on map-like displays should be shown as a single, solid lines, not multiple lines to represent each road edge.

This guideline is supported by the work of Green and Williams, and Williams and Green. ${ }^{[8,9]}$ Participants in experiments made more errors and took longer to make decisions in matching map displays with real-world scenes when the map graphics were outlines.

\section{TURN DISPLAY CONTENT}

\section{Guideline 7.5 - Limit the amount of detail on maps.}

Details fall into three categories. They include line graphics (roads, political boundaries, rivers, etc.), landmarks (buildings, etc.), and labels (street names, route numbers, road names, etc.). Line graphics will have a greater effect on response time than will the other factors. According to Stilitz and Yitzhaky, the time (in seconds) required to locate a street on a map with grids is $(0.38 \mathrm{n})+2.1$, where $n$ is the number of roads in the grid (range of 4 to 25$)$. ${ }^{[91]}$

Guideline 7.6 - Required information includes the road being driven, the name of the road for the next turn, the direction and approximate angle of the next turn, and an indicator of distance to the turn.

These required items concerning the next turn should be shown even if the turn is distant. Additional clarifying information (i.e. landmarks, additional streets) should be limited to items that help drivers prepare for and execute the maneuver.

\section{Guideline 7.7 - Provide landmarks on navigation displays.}

Landmarks should be provided for both visual and auditory navigation displays. At a minimum, landmarks include stop signs, traffic lights, and bridges. (See navigation visual display guideline 17.) The best landmarks are objects that can be seen at great distance (often because of well-lit and recognizable signs), both day and night, are close to the road, near intersections, and remain in place for many years. Gasoline stations and fast food restaurants are generally good landmarks. Landmarks are usually visible from a greater distance than street name signs. Reading street name signs is a particular problem for older drivers at any time and for all drivers at night. In the United States, when people give driving directions, the predominant cues are landmarks. ("Go to the second traffic light and turn right. Go one street past the first stop sign and turn left. The building you want should be on your right. You cannot miss it." )

Use of landmarks was examined in Hoekstra, Wen, Williams, George, and Green. ${ }^{[14]}$ The navigation systems used in Green, Hoekstra, Williams, George, and Wen; and Green , Hoekstra, and Williams also used landmarks. ${ }^{[15,16]}$ Participants rated landmarks as being very helpful. See figure 4 for examples of how traffic signals, bridges, and stop signs might be represented. Flashing lights are depicted as a ball at the center of the intersection with 
radiating lines (the sun). At the present time, many data bases do not have information on landmarks. Data base developers are encouraged to collect it.

The value of landmarks will vary from country to country. In Asia, streets often are not arranged in a grid, and buildings are numbered based on when they were built, not in sequence along a street. As a consequence, based on the author's experience in Asia, navigation instructions are often given by reference to buildings.

\section{Guideline 7.8 - For complex choice points, show all roads and ramps.}

Examples of complex choice points are expressway interchanges and intersections of more than two streets. Cross and McGrath found that drivers experienced difficulty with route guidance at expressway entrances and exits (taking the wrong turn at an interchange, difficulty in finding the ramp, taking an entrance in the wrong direction, etc.). ${ }^{[92]}$ All ramps directly connecting to the planned path should therefore be shown but not necessary in entirety.

\section{Guideline 7.9 - Turn displays should show two turns in a row when the turns are in close proximity (in succession).}

While there has not been empirical work on what constitutes "close proximity," those who have been involved in research on navigation believe that showing two turns is necessary. ${ }^{[55,90]}$ The intent of this guideline is to allow drivers to execute the first maneuver in such a way as to be prepared for the second. Accordingly, "close proximity" will depend on speed and the maneuver in question (crossing several lanes of an expressway, turns on residential streets, etc.). At a minimum, a reasonable working definition for "close proximity" is $0.1 \mathrm{mi}(0.16$ $\mathrm{km}$ ), since that is the accuracy of all displayed information. The "Michigan left turn" screen sequence (a right turn immediately followed by a U-turn) implemented in Green, Hoekstra, Williams, Wen, and George and Green, Hoekstra, Williams, George, and Wen and Green, Hoekstra, and Williams is an example of a close proximity situation. ${ }^{[14,15,16]}$ (See figure 8.)

Guideline 7.10 - In many circumstances, turn displays should show the locale or regional name.

Presenting the locale builds driver confidence in the navigation system. Research does not exist that identifies exactly when locale should be provided (and how specific the locale should be: the county, the city, or the neighborhood). Candidate items of information (in addition to road driven, next turn road, distance to turn and locale) include current location (street address), compass heading, north vector, distance from last turn, distance from last cross street (and its name), distance to nearest landmark (and its name), next cross street (and distance), distance traveled, time traveled, desired lane, driving distance to destination, crow-fly distance and direction to destination, destination name and address, and estimated time of arrival. ${ }^{[6,7]}$ In the route guidance system prototyped for this project, each screen showed the current street address, the distance to the next street and its name, the distance to and direction of the next turn (as well as the street name), landmarks at either place, and the current compass heading. (See figure 4.) 

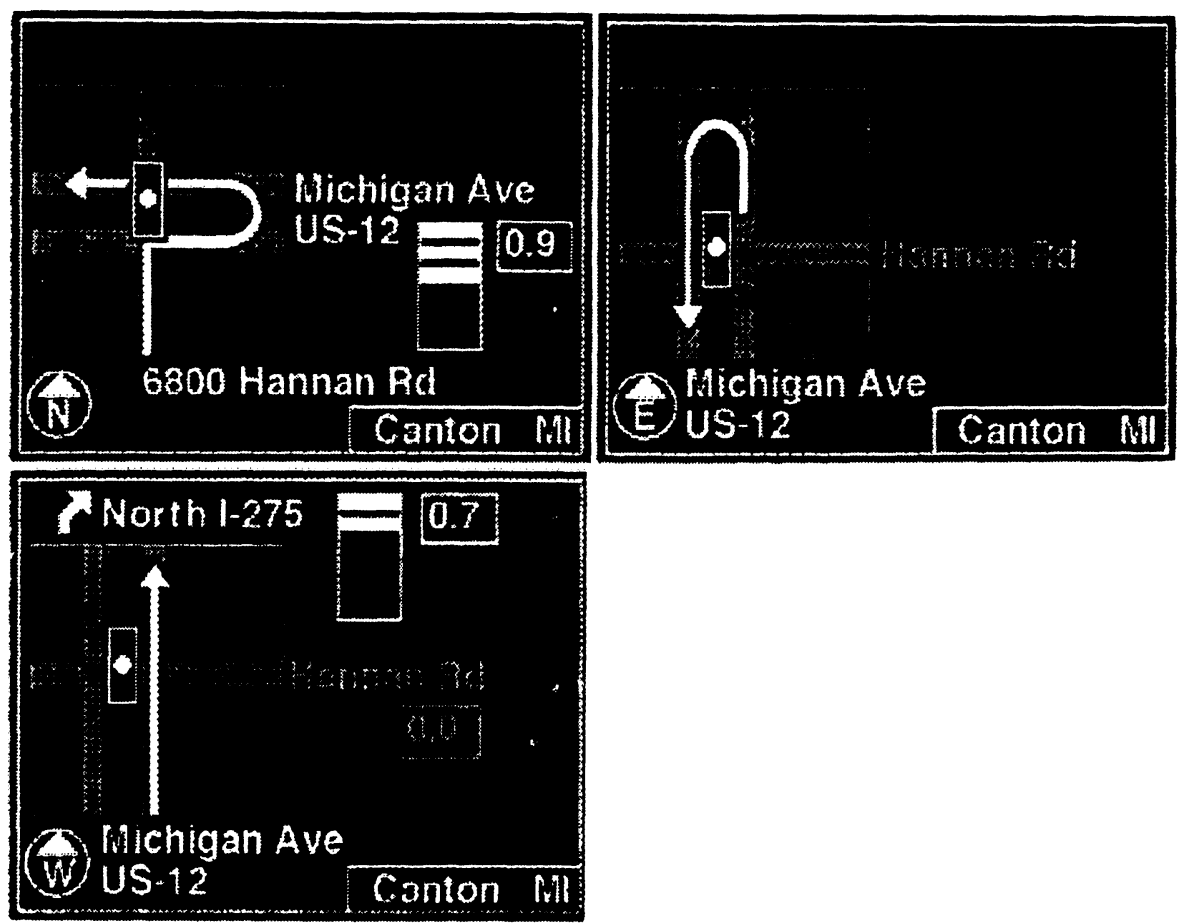

Figure 8. U-turn sequence.

Guideline 7.11 - For route guidance, the compass element should show the heading. For route planning, it should show north.

Since the purpose of the compass information is to determine heading (the direction of travel), showing north instead of the direction of travel forces the driver to make an unnecessary mental computation. When the heading is given, it should be as one of the eight basic directions (N, E, S, W, NE, SE, NW, SW) as was the case for the interfaces prototyped in this project.

There may be circumstances where showing both the heading and north vectors may be useful. For example, if drivers are taking an expressway ramp, knowing which way is north could be useful. The results from Adeyemi suggest that not only should north be shown, but so should other compass headings as well. ${ }^{[93]}$ It is not clear how applicable this is to automotive navigation, since roads generally have labels associated with only the four cardinal directions (north, east, south, west).

Clearly, when other navigation information is not provided, some drivers find compasses useful and purchase them as original equipment options or as aftermarket products. On the other hand, in Green, Hoekstra, Williams, George, and Wen, some drivers did not notice the compass until it was mentioned in the post-experiment briefing, probably because it was not needed for the tasks drivers were given. ${ }^{[15]}$ While it is sensible to place the compass on the navigation display, the penalty for placing it elsewhere (e.g., on a roof header) is unknown.

Note: See Guideline 7.28 for information on map orientation, a related item. 
Guideline 7.12 - If distances to turns are provided and easy to read, time based countdown bars to the turn may not be required.

Countdown bars are a bargraph display showing the distance to the next turn. Normally, the countdown begins when the driver is close to the turn point [within 0.1 miles $(1.6 \mathrm{~km})$ ]. (Figure 9 shows examples from the Ali-Scout interface.) In Green, Hoekstra, Williams, George, and Wen, time-based countdown bars were provided in the navigation display in addition to a distance counter. ${ }^{[15]}$ In later work, they were removed, based on test participant preferences and comments. ${ }^{[16]}$ This change did not result in complaints or an increase in the number of turn errors while driving. On the other hand, in TravTek the countdown bars represented $0.1 \mathrm{mi}(0.16 \mathrm{~km})$ to the next maneuver. In this implementation, the countdown bars aided drivers in anticipating and executing maneuvers. The decision to use or not use countdown bars depends on what additional information is displayed to the driver and how the countdown bars are implemented (e.g., time or distance based). ${ }^{[94]}$

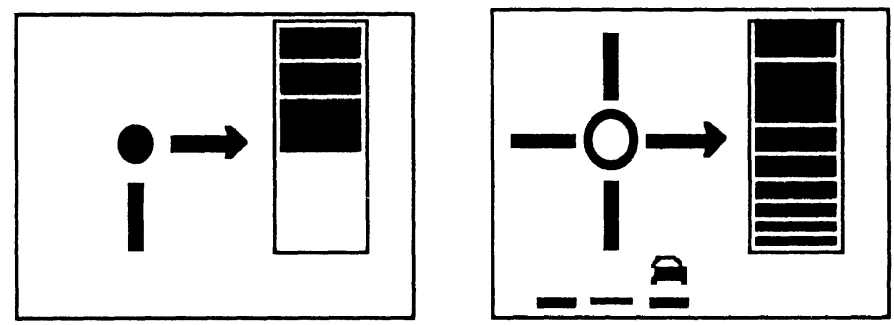

Figure 9. Examples of countdown bars.

Guideline 7.13 - For expressway ramps, give both the route name and direction, and a city locator.

For example, the display should show "I-275 North" and "Flint." The names should be on separate lines, so drivers will not think they are looking for "North Flint." Errors on expressway ramps are common. ${ }^{[88]}$ Giving drivers the opportunity to search for both route and place name signs should reduce errors, and makes in-vehicle displays compatible with signs.

Guideline 7.14 - Showing a plan view with lane details should be avoided in most situations.

While showing lane details (the number of lanes in the current segment, the recommended lane) can be useful (and, in some cases, drivers prefer it), lane details can clutter a map. ${ }^{\left[{ }^{9]}\right.}$ (See figure 10.) The clutter can make the map more difficult to read, though the performance penalties have not been examined in laboratory or on-the-road studies (but should be). There may be exceptions to this guideline where multiple turn lanes are provided. 


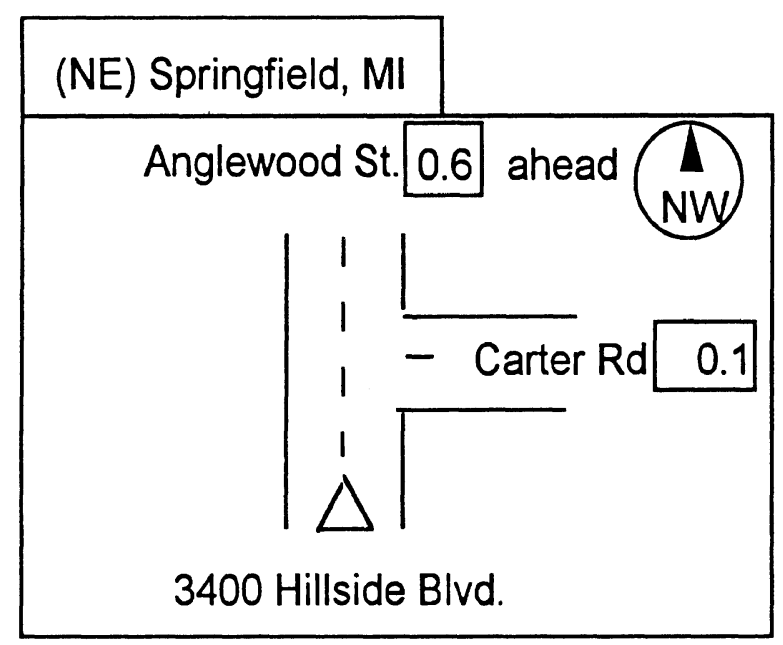

Figure 10. Example of map showing lane details.

\section{Guideline 7.15 - Provide a "destination reached" screen.}

This screen should be different from the last turn instruction and confirm drivers have arrived at their destination.

\section{LABELING OF DETAILS}

Guideline 7.16 - Stop signs, traffic lights, and bridges should be shown as graphics (icons), not text.

Traffic lights and stop signs should be shown in the center of the intersection. (See figure 4.) Usually, space is not available to show them as text. Care must be taken in implementing traffic light icons, so that it is apparent the icons are providing information, not commands, to drivers. If the green ball of a traffic light icon is too bright, drivers may look at it and think they can proceed through an intersection, even though the traffic control device at the intersection might be red in their direction.

The purpose of the stop sign and traffic light icons is to indicate that an intersection is controlled, not to identify the exact location of the traffic control device. If an intersection has lights and a stop sign, the landmark visible from the greatest distance (the light) should be shown in the center of the intersection. Placement of a second landmark adjacent to the intersection may be warranted in some cases.

Bridges (usually shown as outward-facing brackets) should surround the road. (See figure 4.) 
Guideline 7.17 - The planned path should be distinctive from other possible roads and ramps.

This guideline follows the metaphor of computer graphic interfaces showing an option (such as on a menu) as being possible but not desired. Following that metaphor, other possible roads and ramps can be "grayed out." Additionally, names for those other options may be provided to help the driver choose the desired path. This guideline applies to both turn displays and more general displays used for trip planning.

\section{Guideline 7.18 - On detailed maps, exaggerate details about road intersections.}

A common mistake made by drivers is to think roads intersect when they do not. This is a particular problem for the intersection of expressways with lower class roads. ${ }^{[92,95]}$ Intersections are usually shown as dots for overview maps. Non-intersecting roads require that a bridge be shown. Critical details, when drawn to scale, are sometimes not legible.

Guideline 7.19 - Give State abbreviations when cities or regions are shown, to avoid confusing cities and regions with street names.

Failure to include abbreviations was a problem in some of the early interfaces described in Williams and Green. ${ }^{[15]}$

Guideline 7.20 - Give full street names to avoid confusing streets with regions, and streets with each other.

A good example is in Atlanta where there is Peachtree Street, Peachtree Avenue, Peachtree Boulevard, etc. Giving an address as "1000 Peachtree" is incomplete. There may be instances when space is limited and the street name is unique (e.g., there is only a "Main Street" and not a "Main Boulevard" in a locale). In those instances the road designator (street, road, boulevard, etc.) may be omitted.

Guideline 7.21 - Where distances are given, it is desired to give units (mi or km) to help the driver understand that the numbers indicate distances.

In Green, Hoekstra, Williams, George, and Wen and Green, Hoekstra, and Williams, units were not given on turn displays, and drivers almost immediately recognized the units (miles). ${ }^{[15,16]}$ However, if a metric/English switch was unexpectedly set to the metric position, and drivers were unaware of the switch, they might consider the system poor at estimating distances (thinking the units were miles, not kilometers). An option might be to show units only for the nondefault system (metric).

Guideline 7.22 - All text should be horizontal.

The literature on mental rotation shows that the time to read text increases as a function of the angular deviation from horizontal. Horizontal labels should be used even for streets displayed 
vertically. This guideline needs to be considered in light of the overall design of moving map displays. It may be the case that this guideline is violated in order to produce a display that is overall easier to read and uncluttered. Depending on the level of detail (e.g., scale, number of streets) shown on a moving map display, it may be desirable to present text (street names) oriented in the same direction as streets to reduce clutter and improve legibility.

\section{Guideline 7.23 - Use no more than two levels of line thickness on maps to differentiate road class.}

Thicker lines signify higher class/higher speed roads. In the research on traffic information displays, it was difficult to distinguish differences in line thicknesses when three levels of thickness was used to code roads. ${ }^{[10,96]}$ If line thickness is used in this manner, the widths should vary so that the second line is twice as wide as the first discriminable line. (See Stevens, $1975^{[97]}$ or Baird and Noma, $1978^{[98]}$ for more information on Weber's Law.)

Guideline 7.24 - If the navigation system has the desired accuracy, distances should be displayed to the nearest 0.1 miles (equivalent to $0.16 \mathrm{~km}$ ).

This guideline ensures that the navigation system and odometer will be consistent and can be used together.

Guideline 7.25 - Street addresses should be shown to the nearest 0.1 miles (equivalent to $0.16 \mathrm{~km}$ ).

This accuracy is compatible with other parts of the navigation system such as the countdown timer. There may be instances when the local numbering scheme is accurate to some other amount, in which case that accuracy should be used. Providing the exact address is not desired and, because the display changes quickly, it would be distracting.

\section{Guideline 7.26 - Turn arrows should approximate the manner in which drivers think of turns.}

Drivers cluster turns into three basic categories: (1) bear (right or left), a deviation in path from a few degrees to well over 45 degrees; (2) turn (right or left), a deviation of typically 90 degrees; and (3) take/make a sharp (right or left), a deviation of typically 135 degrees. (See reference 99.) For simple interactions, turn arrows on the display can have angles of only 45, 90, or 135 degrees. Arrows should represent only the initial turn geometry, not the position at the end of the maneuver. Therefore, since most expressway exits involve bearing off to one side, not a sharp turn, arrows for them should be at 45 degrees.

\section{DISPLAY ORIENTATION AND PLACEMENT}

Guideline 7.27 - Since turn displays are used often while driving, locate them close to the line of sight, such as on top of the center console or on a HUD. 
Data on look frequency to navigation displays appear in Green, Hoekstra, Williams, George, and Wen; and Green, Hoekstra, and Williams. ${ }^{[15,16]}$ In those two experiments, ease-of-use rating for HUD and instrument panel-mounted navigation displays were the same. In Williams and Green, and Green and William, response times to HUD displays were about 8 percent shorter than those for instrument panel-mounted displays. ${ }^{[9,8]}$ The difference was greater for older drivers. Specific recommendations for display location appear in the Military Standard. ${ }^{[26]}$

\section{Guideline 7.28 - For route guidance, orient map-like displays heading up. For trip planning, orient maps north up.}

What drivers see through the windshield and what drivers see on the in-vehicle displays when they are driving should be compatible (principle 1). The intent of this guideline is to minimize the number of spatial transformations a driver must make for the map and their internal representation of the world to agree. Based on the first author's observations on the use of paper maps, when drivers plan a route, especially at the beginning of a trip, the paper map is held upright (north up) and directions include compass headings ("go north on ..."). When passengers are directing drivers and the heading is steady, they turn the folded map so that it is oriented in the same direction as the vehicle, even though text on the map may then be upside down or sideways. (As an aside, this is not true of Triptiks, which are designed for guidance, and are oriented towards the heading.) Hence, the guidance displays should be heading up. In this orientation, the view out of the windshield and objects on the map are compatible. (See general visual display guideline 11.)

\section{Guideline 7.29 - It is not desirable to rotate turn displays during a turn.}

In Green, Hoekstra, Williams, George, and Wen; and Green, Hoekstra, and Williams, drivers saw a turn display that remained fixed on their screen until after a turn was completed, at which point the next screen appeared. ${ }^{[15,16]}$ This eliminates potential distractions from the changing, peripherally-viewed navigation display. The workload while drivers execute turns is fairly high, and driver looks to the navigation display are much less frequent during a turn than preceding or following it. Often, changing the display during a turn can make drivers' tasks more difficult because they must draw information from a moving display.

If an intersection includes several choice points (and several turns), the display should generally update after each turn, if possible. This may impose accuracy constraints that, in some situations, are not yet technically feasible.

While such situations are not common, drivers in Green, Hoekstra, Williams, George, and Wen encountered an intersection with five legs and two traffic lights. ${ }^{[15]}$ (See figure 11.) If drivers bore left at the first choice point and then stopped at the first light, they were confused because the map view and the road view disagreed. In this instance, a second view of the intersection may have been beneficial if presented immediately after the turn. 


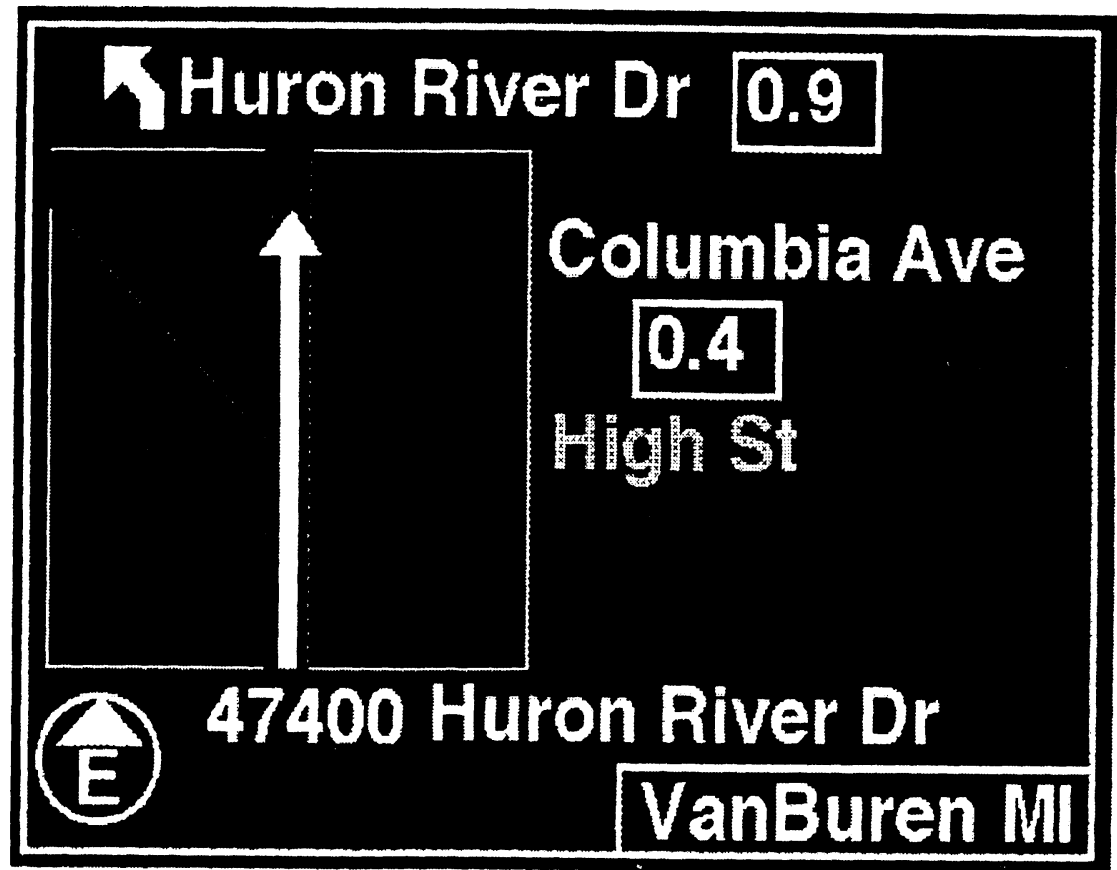

Figure 11. Columbia Avenue fork as an example of a complex intersection. 


\section{NAVIGATION GUIDELINES - AUDITORY OUTPUT}

This sections concerns how computer-generated spoken instructions should be delivered to drivers.

Guideline 8.1 - Auditory instructions should be limited to four chunks in all cases, three or less in most cases.

Key information elements include the relative direction of the next turn (left or right), the distance to the turn, and the associated road name. Chunks commonly formed from them include prepositional phrases (at Green Road) and verb-noun pairs (bear left). Providing four chunks of information or fewer will improve the probability that drivers will remember the instructions. (In the three message sequence provided for guideline 8.2 that follows, the "early" message is three chunks, the prepare and approaching messages are four chunks.) Some judgment is required in deciding what to include in a message, especially in the three versus four chunk case, as the fourth chunk may be a critical piece of information. If one message has four chunks of information and another has two, consider equalizing the number of chunks in the two messages. For data on recall of auditory information related to navigation, see Galling. ${ }^{[100,101,102]}$

Guideline 8.2 - If a series of three messages about a maneuver is given, the following structure, messages, and timing are recommended.

Examples

Early: $\quad$ In 3.5 miles at Green Street, bear left.

Prepare: $\quad$ In 1 mile at the traffic light at Green Street, bear left.

Approaching: Approaching Green Street, at the traffic light at Green Street, bear left.

The "early" maneuver message provides forewarning of upcoming maneuvers. This message occurs shortly after a preceding maneuver is completed. The purpose of the "prepare" statement which provides landmarks, location, distance away, etc. is to signal drivers to move to the appropriate lane and to begin searching for the street, landmark, or exit. The "approaching" message is the last minute reminder; it signals the driver to execute the maneuver. Specifically, messages are structured as shown in table 3.

Distances are expressed in tenths of a mile and the decimal point is noted ("In three point two miles"). This format is preferred because it is more succinct than "three and two tenths of a mile." For distances less than a mile, the zero is not mentioned ("In point nine miles").

Locations include street names ("Huron River Drive," "I 94") and exit numbers with their name ("exit 25, Ford Road"). Major numbered roads (Interstate route 94, Michigan route 14) are referred to by initials (I 94, M 14) to reduce memory load.

Actions permitted include "turn," "bear," and "make a sharp," along with the directions "left" and "right." 
Landmarks are "traffic lights" (including flashing yellow and flashing red lights), "stop signs," "bridges," and "underpasses." Traffic light, the commonly used term, is preferred over traffic signal, the accepted traffic engineering descriptor. Landmarks should be linked to streets using terms such as "at," "just before," or "just after." If a landmark is not present, then use the number of streets ("next," "second," "third") in place of it in the "prepare" message. Note, to use the number of upcoming cross streets for route guidance directions requires a high accuracy vehicle-positioning capability. Depending on the implementation, counting of cross streets may not be a viable solution. ("At the third street, Madelon Street, turn right.") Both the "prepare" and "approaching" messages can have "and make an immediate U-turn" appended to them. For additional information on vocabulary, readers should see Green, Hoekstra, Williams, George, and Wen. ${ }^{[15]}$

Table 3. Message content and timing.

\begin{tabular}{|c|c|c|c|}
\hline \multirow[t]{2}{*}{ Message } & \multirow[t]{2}{*}{ Information Provided } & \multicolumn{2}{|c|}{ When Provided } \\
\hline & & city & highway \\
\hline $\begin{array}{l}\text { Early } \\
\text { (always given) }\end{array}$ & "In" \{distance\} "at" \{location\} \{action\} & $\begin{array}{l}5 \mathrm{~s} \text { after } \\
\text { turn }\end{array}$ & $\begin{array}{l}15 \mathrm{~s} \text { after } \\
\text { turn }\end{array}$ \\
\hline $\begin{array}{l}\text { Prepare } \\
\text { (only given if } \\
\text { enough dist. after } \\
\text { early message) }\end{array}$ & $\begin{array}{l}\text { \{distance }\{\text { location }\}\{\text { action }\} \\
- \text { or - } \\
\text { \{distance }\{\text { \{landmark }\{\text { location }\} \text { \{action }\}\end{array}$ & $\begin{array}{l}1 \mathrm{mi} \\
\text { before } \\
\text { turn }\end{array}$ & $\begin{array}{l}1.9 \mathrm{mi} \\
\text { before } \\
\text { turn }\end{array}$ \\
\hline $\begin{array}{l}\text { Approaching } \\
\text { (always given) }\end{array}$ & $\begin{array}{l}\text { "approaching" }\{\text { location }\} \text { \{action }\} \\
\text { - or - } \\
\text { "approaching" }\{\text { landmark }\} \text { location }\} \text { \{action }\}\end{array}$ & $\begin{array}{l}0.1 \mathrm{mi} \\
\text { before } \\
\text { turn }\end{array}$ & $\begin{array}{l}0.3 \mathrm{mi} \\
\text { before } \\
\text { turn }\end{array}$ \\
\hline
\end{tabular}

In designing the auditory guidance system, the number, content, and timing of messages was considered at various stages of the design of the navigation driver interface developed as a part of this project. ${ }^{[1]}$ It was clear from those discussions that a single message ("turn right now" or "turn right on Main Street") would not provide drivers with enough warning to smoothly decelerate to make the turn, or if presented early enough, might be forgotten. At the other extreme, four-message structures were considered to be too chatty and would have been annoying. The three-message structure was chosen over the two-message structure because it is important to tell drivers about subsequent maneuvers shortly after each maneuver was completed, something a timed two-message sequence may not do. Further, immediate information about subsequent maneuvers reassures drivers the previous maneuver was correct. Two- versus three- message structures were not compared empirically. However, in on-theroad tests of the visual version of the navigation system, drivers looked at the navigation system within a few seconds of completing a turn. ${ }^{[15]}$ While this could be drivers responding to a screen update, it is believed drivers were seeking maneuver feedback. 
Landmarks were provided following the rationale given in navigation visual display guideline 7. In brief, drivers want and naturally use landmarks to navigate. Landmarks were not provided in the early maneuver because often the information would not be useful or would be very difficult to apply ("at the seventh traffic light').

Distances are the first chunk in the early and prepare messages so the drivers will realize they have time to act upon the remainder of the message, and will not hastily maneuver as the message is presented. Of the message chunks, the action is the most important part of the message. The literature on short-term memory shows recall is best when the time between information presentation and recall is minimized (referred to as the recency effect), hence the action chunk was presented last. (See Streeter, Vitello, and Wonsiewicz and the work on Back Seat Driver (Davis) for a discussion of this point and others related to message structure. ${ }^{[47,95]}$

During discussions and early evaluations of this message structure, it became clear that the final instruction needed special attention. Instructing the driver to make a maneuver ("'turn right on Main Street") could create problems as that expression might be viewed as a command, with drivers turning even if they were not at that street yet (which can occur with closely spaced streets) or ignoring stop signs, traffic lights, one way signs, blockage due to traffic, or other information to the contrary, all of which could lead to accidents. Of the words and phrases considered, "approaching" represented the best combination of specificity, brevity, and contrast with other message vocabulary.

When messages should be presented was given less attention than other aspects of the auditory guidance interface. The recommendations for timing of the "prepare" and "approaching" messages were adopted from TravTek (Fleischman), although some thought has been given to the work of Eberhard, and Finnegan and Green. ${ }^{[33,103,104,105]}$ While the TravTek timing recommendations concern only two speeds, experience from TravTek suggests three are desired [ $35 \mathrm{mi} / \mathrm{h}(56 \mathrm{~km} / \mathrm{h})$ or less, 40 to $50 \mathrm{mi} / \mathrm{h}(64$ to $80 \mathrm{~km} / \mathrm{h})$ and 55 to $65 \mathrm{mi} / \mathrm{h}(88$ to $104 \mathrm{~km} / \mathrm{h}$ )]. The interface in this project used times-to-travel to choice points (which included an allowance for the time to give the guidance message). Early messages were presented as soon as a driver was thought to have returned to normal driving speed after having completed a maneuver.

The particular message structure recommended was tested in Green, Hoekstra, Williams, George, and Wen. ${ }^{[15]}$ Few problems were discovered, indicating the design was reasonable. It must be emphasized, however, that variations of the structure (such as changing the order of phrases in each message) were not examined due to limited resources.

\section{Guideline 8.3 - Where timing permits, each decision point should have its own instruction.}

Complex expressway interchanges may have branching exit ramps. Timing and situational constraints may require special guidance messages. Following is an example for an exit ramp that branches in two directions. 
Prepare: In 1 point 5 miles, at Exit 20, Ecorse Road, exit on the right.

Approaching: Approaching "I" 275 North exit.

Special: $\quad$ After the underpass, bear left.

Guideline 8.4 - When a street name changes, tell drivers "(Street name) has changed to (new street name)".

To minimize the number of undesirable messages, this function should be provided upon driver request. For example, a "where am I" function key was employed in TravTek. When this key was depressed, the system informed the driver as to the name of the street they were driving on. ${ }^{[106]}$

Guideline 8.5 - When traveling on city streets, tell drivers "entering (city name)" when they cross a political boundary.

This seems to be reasonable to do in that it provides useful orientation information, especially if a visual display with an identifier for the locale is also provided. However, this guideline has not been tested empirically. As with Guideline 8.4, this function should be provided upon driver request to minimize unwanted voice messages.

Guideline 8.6 - There may be instances when "continue" messages are desired.

If the driver must travel a long distance to the next maneuver, and the navigation system remains silent, the driver may think the system is inoperative. In Green, Hoekstra, Williams, Wen, and George, drivers tended to overestimate the distance traveled, and expected to turn sooner than necessary. ${ }^{[15]}$ Also, even for short distances, there may be major streets intervening between a current location and a desired turn street. It may be necessary to tell drivers not to turn, or to have reminders about the distance to the turn. "Continue" messages were included in Back Seat Driver. ${ }^{[95]}$ An alternative would be to allow the driver to press a button to request a repetition of the "early" message with the current distance. Since the purpose of the research supporting these guidelines was to include a wide variety of turns (and the instructions for them) in the test route, and to have as many of them as possible to examine repeatability, there were few opportunities for "continue" messages in the brief route examined.

Guideline 8.7 - Provide drivers the capability to activate and deactivate auditory prompts and directions.

Drivers will not always desire auditory directions and may find them anoying at times. A function that activates/deactivates auditory prompts should be provided. After the function is activated or deactivated the system should provide the driver with the current status (i.e., "voice prompt off"). If the voice prompt is on, it should be implemented so that it interrupts other audio systems in the vehicle (e.g., radio). ${ }^{[106]}$ 


\section{NAVIGATION INPUT GUIDELINES}

The emphasis of this section is on the entry of destinations, though the entry of other information is also covered. The navigation system examined in this project did not provide a destination entry device as destinations were assumed to be preprogrammed. Guidelines for destination entry are primarily based on the contractor's research from other projects.

Guideline 9.1 - Accepted practice for vehicle motion during entry tasks is as follows:

Table 4. Driver tasks and vehicle motion.

\begin{tabular}{|c|c|}
\hline \multirow{7}{*}{$\begin{array}{l}\text { Tasks carried out } \\
\text { while moving } \\
\text { (or at other times) }\end{array}$} & display brightness and contrast adjustment \\
\hline & voice volume \\
\hline & repeat last voice message \\
\hline & zoom in/zoom out \\
\hline & $\begin{array}{l}\text { "route hop" (resetting the navigation system when the } \\
\text { known and displayed positions differ }\end{array}$ \\
\hline & declutter (show fewer map details) \\
\hline & switch between turn display and overview map \\
\hline \multirow{2}{*}{$\begin{array}{l}\text { Tasks carried out at zero } \\
\text { speed (e.g. stopped at traffic light) } \\
\text { or predrive }\end{array}$} & map scrolling (may be possible while moving) \\
\hline & $\begin{array}{l}\text { switch between north up and heading up display (may be } \\
\text { possible while moving) }\end{array}$ \\
\hline \multirow{4}{*}{$\begin{array}{l}\text { Predrive tasks } \\
\text { (when the vehicle } \\
\text { is in park) }\end{array}$} & destination entry \\
\hline & accessing business listings (yellow pages) \\
\hline & $\begin{array}{l}\text { setting voice (male vs. female voice, etc.) and } \\
\text { infrequently used system options }\end{array}$ \\
\hline & system calibration such as setting the compass \\
\hline
\end{tabular}

Tasks were assigned to these categories based on the extent to which they would interfere with driving, which is primarily due to their duration. The distinction between the zero speed and predrive tasks is that the predrive tasks take longer to complete and may take longer than the portion of a traffic signal cycle that is normally available, thus interfering with traffic flow as the driver delay moving to complete the task. Tasks may be assigned to higher risk categories if the alternative, either stopping or placing the car in park, depending on the task, presented greater risk to the driver. (For data on performing the predrive tasks using a TravTek interface, see reference 107.

Not all of the tasks fit completely into one category. For example, setting the compass involves entering various items to begin calibration and then driving a short distance (sometimes in a circle) to complete calibration. 
Guideline 9.2 - For entering street addresses with a touch screen or keyboard, use either a Qwerty keyboard or a phone keypad.

Destination entry involves both the initial entry of a set of destinations as part of system set up, the addition of new destinations over time, and recall of particular destinations from lists of stored destinations. This guideline concerns the original entry and addition tasks, though it may be applicable to stored entry retrieval in some interfaces.

In another contractor project, Paelke compared four methods for entering cities, streets, and building numbers using a 5 -in $(12.7 \mathrm{~cm})$ diagonal touch screen. ${ }^{[108]}$ Times for the Qwerty keyboard (figure 12) and phone keypad (figure 13) were significantly less than the times for a double press touch screen (similar to that used in TravTek, figure 14) or a scrolling menu (similar to that used by Zexel, figure 15). The primary factor influencing entry time was the number of keypresses required-something a good design should minimize.

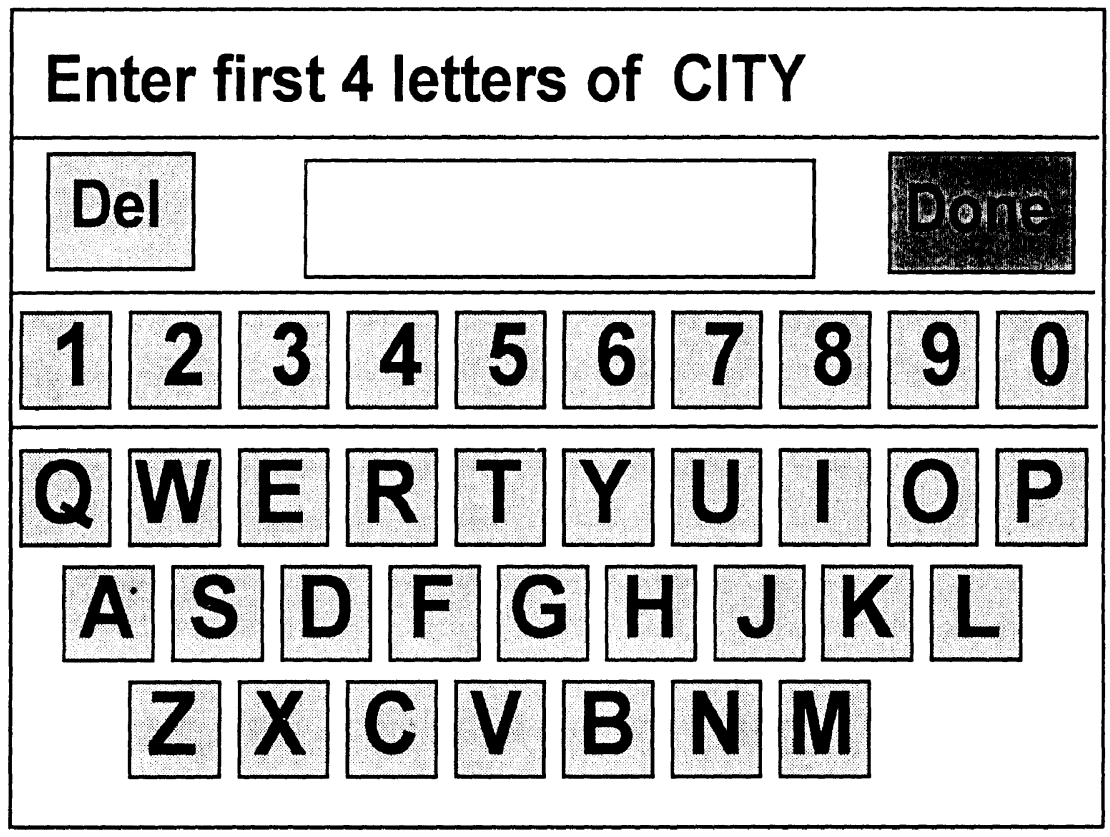

Figure 12. Example Qwerty keyboard. 


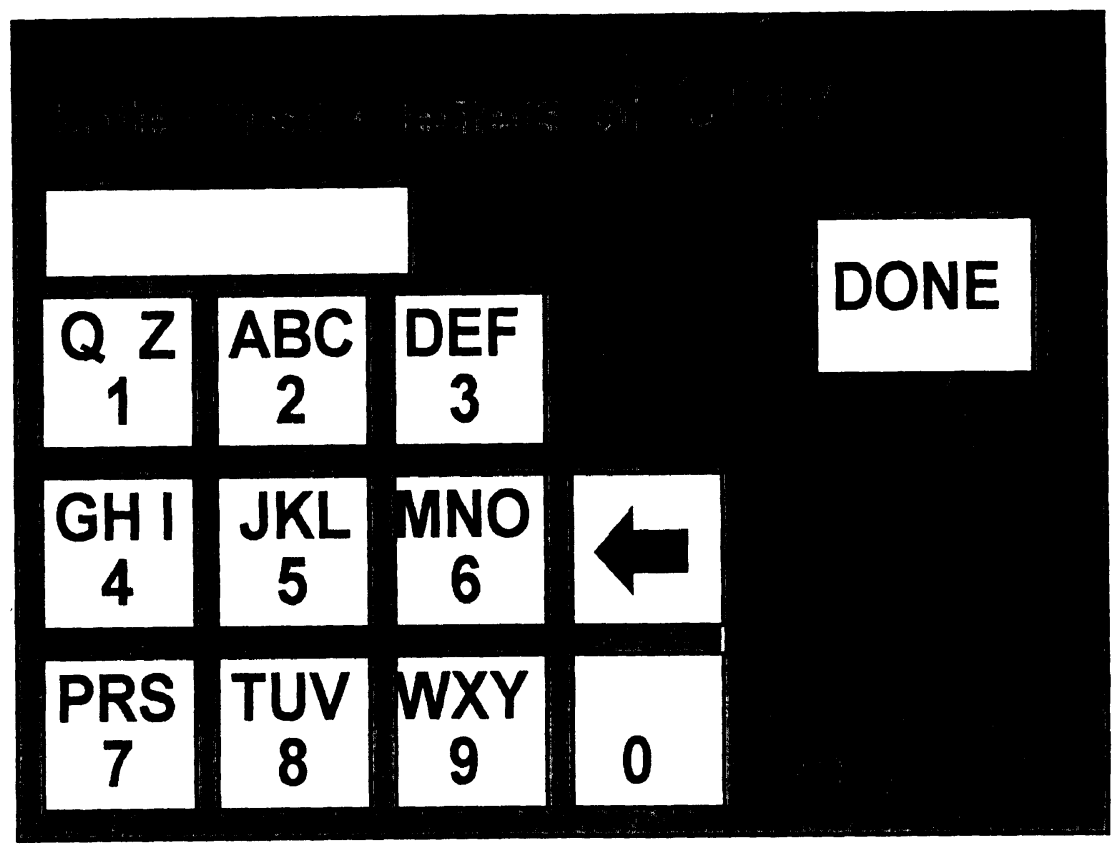

Figure 13. Example phone keypad entry device.

To key in "Williamsburg" with the phone keypad shown in figure 13, the user would press 9455, the numeric equivalent of "will." If there were other cities with the same first four characters (Williams), then a scrolling list would appear to select the desired entry.

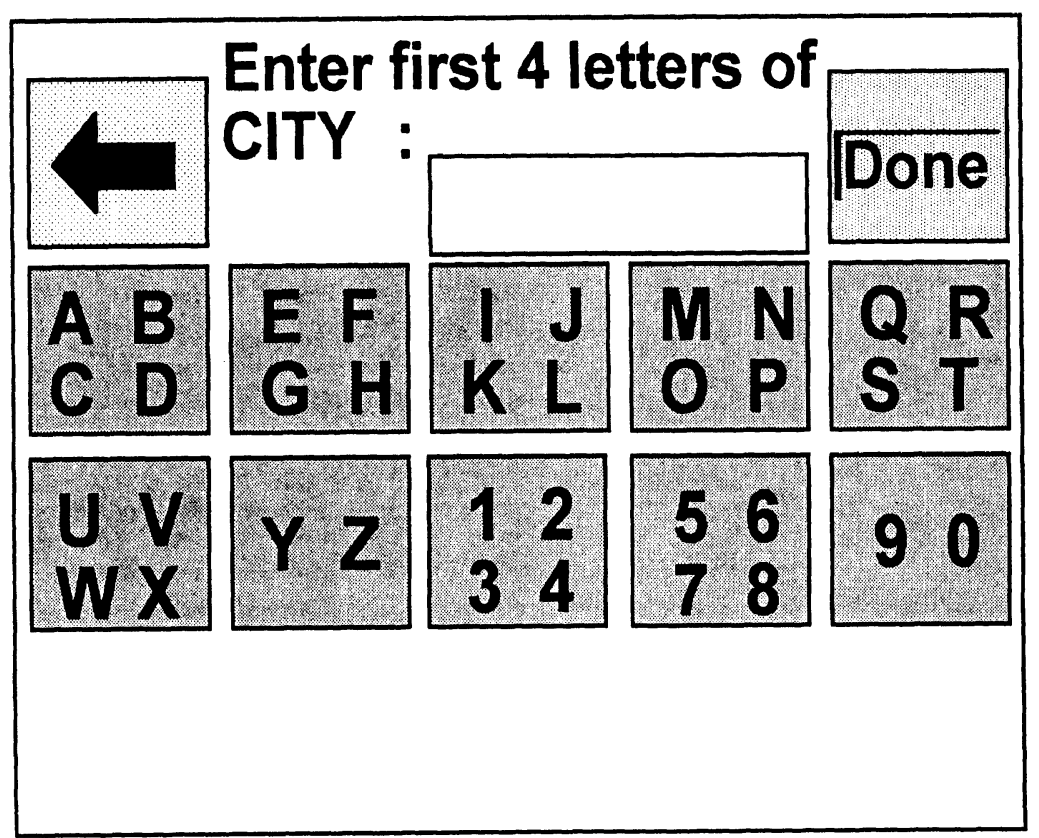

Note: To key in an E when using the doublepress method, the EFGH key was pressed first. This caused those 4 letters to appear at the bottom of the screen. The user then pressed the $\mathrm{E}$ key to select it.

Figure 14. Example doublepress keyboard. 


\section{Select CITY}
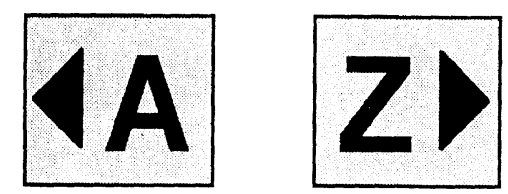

\section{DONE}
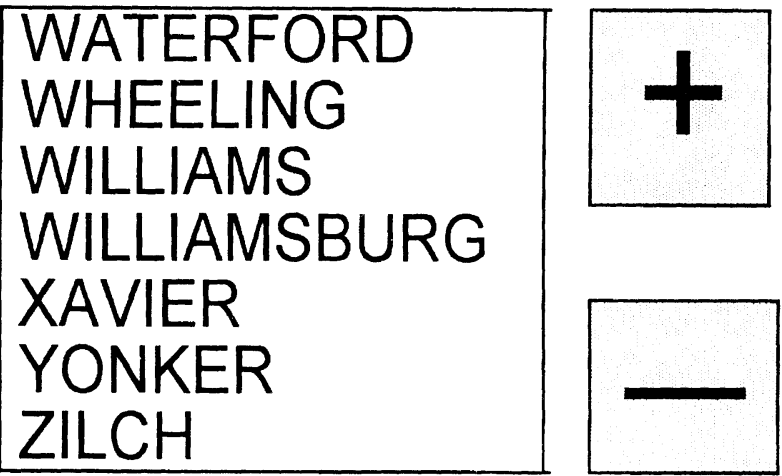

Figure 15. Scrolling list method.

Guideline 9.3 - Where phone keypads are used for text entry, provide some method to handle "q," "z," hyphens, and spaces that occur in names.

The standard telephone 12-key matrix (figure 20 in the next section) does not provide a label for the "q" and "z" keys. In examining this issue, Marics found no strong stereotypes when labels were not provided. ${ }^{[109]}$ One common solution is to put $\mathrm{q}$ and $\mathrm{z}$ on the $1 \mathrm{key}$. For methods to determine which character on each key is desired, see reference 110 .

Guideline 9.4 - Either staggered Qwerty keyboards or Qwerty matrix designs are acceptable for alphanumeric entry.

Other input devices may also be used for destination entry. Coleman, Loring, and Wiklund report data on typing on reduced-size, touch screen keyboards. ${ }^{[11]}$ They also found that alphabetic arrangements were not desired.

Guideline 9.5 - Methods may need to be provided to enter destinations by a general area/neighborhood, intersection, business name (e.g., Sears, Sunoco), and class of business (gas station, restaurant, hotel/motel, rental car, airport, park, etc.). There may also be a need to identify the destination by its phone number.

At this time, there is no data on how often each of these entry methods is used, though some difficulty is expected with systems that use coordinates (e.g., longitude and latitude). Giving the driver the flexibility to select destinations in multiple ways is desired as it allows entry schemes that are compatible with driver needs. However, doing so makes the interface more complex, as there are more options from which to choose. 
Guideline 9.6 - If possible, methods for automating destination entry should be developed.

Experience with many systems, as well as research on destination entry, has shown that destination entry can be slow, time-consuming, and difficult. ${ }^{[108]}$ There may be merit to in-car input devices to automatically read sources of addresses, such as business cards, tickets to sports and entertainment events, advertisements in phone books, and so forth. Bar code readers and text scanners are possible options. 



\section{TRAFFIC INFORMATION GUIDELINES}

Guidelines in this section concern basic issues, graphic displays, text displays, and information retrieval. These guidelines concern only presenting congestion information to drivers, not route selection instructions. Route selection was not examined in the interfaces prototyped. Further, in this project, traffic information was examined separately from navigation, though in some products the two functions might be tightly coupled.

\section{BASIC}

Guideline 10.1 - Traffic information systems should convey the primary items of interest to drivers as listed below:

- $\quad$ Road with blockage.

- Distance to blockage.

- Location of blockage or location where speed decreases.

- Blockage cause (normal congestion, accident, construction).

- Congestion level or travel speed (through problem) or travel time.

- Lanes blocked or open.

- Length/area of congestion.

These items are listed approximately in their order of importance, so presenting information on the length of congestion is not nearly as critical as which road is blocked. As a corollary, presentation of additional secondary information (e.g., estimated time of normal flow) is discouraged, to avoid overloading drivers.

Green, Serafin, Williams, and Paelke; and Appendix C of Serafin, Williams, Paelke, and Green describe the rationale that served as a basis for this guideline. ${ }^{[6,7]}$ In brief, functions and features for driver information systems were examined in terms of their benefit for reducing accidents, reducing congestion, and satisfying driver needs and wants. Benefits associated with each feature for aspects of each dimension were rated on a five-point scale. For example, ratings were obtained as to how much information concerning distance to blockage (a feature) reduced accidents due to excess speed, inattention, etc. These aspects were weighted based on how often they led to accidents. Each of the three dimensions was then weighted based on its utility. This method provided an estimate of the benefit of each of the information elements. Information elements were evaluated independently. However, some elements provide duplicate information (for example, time and distance versus speed). In those cases duplicate information was omitted.

Further, the need to indicate the cause is reinforced by work at the Texas Transportation Institute (TTI) on variable message signs. ${ }^{[112]}$ That research shows that merely telling drivers of the effect on traffic is insufficient.

Where possible, messages about lane closure (due to accidents, construction, etc.) should, include information about which lanes are closed. For example, green arrows are often used 
to communicate clear lanes, and red X's, blocked lanes. Lane numbers are not desired. (See figure 16.)

If the term "lane blocked" is used, the assumption is that the blockage is temporary, often due to an accident. The term "lane blocked" is preferred over "lane condition." "Closed" implies a long-term problem. Research related to communicating lane blockage is summarized in reference 112 .

Guideline 10.2 - Traffic information may be presented either auditorially, as text, or as graphics.

The modality for traffic information was not investigated in this research project. However, in the TravTek operational test, traffic information (e.g., an incident ahead) was presented auditorially, graphically (symbols showing the location of the incident), and with text. Details regarding the TravTek auditory interface are provided by Means et al. ${ }^{[106]}$

\section{Guideline 10.3 - Use text or graphics to present traffic information.}

In Hoekstra, Williams, Green, and Paelke, congestion shown as text or graphics resulted in significantly fewer errors in making decisions about the fastest of two alternative routes, and was preferred by drivers over either single video frames or moving video of traffic. ${ }^{[113]}$ (The video was recorded by road-side cameras). Drivers were also better at estimating the speed of traffic when using the nonvideo displays.

\section{GRAPHIC DISPLAYS}

\section{Guideline 10.4 - Use color coding to indicate speed on each road segment.}

To drivers, the information element of interest is the mean speed on a segment, not the number of vehicles per hour per lane. Usually, these two elements are well correlated, but not always. Indicating speed is important because it determines the time to traverse a link.

In the design studies conducted by Paelke; and Paelke, Green, and Wen for this project, several methods of showing traffic were examined. ${ }^{[96,10]}$ Line width coding (wider lines indicating more traffic) required too much space for presentation of three readily discriminated widths. Various dynamic codes (moving dots or miniature cars to show speeds) would require long look times, as was the case for the video presentation formats in Hoekstra, Williams, Green, and Paelke. ${ }^{[13]}$ Various line break codes (dashed lines where gaps and gap patterns varied) proved difficult to discriminate, especially on short road segments. While segment length will vary with the map, the examples considered were major Detroit highways-a fairly typical representation-and were shown on a 5 -in $(12.7 \mathrm{~cm})$ display, which is also typical.

Paelke; and Paelke, Green, and Wen explored a limited number of color coding schemes. ${ }^{[96,10]}$ Of those explored, the most effective scheme was green to represent speeds in excess of 55 $\mathrm{mi} / \mathrm{h}(88 \mathrm{~km} / \mathrm{h})$, yellow for $25-55 \mathrm{mi} / \mathrm{h}(40-88 \mathrm{~km} / \mathrm{h})$, and red for 0 to $24 \mathrm{mi} / \mathrm{h}(39 \mathrm{~km} / \mathrm{h})$. 
Orange was misunderstood to represent construction or other nonspeed related information (e.g., bus route), and therefore should not be used.

Paelke; and Paelke, Green, and Wen also considered using miniature speed limit signs (figure 16) to show speed on each link. ${ }^{[96,10]}$ Several color coding schemes were preferred over the miniature signs. Providing both speed and color is not recommended, as the speed limit signs make the display extremely difficult to read.

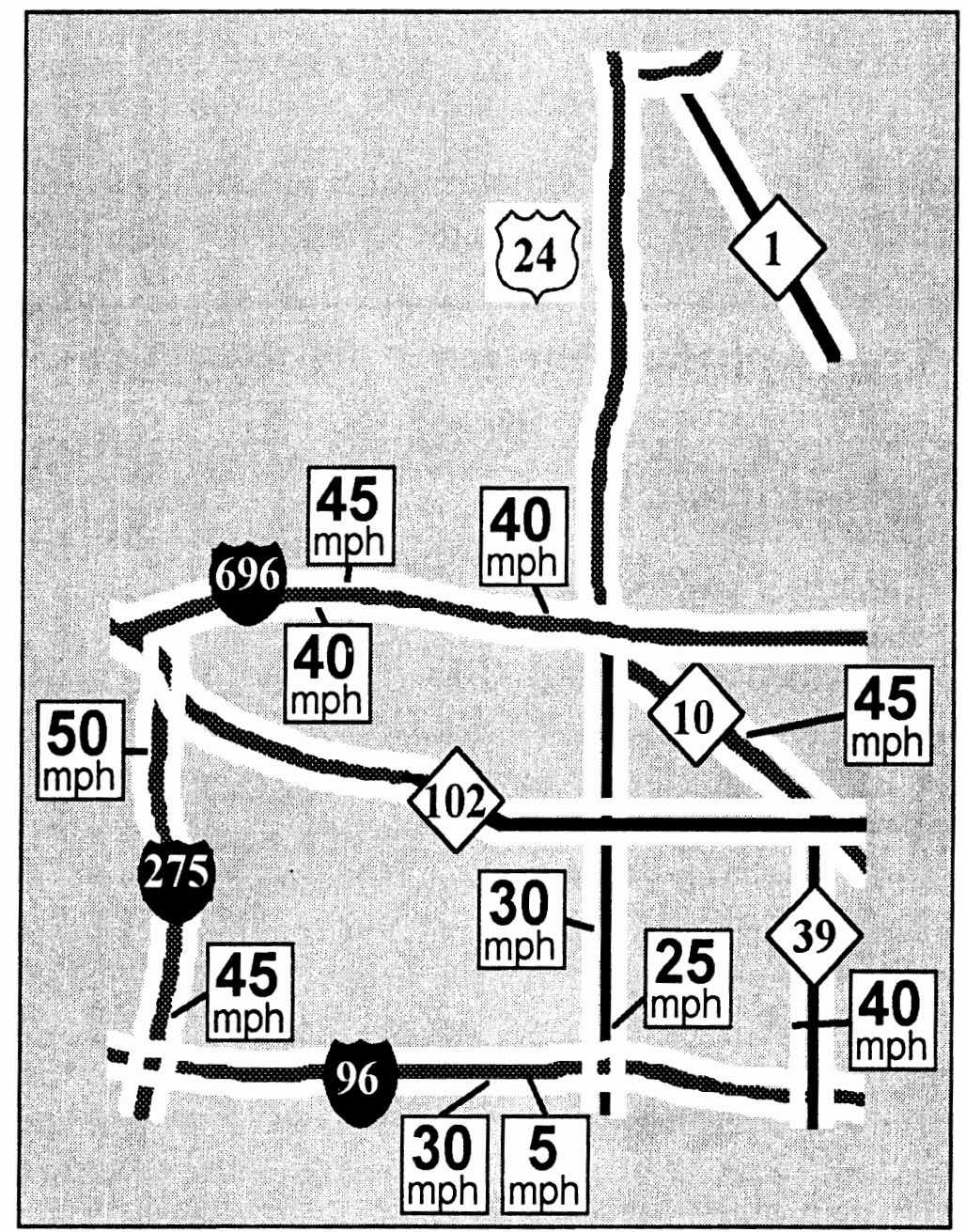

Figure 16. Graphic-based system with travel speeds.

\section{Guideline 10.5 - Use "thick" lines to represent roads when using color coding.}

The color of an area is much easier to identify than the color of a line. Furthermore, it is quite possible that the congestion level on both sides of a road will not be the same. In Paelke, Green, and Wen, the color coded lines were $2 \mathrm{~mm}$ wide with a black 1-mm line between them in overview displays. ${ }^{[10]}$ This is much wider than the required width for a border. For detailed displays showing one link of a network, even wider lines were used. To enhance color contrast, the background was gray. The need to use a gray background will 
depend on display characteristics and the line width chosen. Although line width was not explored empirically, thin lines were problematic.

In summary, the use of graphics in navigation displays is a very powerful presentation tool. Real-time interaction with graphics is not a well-researched topic. How much information can and should be displayed, and what level of manipulation (zoom, move back and forth between views) should be allowed as a secondary task are important for the automotive research community to address.

\section{TEXT DISPLAYS}

Guideline 10.6 - Text-based traffic information screens should not contain more information than is shown on the example screen below (figure 17).

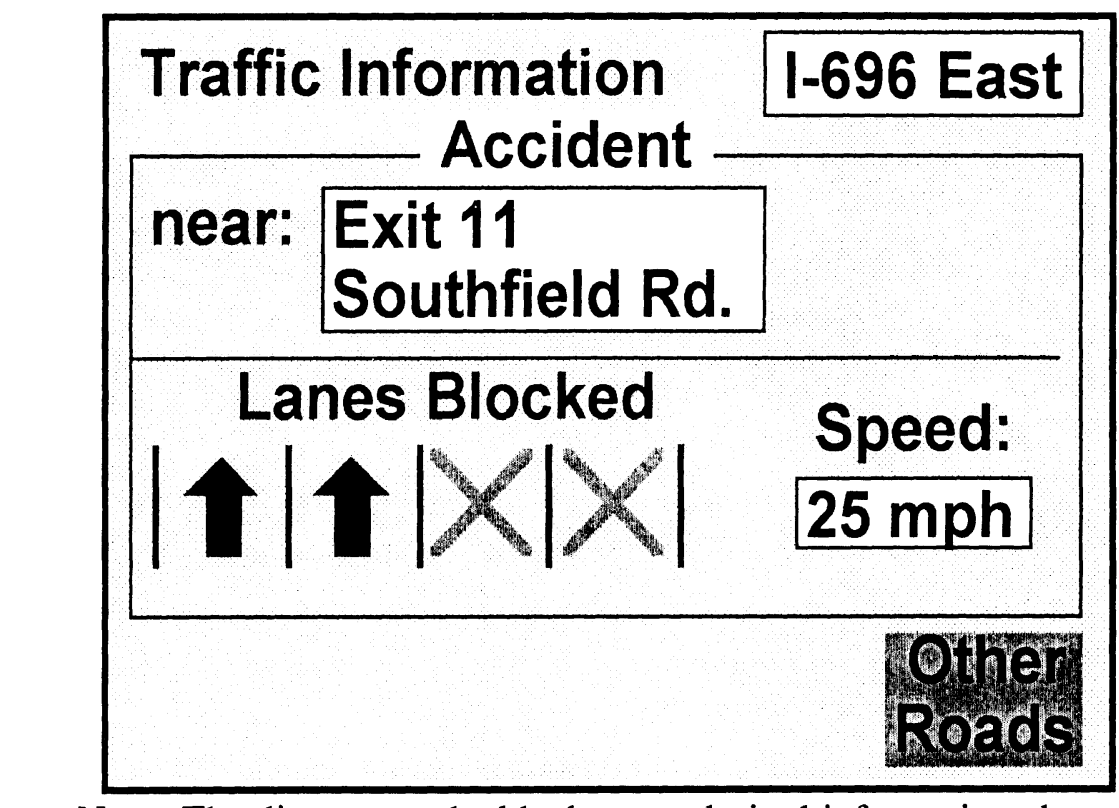

Note: The distance to the blockage, a desired information element, was available on a previous screen used to retrieve the screen shown here.

Figure 17. Example traffic information screen.

This guideline is specified by example because comprehensive data does not exist to relate the time to read a screen of mixed text and graphics to variations in content. Also lacking is a scheme to quantify the information presented.

However, Paelke, Green, and Wen; and Green, Hoekstra, Williams, George, and Wen have examined driver eye fixations to the display shown and to similar displays. ${ }^{[10,15]}$ Eye fixation times were longer than desired. Potential improvements to figure 16 include replacing "I-696 East" with the route number in a shield, deleting the word speed, and replacing the word "near" with "accident" (and deleting "accident" as a heading). 


\section{INFORMATION RETRIEVAL}

Guideline 10.7 - To retrieve traffic information on a specific route, a touch screen map is recommended over a scrolling menu or a phone keypad.

It is certainly conceivable that real-time information will be available for driver retrieval while the car is in operation. Parameters of concern are time, accuracy, and visual/attentional requirements to interact with text displays such as those under consideration for navigation.

Paelke, Green, and Wen examined these three methods for retrieval of traffic information, and found the touch screen map required the shortest time per entry. ${ }^{[10]}$ The bidirectional scrolling menu was a second choice. Figures 18, 19, and 20 are graphic representations of the three methods.

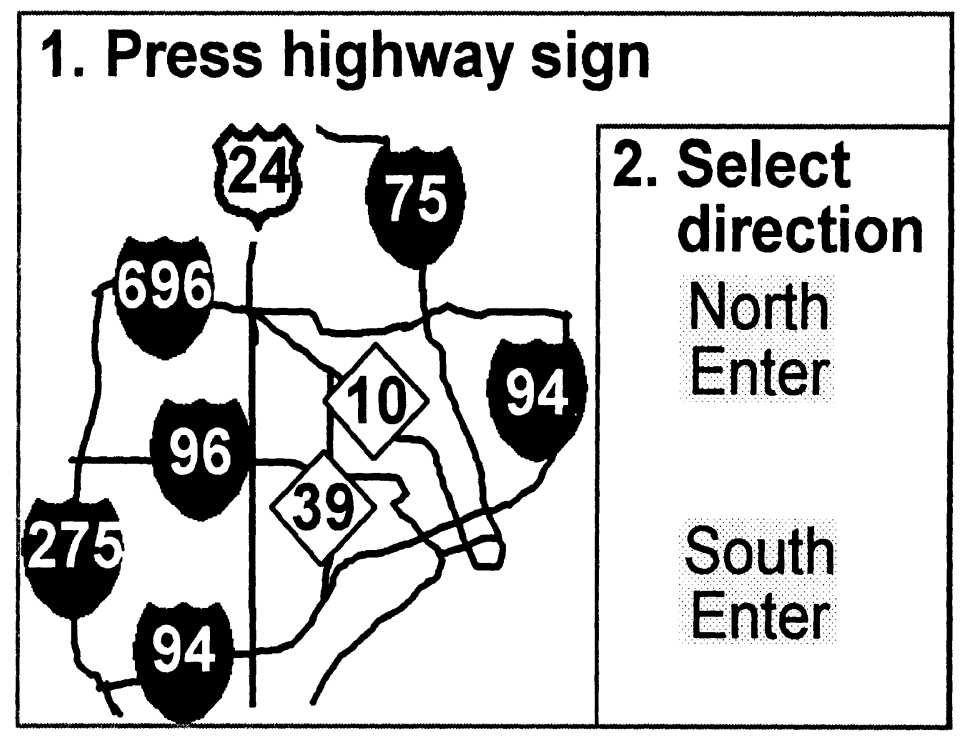

Figure 18. Touch screen map of Detroit highways used for selection.

That research also estimated retrieval performance with a unidirectional scrolling menu. Using that interface resulted in long retrieval times and is not recommended.

Retrieval of traffic information while driving is permitted, though automating that process, to reduce driver workload, is recommended. Retrieving traffic information while driving increased the standard deviation of lane position approximately 1 to 3 in $(2.5$ to $7.5 \mathrm{~cm})$ over a baseline condition in a simulator. ${ }^{[10]}$ If this task proves to be very infrequent, as expected, its impact on driving should be minimal. 


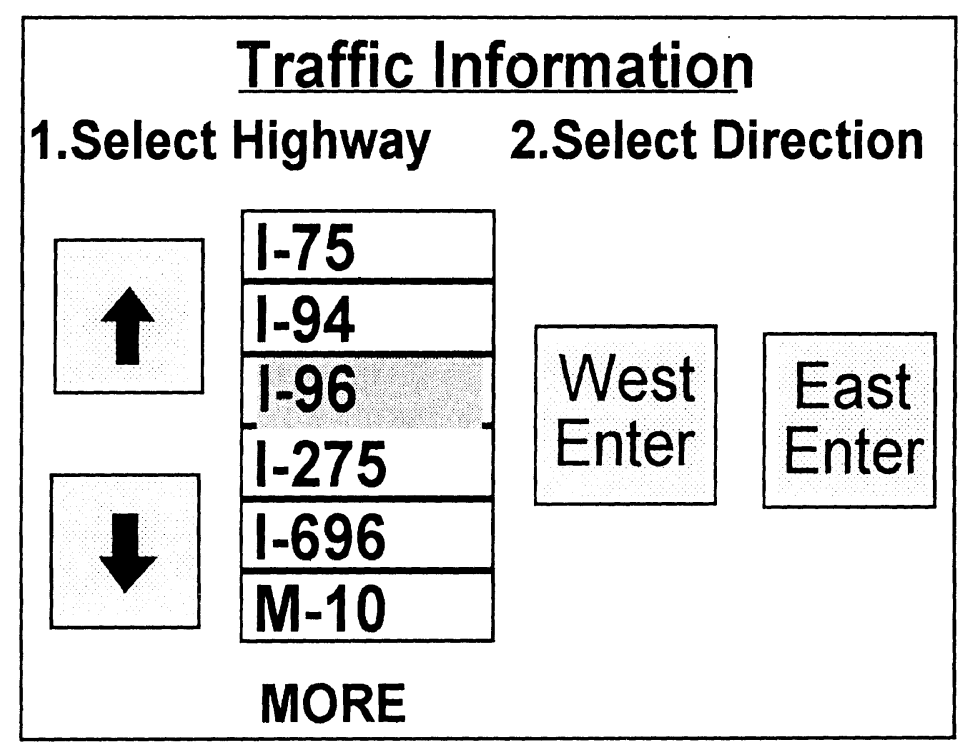

Figure 19. Bidirectional scrolling menu interface.

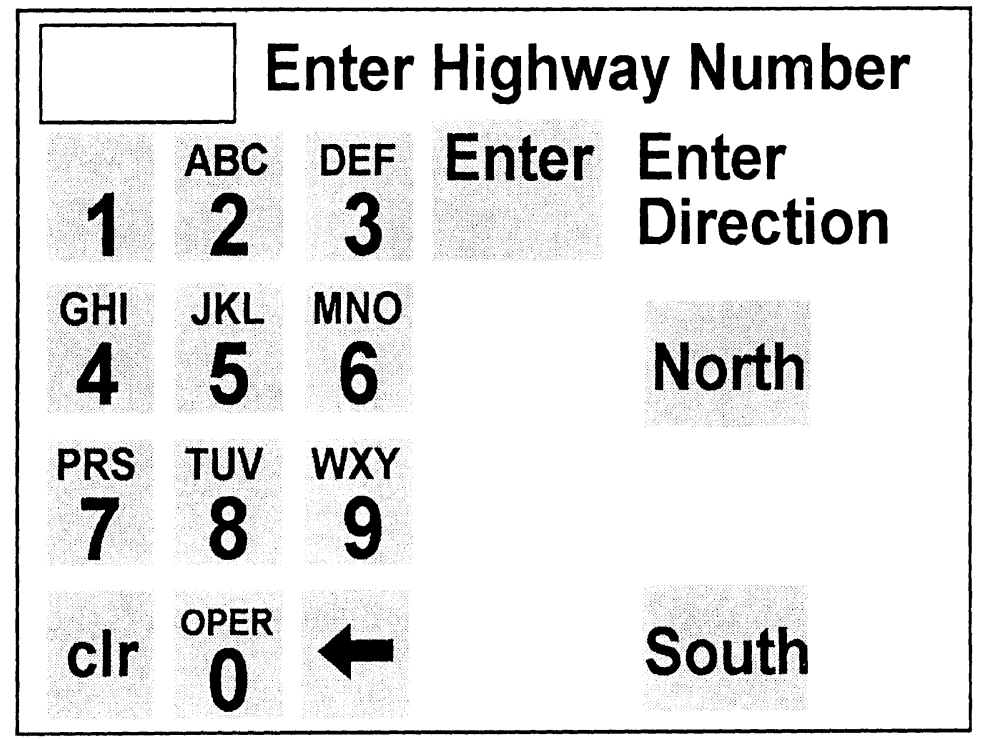

Figure 20. Phone keypad used for highway number entry. 


\section{CAR PHONE GUIDELINES}

The cellular phone design guidelines concern basic issues, voice dialing, and manual dialing and handset design. While some work was done on phone design as part of this project, the effort was not as extensive as that for other systems.

\section{BASIC}

Guideline 11.1 - Car phones should operate like phones people have at home.

The metaphor for a car phone is "plain old telephone service" (POTS), the service most customers have at home. This is the most important guideline for car phone design. (See reference 114 for details.)

The use of "send" to make a connection and "power" to turn a phone on and turned off are notable inconsistencies.

Guideline 11.2 - The recommended transmission procedure is: enter the phone number, press "send" or "dial," wait for the other party to answer, converse with the other party, and then press "end" to terminate the call.

The phone needs to be turned on so this sequence can commence and turn off when it is completed.

Guideline 11.3 - Removing the handset from the cradle should not initiate a call.

Guideline 11.4 - Calls can be terminated by pressing the end key, or by saying "end" or "hang up."

Guideline 11.5 - Calls can be answered by removing the phone from the cradle.

This guideline is based on the research of Walker. ${ }^{[15]}$

Guideline 11.6 - Status indicators should be provided for "in use" (originated or answered call in progress), "no service" (outside of coverage area), and "roam" (when in the service area of another provider).

Guideline 11.7 - A redial capability for the last number is desired.

Guideline 11.8 - The display for the phone should be designed so that the number dialed, including the area code, can be shown without scrolling. 
Guideline 11.9 - The display for the phone should automatically clear when a new number is dialed, after termination of a call, or if one minute has elapsed since entry of the previous digit.

This guideline is based on the research of Walker. ${ }^{[15]}$

\section{VOICE DIALOG}

Guideline 11.10 - Voice (hands-free) dialing is preferred over manual dialing.

Several studies have examined dialing a phone while driving. They have shown that voice dialing is less distracting and is preferred by drivers. (See reference 116 for a review.) Design requirements for voice recognizers are described elsewhere. Speaker independence is desired (no training required, recognition not affected by regional pronunciation differences).

Guideline 11.11 - For voice dialing, use speech prompts to cue the user to provide information.

The four following recommendations are based upon the research of Schwab, Ball, and Lively. ${ }^{[47]}$

Guideline 11.12 - Do not make speech prompts verbose.

For example, shorten "Again. Please say the name that goes with this number." to "Again."

Guideline 11.13 - Give drivers the option of speaking a string of numbers or a name associated with the phone number to dial.

Drivers might want to say "call office" to place a call.

Guideline 11.14 - Use beeps to indicate when the user should start and stop speaking.

Guideline 11.15 - For voice dialing, store the first and last names together as one string.

Guideline 11.16 - Verbal commands and button labels should use the same terms.

Commands of interest include "dial," "store," "recall," and "clear." This is an instance of the consistency principle (principle 1). 
Guideline 11.17 - The voice command "clear" clears the entire number, not just one digit.

In some systems, this may be inconsistent with manual dialing.

\section{MANUAL DIALING AND HANDSET DESIGN}

Guideline 11.18 - When performing such functions as dial or store, the user enters the number first and then presses the function key.

Guideline 11.19 - The handset should be mounted in a location such that drivers need not fully extend their arms to reach the phone handset.

The preferred location is on or adjacent to the instrument panel near the driver, not in a visor. A touch screen is also a possibility for interacting with a phone, rather than needing an additional interface on the phone itself for operation.

Guideline 11.20 - Keys for digits on the handset should be arranged in a 4 by 3 matrix with the numbers 1,2 , and 3 across the top row.

A 6 by 2 number pad is not desired. See reference 117 for supporting research for this and the previous guideline.

Guideline 11.21 - Space keys on handsets so they can be reached with a thumb.

Many drivers hold the handset in their right hands and dial with their thumbs. Phones may also be dialed with any finger when mounted in a cradle.

Guideline 11.22 - The button labels indicated below are favored if there is space for only three characters (or four small characters):

- Power pwr

- Transmit phone number dial

- End of conversation end

- Delete del

- Memory mem

- Recall rcl

Note: This suggestion is based on a very limited sample. Noteworthy is the preference for "dial" (to transmit a phone number) over "send," which is current practice. (See reference 11 for details.)

Guideline 11.23 - The display for the phone can be on the handset, a remote unit on top of the instrument panel, or on a HUD. 
Guideline 11.24 - The "store" and "recall" buttons, used for similar functions, should be adjacent to each other.

This is an instance of the grouping principle in the general guidelines.

Guideline 11.25 - The power button should be identified prominently.

New users often forget to turn the unit on before dialing, and off when talking is complete. Prominence may be achieved by making the power button a different color, larger, or a different type of switch. 


\section{VEHICLE MONITORING GUIDELINES}

This section concerns the system that warns the driver when the vehicle shows signs of malfunctioning or needing maintenance. Key parameters monitored include engine temperature and engine oil pressure. Guidelines in this section address the format of the information, primary and additional warnings, coding, and an example implementation.

\section{FORMAT}

Guideline 12.1 - Rely upon text messages supplemented by standard international symbols to communicate warnings.

There has been little work comparing the effectiveness of alternative formats, though Baber and Wankling found that text can be more informative than symbols alone. ${ }^{[18]}$ Green and Burgess; and Green found that driver understanding of combined messages (e.g., the air filter symbol, generated by combining the air and filter symbols) can be poor. ${ }^{[119,120]}$ Voice messages should not be used, except for the most urgent and unusual warnings. In the past, customers have responded negatively to important but common messages (e.g., "Your door is ajar.").

Figure 21 shows an example of how that was accomplished in the interface developed as part of this project.

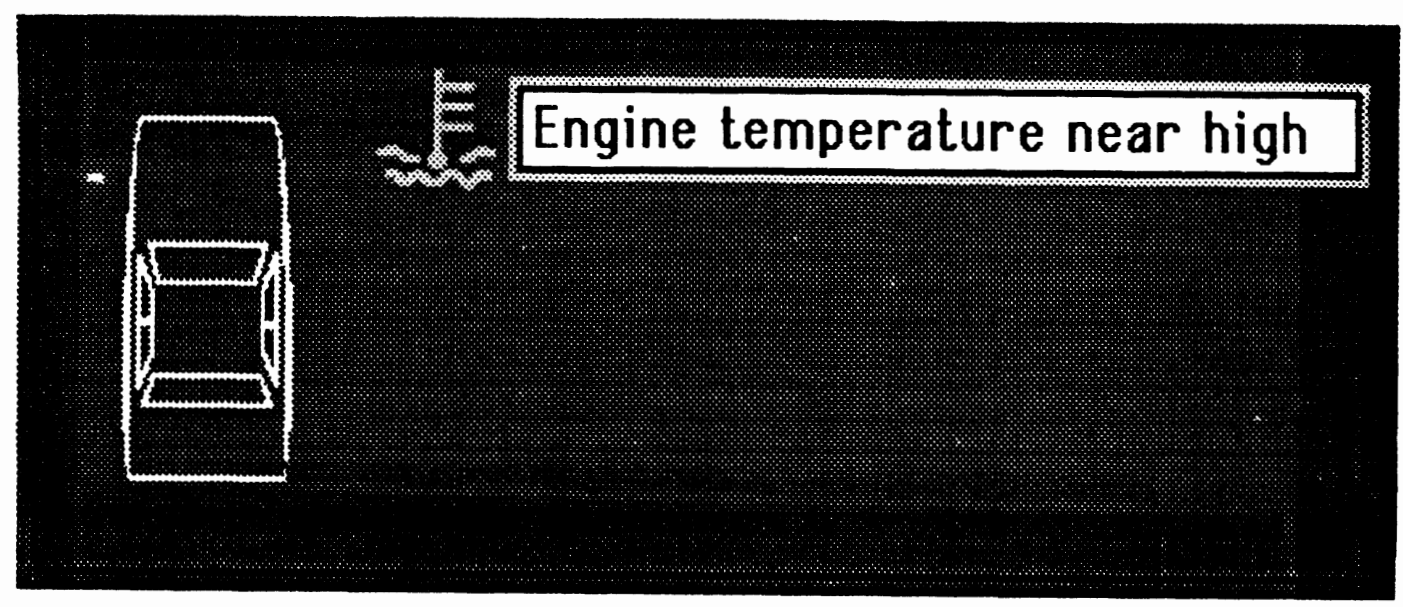

Figure 21. Text and symbol for engine temperature warning. 


\section{PRIMARY WARNINGS}

Guideline 12.2 - The following primary set of warning messages is recommended:

Table 5. Recommended warning messages.

\begin{tabular}{|l|l|}
\hline \multicolumn{1}{|c|}{ Message Type } & Recommended Primary Warning Messages \\
\hline Add Fluid & Add brake fluid \\
& Add clutch fluid \\
& Add engine oil \\
& Add power steering fluid \\
& Add radiator fluid \\
& Add transmission fluid \\
& Add windshield washer fluid \\
\hline Replace Part & Replace back-up lamp \\
& Replace brakelamp \\
& Replace fog lamp \\
& Replace fuse (number) (system) \\
& Replace headlamp \\
& Replace high-beam lamp \\
& Replace tail lamp \\
& Replace turn signal lamp \\
\hline Service Needed & Alternator drive belt service needed \\
& Brake service needed \\
& Clutch plate service needed \\
& Suspension service needed \\
& Tire rotation needed \\
Wheel alignment service needed
\end{tabular}

The specific messages provided will vary from vehicle to vehicle, with inclusion depending upon vehicle cost goals and the particular market segment targeted.

Research describing the development and evaluation of these messages appears in Green , Hoekstra, and Williams. ${ }^{[16]}$ Based on in-house expertise, a list of approximately 100 maintenance items that could be displayed was developed. That list was reduced to 50 items of the highest priority. Following the same procedure as for the traffic information elements, members of the research team rated the elements in terms of their ability to reduce accidents, reduce congestion, and satisfy driver needs and wants. (See reference 6 and appendix $C$ of reference 7.) The warnings identified as most important in that evaluation were grouped into patterns. Some 60 drivers selected the words most appropriate for each warning. Those 
warnings were then combined with a mimic to develop the complete warning interfaces.

Selected warnings using that interface design were then shown to 20 drivers, which served as the basis of the interface used in the on-the-road experiments. ${ }^{[15]}$ Thus, the recommendations for the vocabulary shown are based primarily on driver preferences from a limited sample, evidence which is not very strong, although limited driver comprehension data was considered as well. Additional driver performance and comprehension data is desired for these messages and alternatives.

As part of that research, data was collected on driver understanding of the problems and components of interest, knowledge that affects comprehension of associated warnings. Level of understanding falls into three categories:

- Sufficient understanding of:

blown fuse

low tire pressure

low engine oil level

low power steering fluid

low radiator fluid

worn tire

poor wheel alignment

shock absorber function problem

- Marginal understanding of:

antilock brake function

reasons for oil change

battery function

strut function

low brake fluid

clutch function

- Insufficient understanding of:
alternator function
oxygen sensor function
alternator failure
master cylinder function
antilock brake failure
transmission fluid function
fuse function
catalytic converter function
low oil pressure
accessory drive belt

Suggestion: When driver understanding is inadequate, provide supplemental information to drivers in the owner's manual, and when vehicles are delivered, in order to improve drivers' understanding of their vehicles. 


\section{ADDITIONAL WARNINGS}

Guideline 12.3 - If a larger set of messages is desired, selection from those listed in tables 6 through 11 is recommended.

Table 6. Warning messages for unscheduled maintenance problems requiring immediate attention that are understood by drivers.

\begin{tabular}{|c|c|c|}
\hline Rank & Information Element & Possible messages \\
\hline 14 & Engine temperature & $\begin{array}{l}\text { High engine temperature } \\
\text { Hot engine } \\
\text { Engine overheating } \\
\text { Engine is overheating } \\
\text { Engine overheated }\end{array}$ \\
\hline 20 & Oil pressure & $\begin{array}{l}\text { Low/high engine oil pressure } \\
\text { Poor oil circulation - serious } \\
\text { Serious lack of oil pressure } \\
\text { Engine seizure imminent }\end{array}$ \\
\hline 21 & Oil pump failing & Oil pressure getting low \\
\hline 22 & Oil change & $\begin{array}{l}\text { Unscheduled oil change needed } \\
\text { Oil change needed now }\end{array}$ \\
\hline 23 & Oil level & $\begin{array}{l}\text { Low oil level } \\
\text { Add engine oil (10W-40) } \\
\text { High engine oil level } \\
\text { Too much engine oil } \\
\text { Engine oil level (too) high } \\
\text { Excess engine oil } \\
\text { Excessive engine oil } \\
\text { Drain (some) engine oil }\end{array}$ \\
\hline
\end{tabular}

The rank in the table refers to the desirability of each warning, with smaller values being more desired. The ranking was determined by considering to what degree the warning might reduce accidents, improve traffic flow, and satisfy driver needs and wants. (See references 6 and 7 for details.

Table 7. Warning messages for critical status problems, which drivers are expected to correct.

\begin{tabular}{|l|l|l|}
\hline Rank & Information Element & Possible messages \\
\hline 24 & Doors open & no text (show mimic with door open) \\
\hline & Fuel door open & no text (show mimic with fuel door open) \\
\hline 25 & Hood open & no text (show mimic with hood open) \\
\hline 26 & Trunk/Hatch open & no text (show mimic with item open) \\
\hline
\end{tabular}

Shown in figure 22 is an example of a warning from the final interface prototype indicating both the trunk and a door are open. 


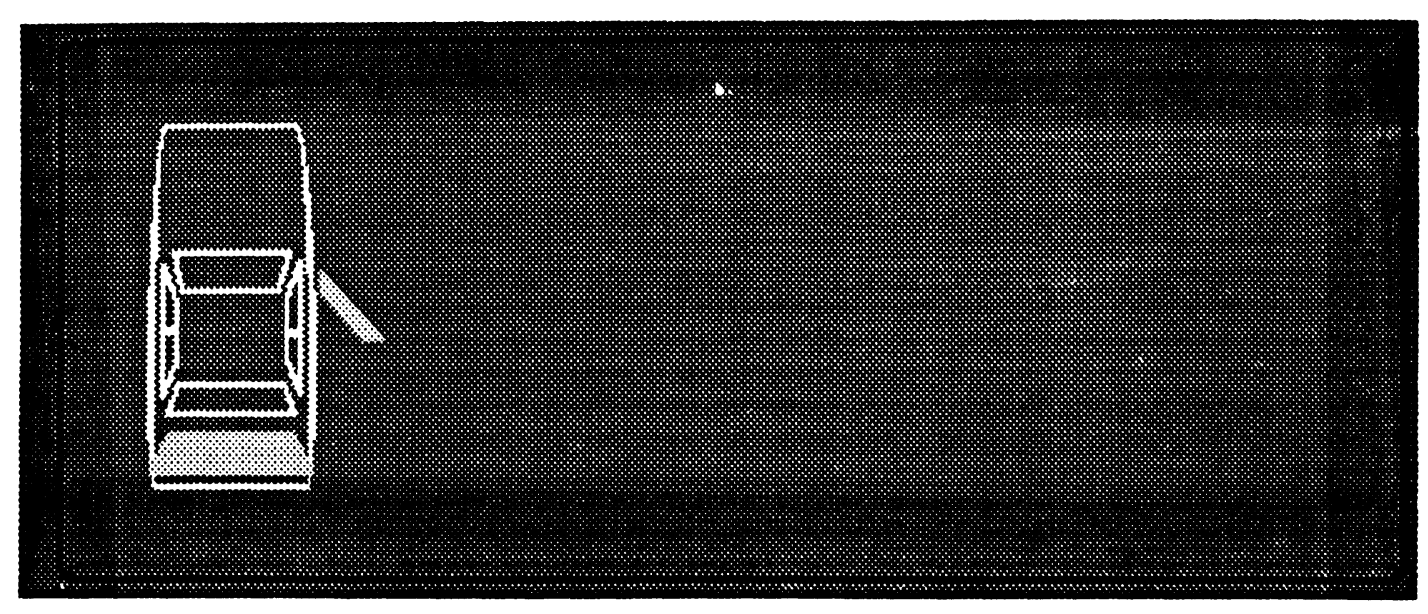

Figure 22. Trunk and door opening warning messages.

Table 8. Warning messages for unscheduled maintenance problems, which drivers are expected to correct.

\begin{tabular}{|c|c|c|}
\hline Rank & Information Element & Possible messages \\
\hline 3 & Tire pressure & Low/high tire pressure \\
\hline 8 & Engine coolant level & $\begin{array}{l}\text { Low engine coolant } \\
\text { Low radiator fluid } \\
\text { Radiator fluid (too) low } \\
\text { Add radiator fluid } \\
\end{array}$ \\
\hline 12 & Brake fluid level & $\begin{array}{l}\text { Low brake fluid (level) } \\
\text { Add brake fluid } \\
\text { Brake fluid level (too) low } \\
\text { (Additional) brake fluid needed }\end{array}$ \\
\hline 15 & Low fuel warning & $\begin{array}{l}\text { Low fuel } \\
\text { Get gas }\end{array}$ \\
\hline 15 & Oil level getting low & $\begin{array}{l}\text { Getting low on oil } \\
\text { Oil level getting low } \\
\text { Oil level down } 1 / 2 \text { quart }\end{array}$ \\
\hline 35 & Washer fluid level & Low washer fluid \\
\hline
\end{tabular}

Table 9. Warnings messages for scheduled maintenance problems, which drivers are expected to understand.

\begin{tabular}{|l|l|l|}
\hline Rank & Information Element & Possible messages \\
\hline 13 & Tire rotation needed & $\begin{array}{l}\text { Periodic tire rotation [required] } \\
\text { Regular tire rotation [required] } \\
\end{array}$ \\
& & $\begin{array}{l}\text { Rotate tires } \\
\text { Have tires rotated }\end{array}$ \\
\hline 48 & Oil change & Periodic/normal/regular oil change \\
\hline
\end{tabular}


Table 10. Warning messages for driver information.

\begin{tabular}{|l|l|l|}
\hline Rank & Information Element & Possible messages \\
\hline 33 & Fuel quality indicator & Bad fuel/gasoline/gas/petrol \\
& & (Some) water in fuel \\
& & Fuel octane too low \\
& & Low fuel octane \\
\hline
\end{tabular}

Table 11. Warning messages for unscheduled maintenance problems, which drivers are not expected to understand.

\begin{tabular}{|c|c|c|}
\hline Rank & Information Element & Possible messages \\
\hline 16 & Suspension health & $\begin{array}{l}\text { Poor suspension health } \\
\text { Check shock absorbers } \\
\text { Check shocks } \\
\text { Problem with suspension } \\
\text { Suspension maintenance required }\end{array}$ \\
\hline 31 & Engine coolant quality & $\begin{array}{l}\text { Poor engine coolant quality } \\
\text { Poor radiator fluid quality } \\
\text { Radiator fluid contaminated } \\
\text { Oil in engine coolant } \\
\text { Add antifreeze to radiator } \\
\text { Radiator maintenance required }\end{array}$ \\
\hline 34 & $\mathrm{O}_{2}$ sensor health & $\begin{array}{l}\text { Faulty/defective/broken/bad oxygen sensor } \\
\text { Fuel injection system maintenance } \\
\text { Engine computer sensor } \\
\text { Fuel economy sensor }\end{array}$ \\
\hline 39 & Steering fluid level & $\begin{array}{l}\text { Low (power) steering fluid level } \\
\text { Power steering fluid low } \\
\text { Add power steering fluid }\end{array}$ \\
\hline 40 & Alternator maintenance & $\begin{array}{l}\text { Battery is being drained } \\
\text { Drain on battery } \\
\text { Car may not start next time (alternator) } \\
\text { Problem with alternator } \\
\text { Have alternator repaired }\end{array}$ \\
\hline 41 & Battery current & $\begin{array}{l}\text { Low/high battery current } \\
\text { Battery maintenance (required) }\end{array}$ \\
\hline 42 & Battery voltage & $\begin{array}{l}\text { Low/high battery voltage } \\
\text { Battery maintenance (required) }\end{array}$ \\
\hline 44 & Drive belt loose & $\begin{array}{l}\text { Adjust drive belt } \\
\text { Tighten drive belt } \\
\text { Drive belt loose }\end{array}$ \\
\hline 46 & Fuel pump shutoff & $\begin{array}{l}\text { Fuel shutoff } \\
\text { Fuel cutout }\end{array}$ \\
\hline
\end{tabular}


Table 12. Warning messages for unscheduled maintenance problems, which the drivers are expected to understand.

\begin{tabular}{|c|c|c|}
\hline Rank & Information Element & Possible messages \\
\hline \begin{tabular}{l|l}
1 &
\end{tabular} & Turn signal lamps & $\begin{array}{l}\text { Turn signal lamp burned out } \\
\text { Turn indicator bulb out } \\
\text { Blinker bulb out }\end{array}$ \\
\hline 2 & Tire wear level & $\begin{array}{l}\text { Excessive tire wear } \\
\text { Worn out tire } \\
\text { Worn tire } \\
\text { Thin tire tread } \\
\text { Tire is worn }\end{array}$ \\
\hline 4 & Brake lamps & $\begin{array}{l}\text { Brake lamp burned out } \\
\text { Brake bulb out }\end{array}$ \\
\hline 5 & Tail lamps & $\begin{array}{l}\text { Tail lamp burned out } \\
\text { Presence bulb burned out } \\
\text { Tail light } \\
\text { Rear lamp } \\
\end{array}$ \\
\hline 7 & Brake maintenance & $\begin{array}{l}\text { Excessive brake wear } \\
\text { Worn brakes }\end{array}$ \\
\hline 9 & Head lamps & $\begin{array}{l}\text { Head lamp burned out } \\
\text { Head light burned out } \\
\text { Bulb }\end{array}$ \\
\hline 30 & Transmission & $\begin{array}{l}\text { Transmission maintenance (required) } \\
\text { Gear box repair/fault/fix/service } \\
\text { Get transmission fixed }\end{array}$ \\
\hline 43 & Catalytic converter health & $\begin{array}{l}\text { Emissions system repair } \\
\text { Replace catalytic converter } \\
\text { Catalytic converter needs replacement }\end{array}$ \\
\hline 43 & Engine knock indicator & $\begin{array}{l}\text { Tune-up required (engine knock) } \\
\text { Engine misfiring }\end{array}$ \\
\hline 45 & Engine timing & $\begin{array}{l}\text { Tune-up required (engine timing) } \\
\text { Timing adjustment needed }\end{array}$ \\
\hline 47 & Fuse status & $\begin{array}{l}\text { Fuse }(\#) \text { burned out }(<\text { system name }>) \\
<\text { system name }>\text { fuse is out }(\#)\end{array}$ \\
\hline 49 & Bright head lamps & $\begin{array}{l}\text { High beams } \\
\text { Brights }\end{array}$ \\
\hline 50 & Fog lamps & Fog lamp burned out \\
\hline
\end{tabular}

\section{CODING}

Guideline 12.4 - The following color codes are recommended.

In general, red is associated with danger, and yellow is associated with caution. Accordingly, red should be used for highly critical warnings demanding immediate action by the driver. 
Yellow should be used for less critical warnings. White should be used for status indicators or noncritical messages. For common messages, the color codes shown below are recommended. Color coding helps drivers understand the urgency of a message, though there is no guarantee that drivers will notice the color coding. The color codes for primary warning messages developed as part of this project were selected based on opinions of the interface developers and conform to accepted practice. (See table 13.)

Table 13. Primary warning message color codes.

\begin{tabular}{|c|l|}
\hline Color Code & \multicolumn{1}{|c|}{ Warning Message } \\
\hline white & Low fuel \\
\hline yellow & Worn tire \\
\hline red & Low oil pressure! \\
\hline yellow & Engine temperature near high \\
\hline red & High engine temperature! \\
\hline white & Replace turn signal lamp \\
\hline white & Replace air filter \\
\hline yellow & Antilock brake system failure \\
\hline yellow & Low tire pressure \\
\hline yellow & Add engine coolant \\
\hline red & Power brake failure! \\
\hline yellow & Worn tire \\
\hline yellow & Replace turn signal lamp \\
\hline yellow & Oil change needed 500 miles \\
\hline yellow & Oil change 200 miles overdue \\
\hline yellow & trunk and door open \\
\hline
\end{tabular}

Guideline 12.5 - Supplement color codes with other information to communicate the seriousness of a warning.

Do not depend on color coding to communicate the warning. Other coding schemes include flashing and supplemental tones, as well as the choice of words in a message.

Guideline 12.6 - Where reference to normal values for common engine and vehicle parameters is needed, provide them in the text messages or on scale markings.

Drivers do not know normal values for common engine/vehicle parameters (normal and abnormal temperatures, oil pressure or capacity, fuel capacity). ${ }^{[59]}$ Therefore, a digital display of engine temperature would be inappropriate, since drivers lack a basis for determining what is abnormal. 


\section{Guideline 12.7 - Do not rely solely on a mimic to communicate spatial cues.}

In the design examined in this project, the mimic was used to indicate which door is open, which tire needs air, and which headlight or taillight is out. In the Williams, Hoekstra, and Green research on vehicle monitoring, drivers experienced some difficulty in interpreting the mimic. ${ }^{[13]}$ Driver understanding of word alternatives is untested.

For situations where the location is known (because it is given in the text) or would not be specifically defined by the mimic (by highlighting the hood for an engine-related function) and text messages are provided, a mimic should not be used. This added information will increase the time to make decisions, but will not add useful information.

\section{Guideline 12.8 - Use flash coding for messages needing immediate attention.}

Flashing text is difficult to read, and should not be used. Either a light next to the text, a bar beneath it, or a box around it should flash. For priority 4 messages (see table 14), the on/off cycle of $75 / 25$ is suggested with a 1-s cycle duration. For priority 5 messages, $2 \mathrm{~Hz}$ is recommended with the same duty cycle. (The cycle split and flash rate needs further review. The rate and split for CRT's will depend on the phosphor employed.)

Guideline 12.9 - Provide auditory alerts (tone, chime, etc.) only for items needing immediate attention (priority 4 and 5).

Auditory alerts can be distracting and can unnecessarily draw attention from the road. The use of auditory alerts needs to be consistent across systems. More tones should be associated with more critical messages. It is suggested that a single tone (beep or bong) indicate a navigation screen alert or be a forewarning of voice guidance to follow. Two successive tones should be used for priority 4 messages in table 14. Three tones (over a period of 1 to 2 seconds) are suggested for priority 5 messages in table 14 . Voice messages for priority 5 warnings should repeat continuously until the problem is solved.

\section{EXAMPLE IMPLEMENTATION}

One implementation of a warning display is to provide multiple lines of text with an adjacent mimic and symbols. For that design, the following guidelines should be followed:

\section{Guideline 12.10 - List messages in priority order, with the highest priority message at the top of the list.}

Messages should be prioritized as shown in tables 14 and 15 . The tables also provide recommendations for the use of color and other codes. Priorities were assigned based on how soon maintenance was needed, how expensive the damage would be if not attended to, and the magnitude of the risk to the driver for safety-related items. Input to this classification came from in-house expertise and contacts in industry. Decisions were made by members of the research team without reference to a formal, computationally-based classification scheme. 
Table 14. Maintenance problem priority.

\begin{tabular}{|l|l|}
\hline Priority level 1: & $\begin{array}{l}\text { Scheduled maintenance items that are almost due. How far ahead of } \\
\text { the actual maintenance due date the item should appear is a } \\
\text { question. (In the tests conducted as part of this project, it was 500 } \\
\text { mi (805 km).) }\end{array}$ \\
\hline Priority level 2: & $\begin{array}{l}\text { Driver maintenance items that are not immediately critical (washer } \\
\text { fluid, add oil, add radiator fluid). This priority is, of course, based } \\
\text { on the assumption that the warning appears early in the criticality } \\
\text { (e.g., 1 pint of oil low is minor). The driver could be informed at } \\
\text { this point, as opposed to when the message is a higher priority (the } \\
\text { quart low mark). }\end{array}$ \\
\hline Priority level 3: & Unscheduled maintenance items. \\
\hline Priority level 4: & $\begin{array}{l}\text { Driver's immediate attention and action items, such as low oil } \\
\text { pressure, accompanied by tone at onset, color coded, flashed for 1 } \\
\text { minute after onset, then remains steady. } \\
\text { Note: The 1 minute interval was selected to give the driver ample } \\
\text { time to look down at the warning. This interval takes into account a } \\
\text { variety of traffic conditions, some of which may not provide an } \\
\text { opportunity to examine a warning immediately. }\end{array}$ \\
\hline Priority level 5: & $\begin{array}{l}\text { Driver and occupant critical safety items, such as engine fire, } \\
\text { accompanied by voice message, flashing light next to message, tone } \\
\text { for alert. } \\
\text { Note: Because of the problem of false alarms, this category is } \\
\text { reserved for rare and extremely dangerous situations. }\end{array}$ \\
\hline
\end{tabular}

The vehicle monitoring warnings associated with each level of message priority are shown in table 15 .

Table 15. Warning message priority.

\begin{tabular}{|l|l|}
\hline Level 1: & $\begin{array}{l}\text { No tone at first appearance. Tone at engine start-up. No color bar around } \\
\text { message. Yellow bar if ignored for period of time, then red if ignored } \\
\text { longer. }\end{array}$ \\
\hline Level 2: & $\begin{array}{l}\text { No tone at first appearance. Tone at engine start-up. No color bar around } \\
\text { message. Yellow or red bar if situation worsens, e.g., one pint low on oil } \\
\text { becomes one quart. }\end{array}$ \\
\hline
\end{tabular}

Assignment of levels for maintenance problem and warning message priority was done on a case-by-case basis by members of the research team. Resource constraints did not permit development of a more formal evaluation scheme. 
Guideline 12.11 - If a scheduled maintenance item is ignored, it moves up in priority level based on the ratio of the number of overdue miles to the recommended number of miles for maintenance.

The maintenance interval (e.g., every $5000 \mathrm{mi}(8050 \mathrm{~km})$, every $30,000 \mathrm{mi}(48,300 \mathrm{~km}))$ is system dependent.

Guideline 12.12 - If a driver maintenance item is ignored, it moves up in priority level based only on increasing need for the maintenance.

Guideline 12.13 - When a countdown is provided for a message, it should indicate total miles until scheduled maintenance is due or total miles maintenance is overdue, not the associated time.

The authors believe that drivers can be more effective in scheduling maintenance when distance is provided. Variations in mileage accumulation (due to long trips) can markedly affect when maintenance is desired. Time measures (e.g., service every 6 months) are not sensitive to these variations.

Suggestion - Warning messages on a multiple-line display might be prioritized.

Each warning should have an internal priority number, e.g., from 1 to 100 $(100=$ highest priority $)$, for each level of priority. For example:

Transmission maintenance (unscheduled)

first appearance: 80

ignored for 300 miles: 85

ignored for 600 miles: 90 , etc.

Oil change (scheduled)

500 miles from due: 5

200 miles from due: 20

due: 30

200 miles overdue: 35

500 miles overdue: 50

1000 miles overdue: 60 , etc.

The appearance of yellow and red warning indicators [probably as light-emitting diodes (LED's)] and the addition of tones or speech can then be assigned numbers.

e.g., Yellow LED at priority level 55

Red LED at priority level 75

tones and/or flashing at priority level 90

speech at priority level 95 
Items are listed in the display in order of decreasing priority, with the most urgent warning at the top of the list. Warnings are reordered as priorities change. For warnings of the same urgency, the most recent warnings would appear at the top of the text window and older warnings would be moved down accordingly. Since the design suggested allows for only four warnings to be displayed, less urgent warnings would not be displayed (on the mimic or in the text window) while the transmission is not in park. The next time the transmission is in park, the warning would be displayed; the screen with four warnings would alternate with the screen with the additional warnings. 


\section{IVSAWS GUIDELINES}

The In-Vehicle Safety Advisory and Warning System (IVSAWS) informs drivers of road hazards. Hazards for which there will be IVSAWS warnings include emergency vehicles, accidents, new or broken traffic control devices, etc. Each hazard has a low power radio transmitter that broadcasts a coded message identifying the type of hazard present. Vehicles will receive the broadcasts and present warnings to drivers either visually or auditorally. These guidelines are divided into the following categories: basic, graphics, and location coding.

\section{BASIC}

Guideline 13.1 - Because IVSAWS warnings are likely to occur with some regularity, they should be presented visually.

Experience with a simulated IVSAWS interface suggests that several warnings might occur in a 30-minute journey. ${ }^{[15]}$ While voice warnings can be effective in communicating warning information, frequent voice warnings will become annoying, and their usefulness will suffer. Voice, and to a lesser extent, other auditory warnings are generally associated with urgent and important occurrences, much more so than for visual warnings. Annoyance will be considerable if some of the warnings are false alarms, a likely possibility for early versions of IVSAWS interfaces.

Guideline 13.2 - IVSAWS warnings should be accompanied by an auditory alert, such as one or two tones, to draw attention quickly.

In selecting tones, follow the guidelines on intensity and discriminability described in the auditory displays guidelines. Where different systems use alerting tones for different purposes, tones should be selected to minimize opportunities for confusion. This is of particular concern for the alerting tones for the navigation and vehicle monitoring systems. In the implementation of IVSAWS in this project, two tones were presented. ${ }^{[15,16]}$

\section{GRAPHICS}

Guideline 13.3 - The graphics shown below are recommended for IVSAWS hazard warnings.

As part of this project, Hoekstra, Williams, and Green examined driver responses to IVSAWS warnings, and it is from that research that the recommended warnings emerged. ${ }^{[12]}$ In those experiments, three groups of 25 drivers ranked candidates for warning symbols in the first experiment. In the second, 20 drivers responded to alternative candidate warnings. The sample sizes were sufficient to determine if the alternatives were reasonable (and were within resource constraints), but insufficient for a national standard. Additional validation tests (and examinations of alternatives) are desired. 
Further, many of the messages use all upper case characters where mixed case is clearly an option (and is recommended by the general visual displays guidelines). The mixed case alternatives have not been tested, but the change from all upper case to mixed case should not affect understanding of these warnings. For warnings related to road construction, mixed case warning messages may be inconsistent with current highway signing practice.

Two options for warning formats are recommended. In the first format, a two-panel design, one panel contains the basic warning (for example, school bus unloading), and the second panel contains location information. Figure 23 shows an example of how two-panel warnings appeared on the prototype developed as part of this research program. For most basic warnings, the left panel could either be a strictly graphic format or a mixed text-graphic format. In selecting warnings, designers should be consistent within categories. (That is, if one traffic control device warning is text, all traffic control warnings should be text.) These options are provided because the supporting research did not identify a single best option. ${ }^{[12]}$

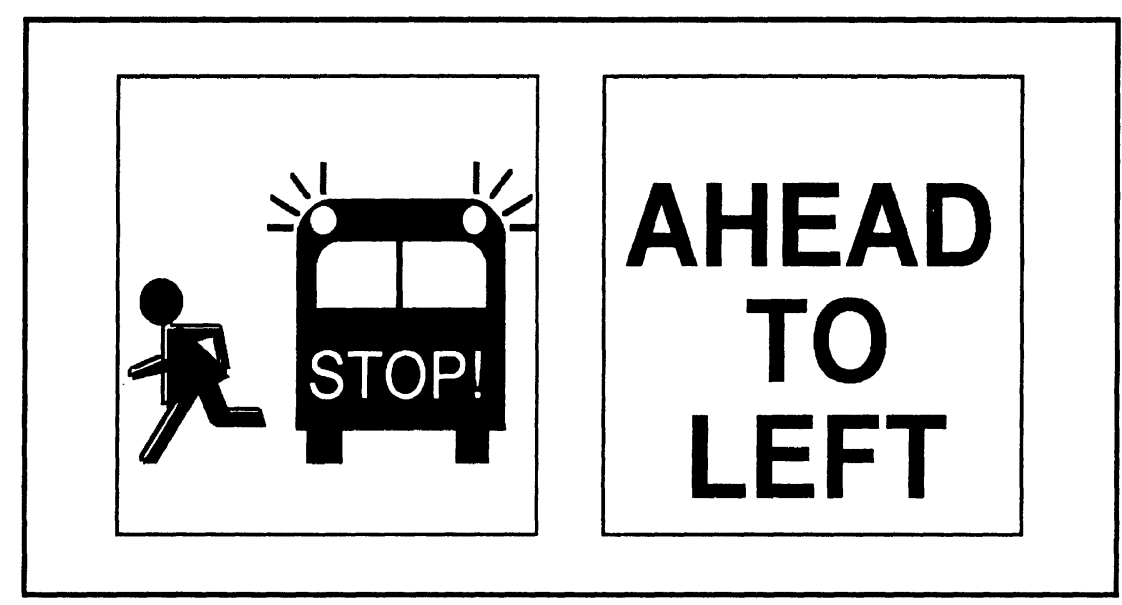

Figure 23. Example of two-panel warning.

In the second format, a one-panel design, the warning and location cue are combined, requiring only half of the space of the two-panel design. In some cases, fitting the basic warning and location cue onto one panel will be difficult. In the one-panel design, the format can be mixed text-graphic, strictly text, or strictly graphic. Figures 24 to 31 show examples of warnings developed as a part of this project. 


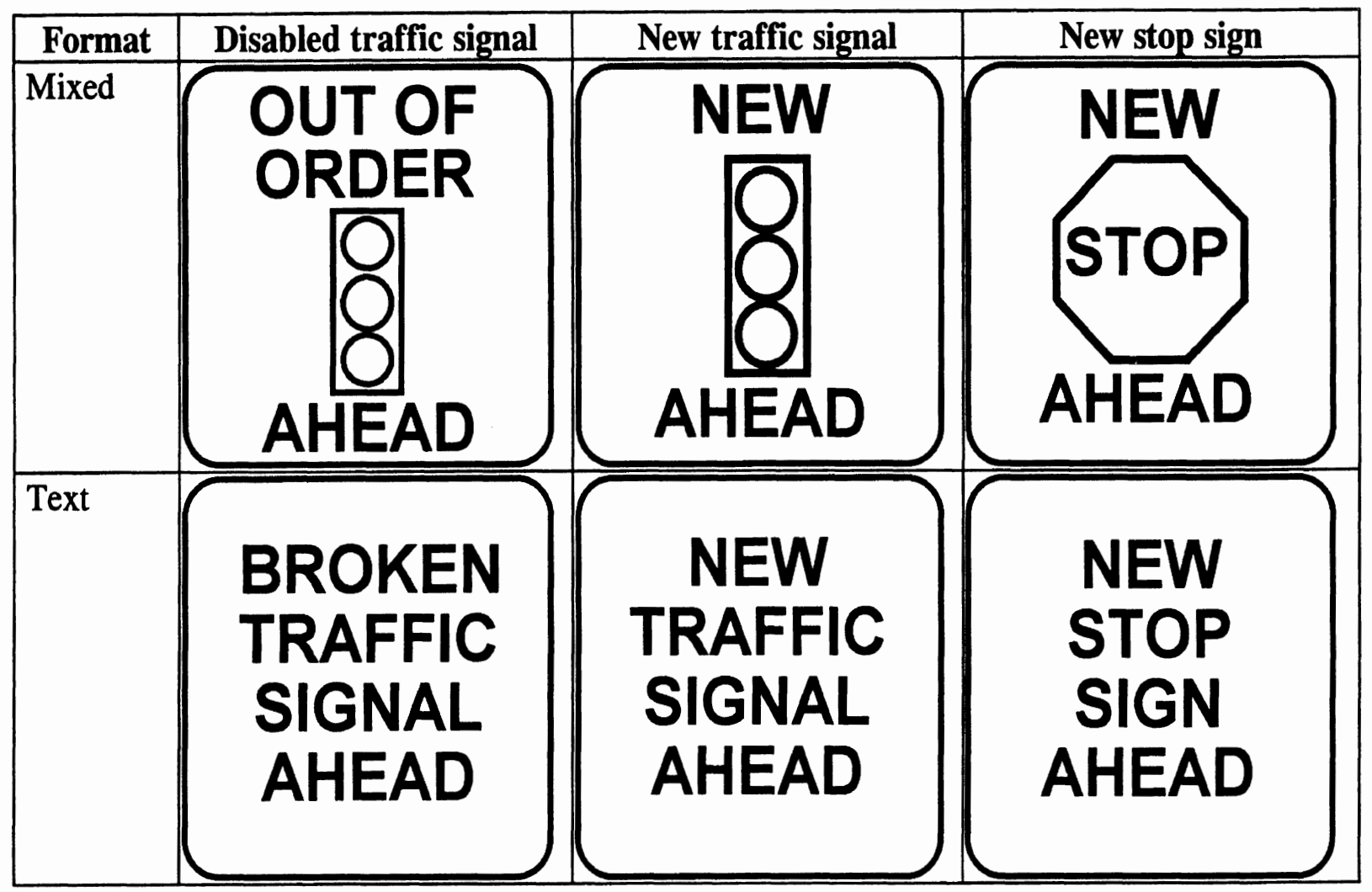

Figure 24. Recommended in-vehicle warnings for traffic control devices (new and out of order).

While desired, a warning for a new yield sign was not tested. The authors believe that a logical extension of this research would be to substitute a yield sign for the existing sign/signal graphics and assume that the message will be understood. 


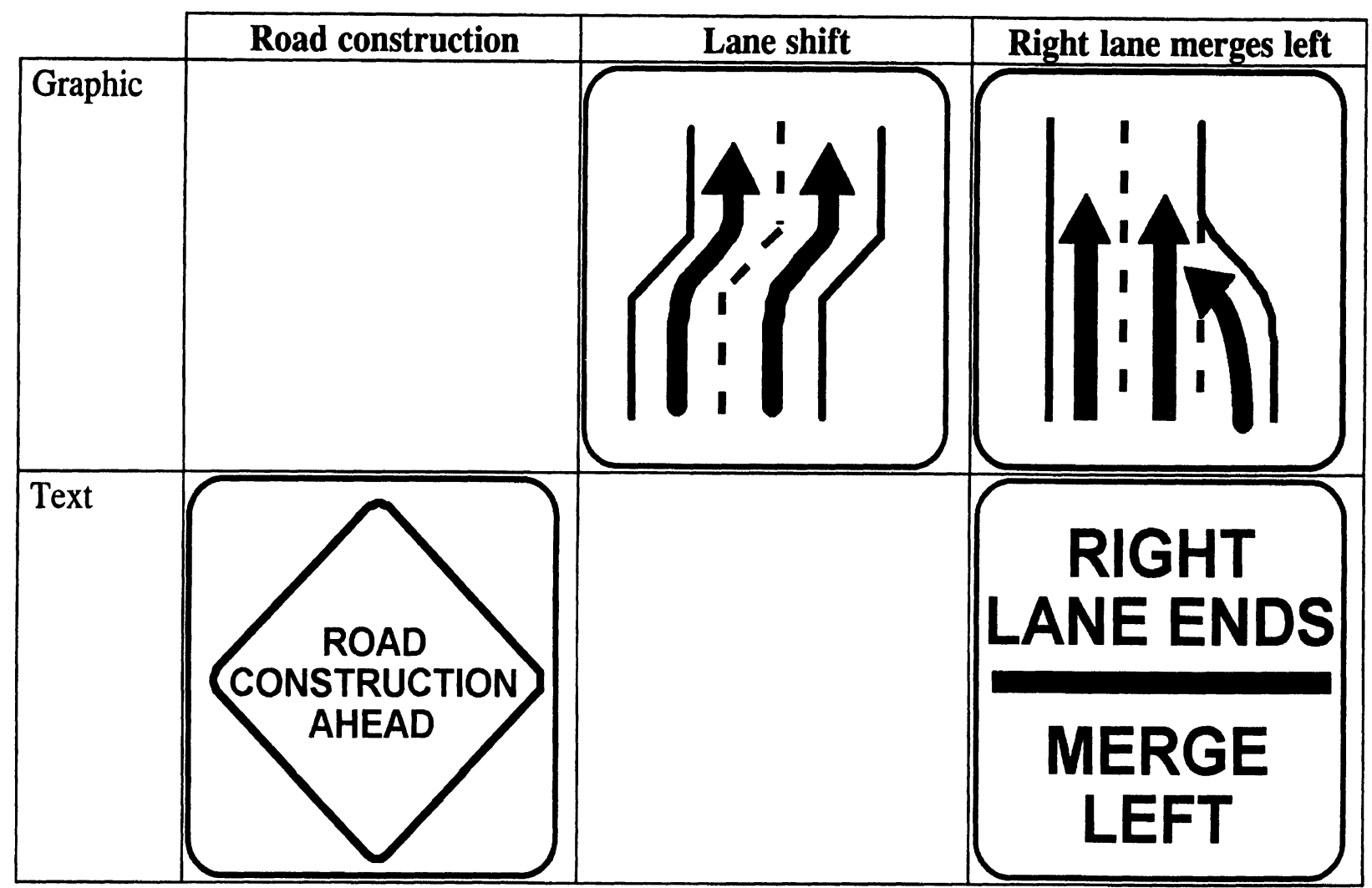

Figure 25. Recommended in-vehicle warnings for road construction.

There may be circumstances where "road work" is more appropriate than "road construction." The advantage of "work" is that larger characters (and greater legibility distance) are achieved for a sign of a fixed size. 


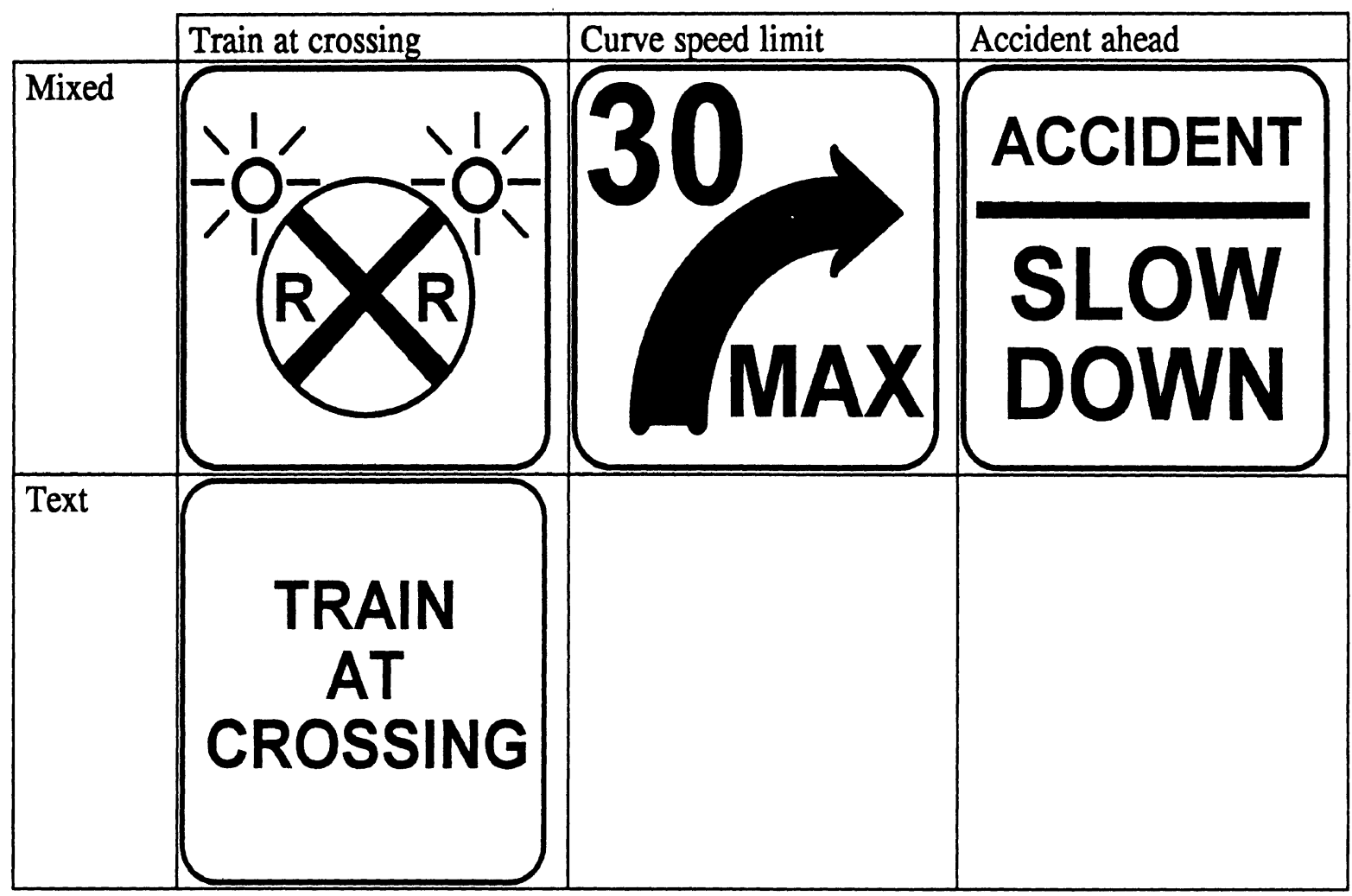

Figure 26. Recommended in-vehicle warnings for miscellaneous hazards (train at crossing, curve speed limit, and accident ahead). 


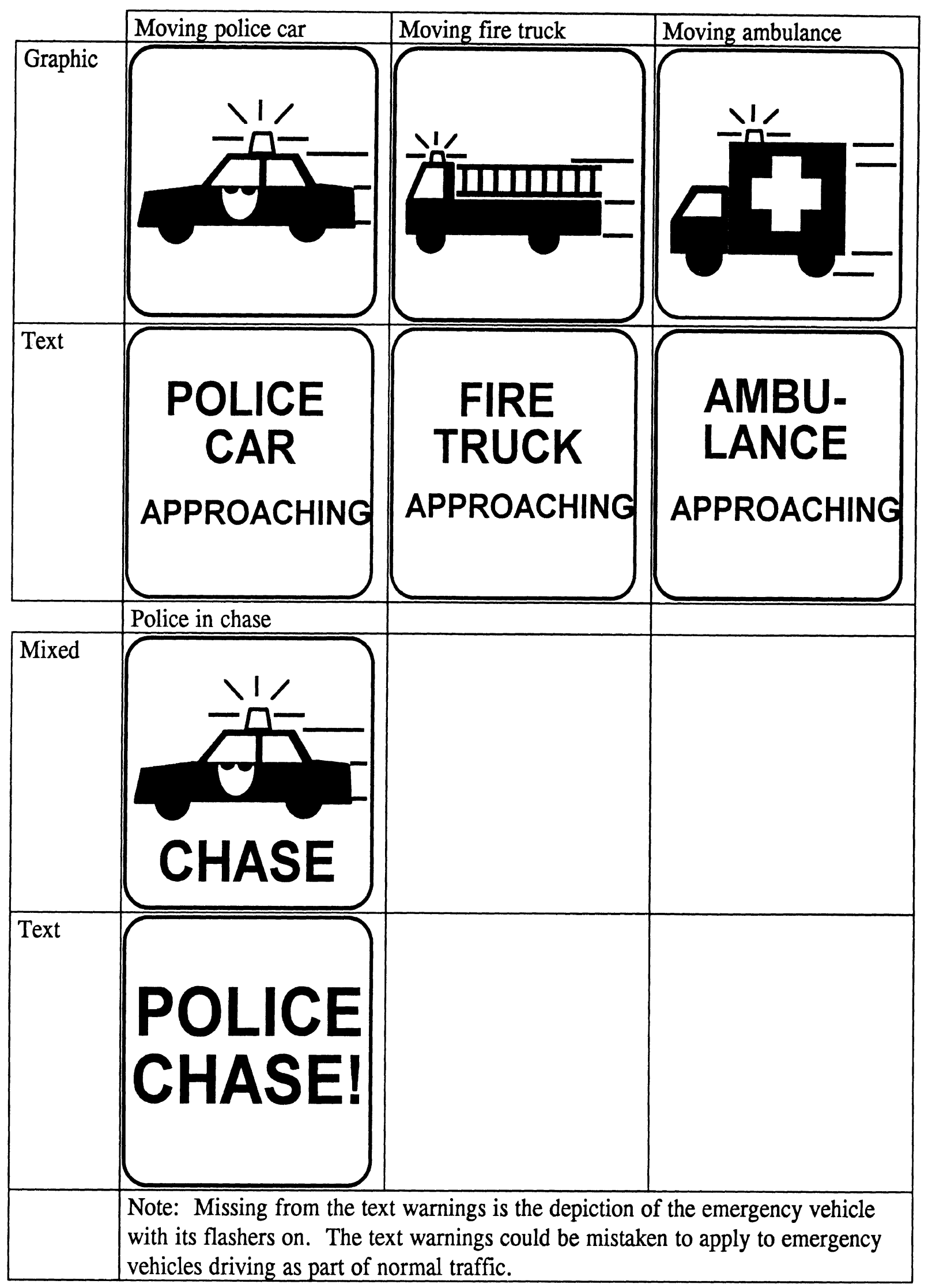

Figure 27. Recommended warnings for moving emergency vehicles. 


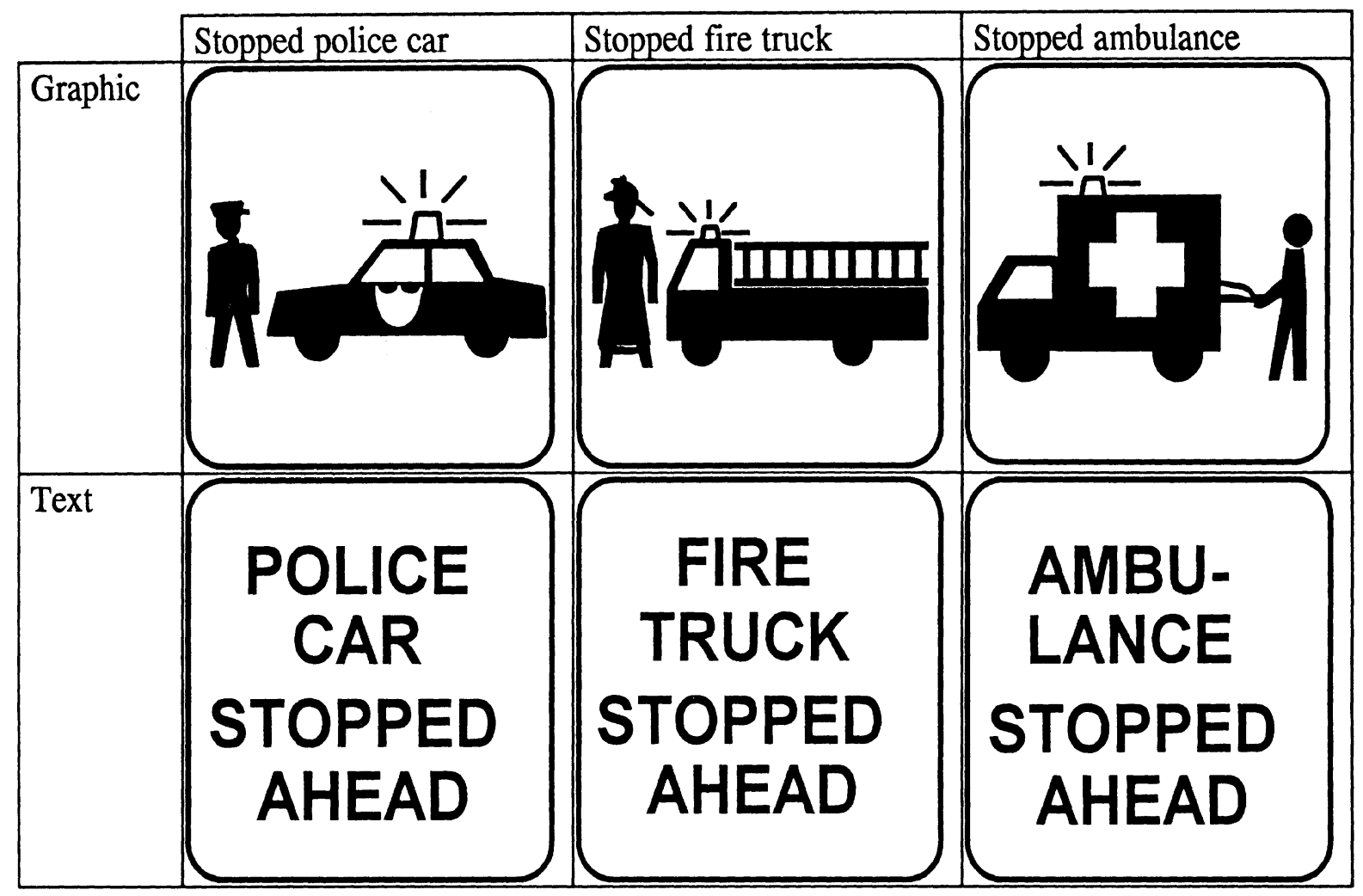

Figure 28. Recommended warnings for stopped emergency vehicles.

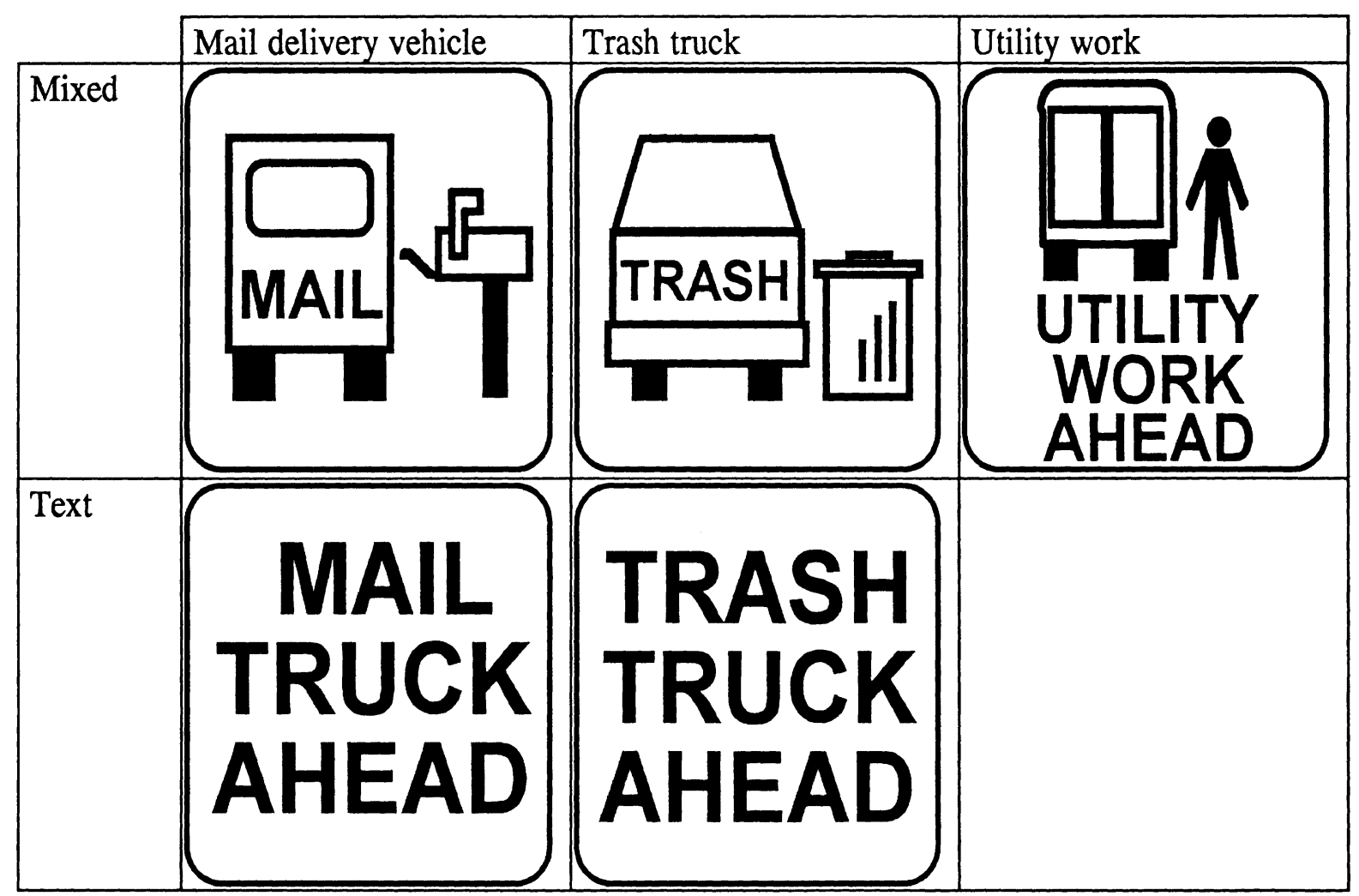

Figure 29. Recommended warnings for vehicles that make frequent stops. 


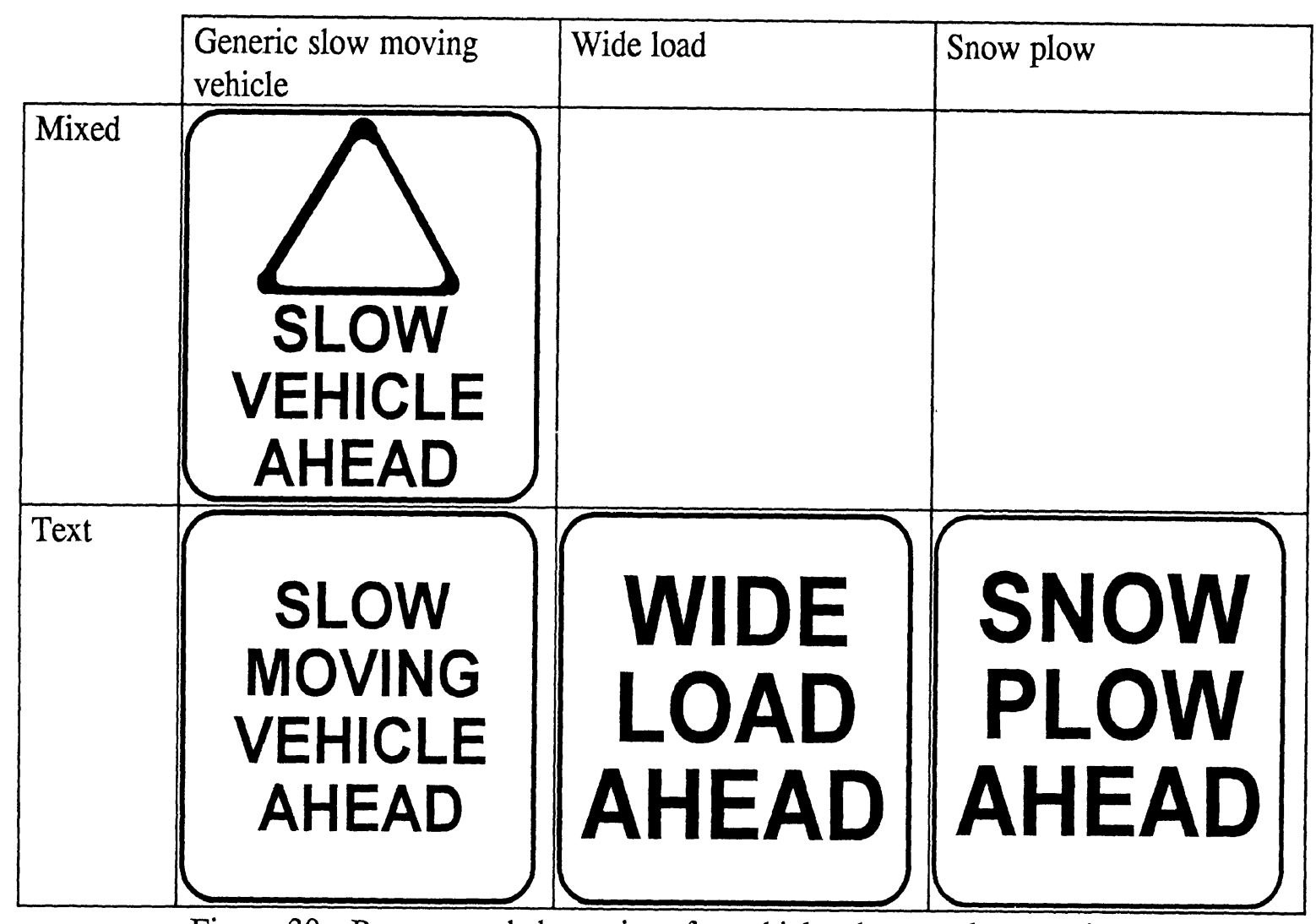

Figure 30. Recommended warnings for vehicles that are slow moving. 


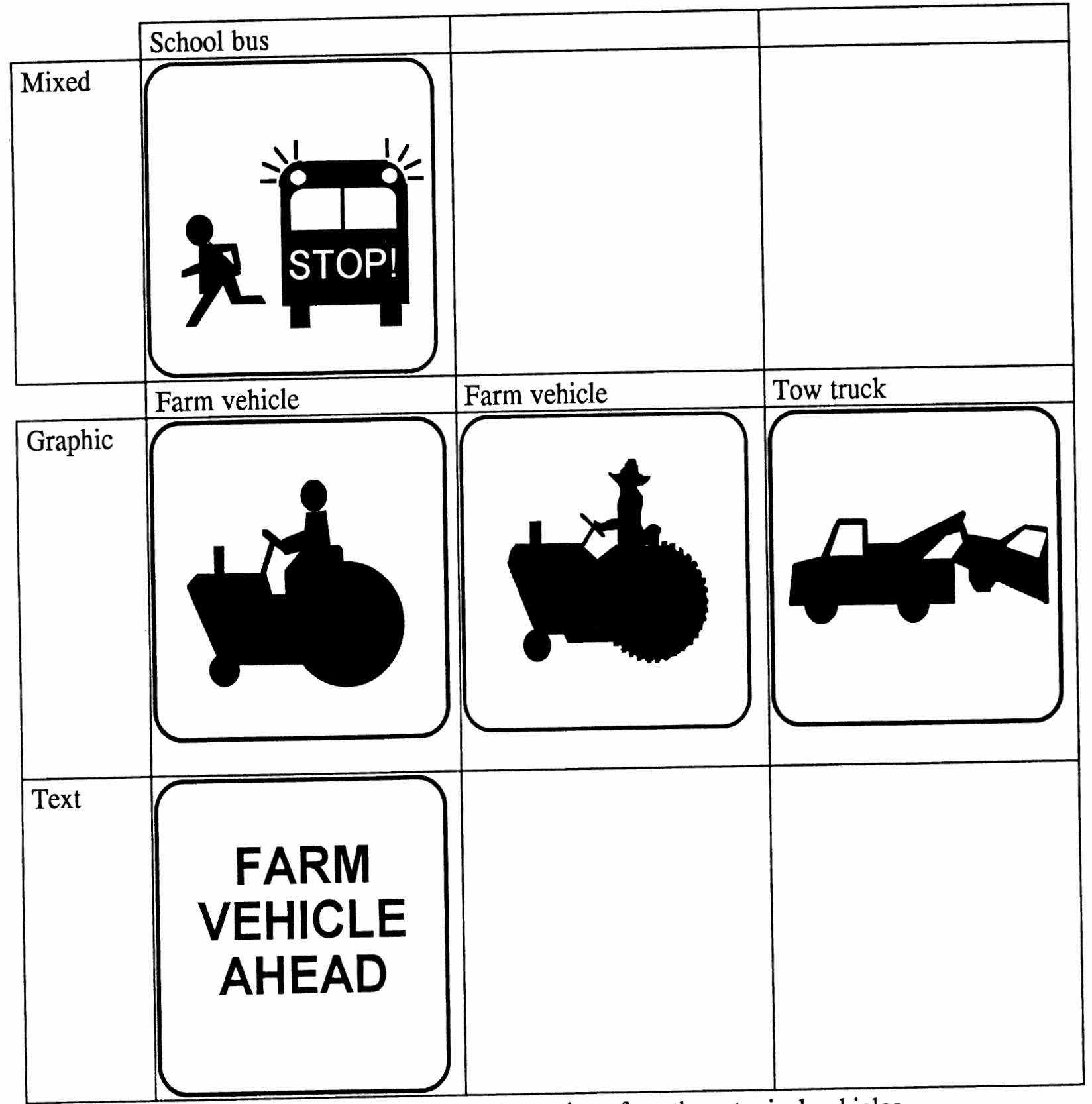

Figure 31. Recommended warnings for other atypical vehicles (school bus, tow truck, and farm vehicle).

\section{LOCATION CODING}

Guideline 13.4 - The relative location of the hazard should include the words "ahead," "behind," "left," "right," "ahead to left," and "ahead to right."

Experimental data concerning the understanding of these location cues and alternatives appears in Hoekstra, Williams, and Green. ${ }^{[12]}$ Other alternatives examined (and not recommended) are shown in figure 32 . 

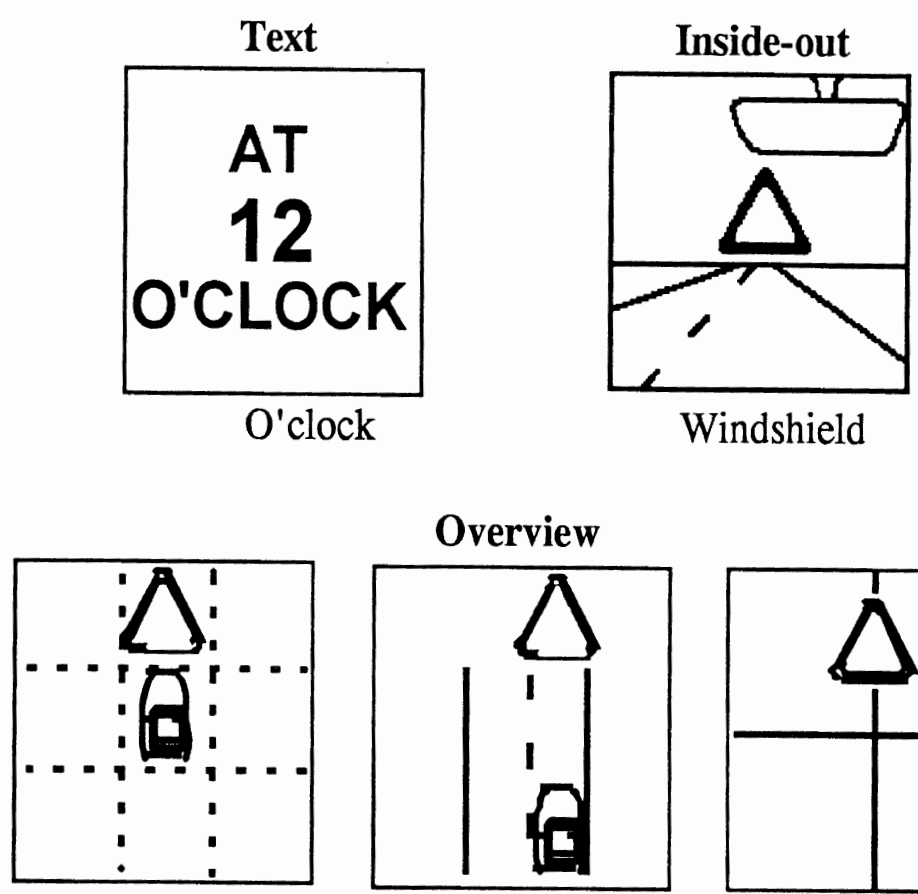

Grid

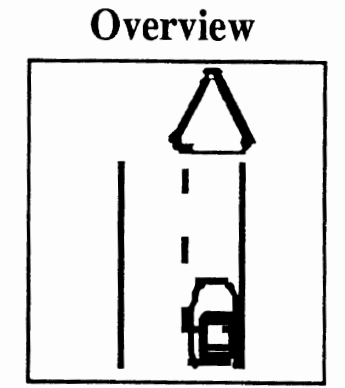

Overview

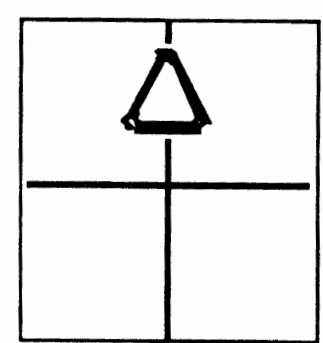

Plot

Arrow/Pointer

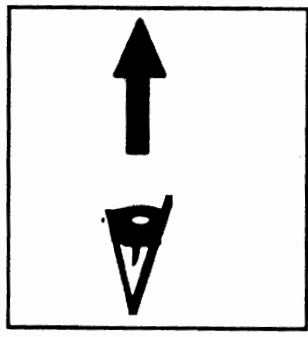

Eye

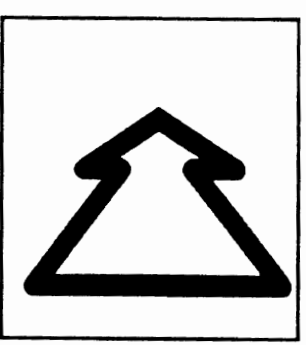

Perspective Arrow

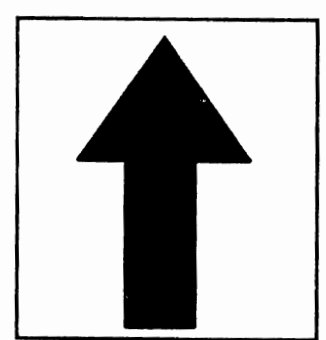

Arrow

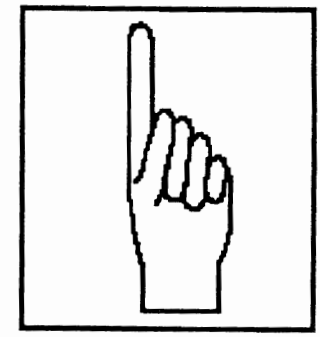

Hand

Figure 32. Location codes not recommended for a hazard ahead.

While it does take time to read the words identifying the hazard location, this interval should be far less than the additional time needed to search the environment for a hazard whose location is unknown. (This assumes a design similar to that in the supporting research: an LCD unit mounted atop the instrument panel. The LCD unit displayed the warning with an adjacent location cue, a two panel design. This is the most likely implementation.) 


\section{INTEGRATION GUIDELINES}

Integration concerns how interfaces for various functions (route guidance, IVSAWS, etc.) are combined. In the project associated with developing these guidelines, most of the effort was focused on interfaces for the individual functions, not on their integration. A guiding philosophy of this project was to provide direct access to features, so minimal integration was desired.

The initial on-the-road experiments, however, did touch upon integration issues. ${ }^{[15]}$ The interface prototyped consisted of two 5 -in $(12.7 \mathrm{~cm})$ LCD units mounted on top of the center console. On the left unit route guidance and traffic information were presented, with route guidance being the default. When a hypothetical congestion message was received, the traffic information screen (accompanied by a tone) replaced the default route guidance screen for several seconds, after which route guidance information automatically reappeared. In the test scenario examined, traffic information only was schedule to appear during straight expressway sections at some distance from exits, so the route guidance screen was not critical at that moment. Preemption strategies and controls for screen selection were not considered.

The right LCD unit showed either vehicle monitoring information or IVSAWS warnings, with vehicle monitoring as the default. As with the left screen, when an IVSAWS warning occurred, it replaced the default vehicle monitoring screen for a few seconds, after which the vehicle monitoring screen reappeared. As with the left screen, pre-emption strategies and controls for screen selection were not considered.

Thus, this section is short, because much of what constituted integration in this project involved following the consistency principle in the general guidelines section. However, in real products, direct access to all features and functions may not be viable. Commonly, access is achieved by organizing functions and features as a hierarchical menu. In those hierarchical interfaces, one multidirectional switch or several discrete switches are provided. For example, figure 33 shows an interface consisting of five buttons with replaceable labels. To select a particular destination, the driver first depresses the button labeled "nav." Subsequently, new labels appear and the driver depresses the "select dest" (destination) button, after which a third set of labels appear. The labels could appear on small LED labels on or below each switch, or on adjacent LCD or CRT displays. 


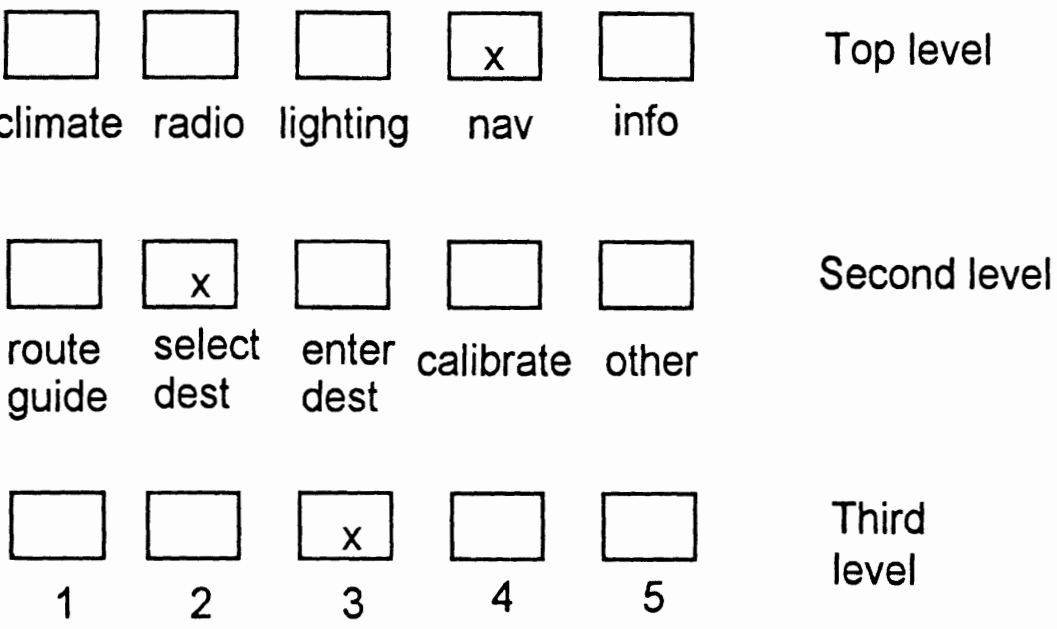

Figure 33. Example of a hierarchical menu employing multiple buttons.

Figure 34 shows an example implementation of a similar interface based upon a single fourposition rocker switch with replaceable labels. The " $\mathrm{x"}$ next to each label indicates the actuation sequence (from left to right).

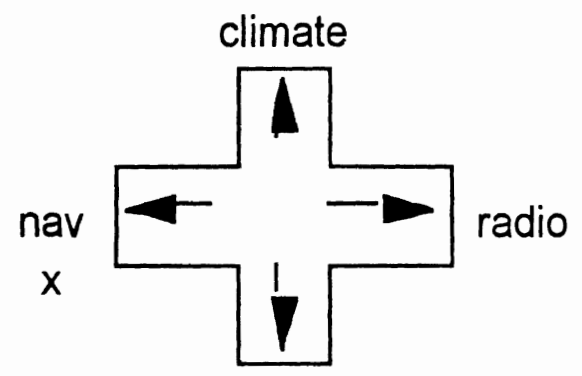

lighting

Top level

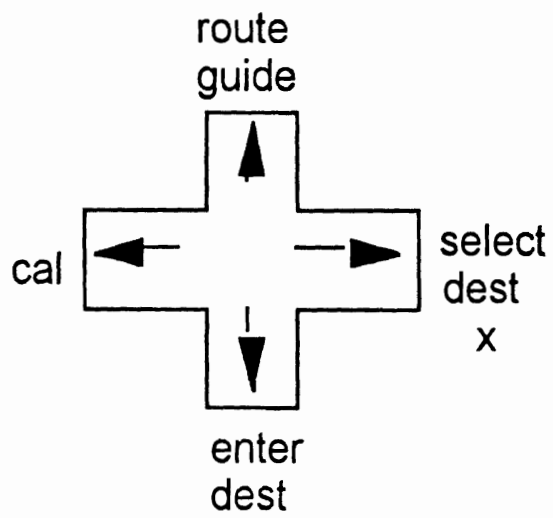

Second level

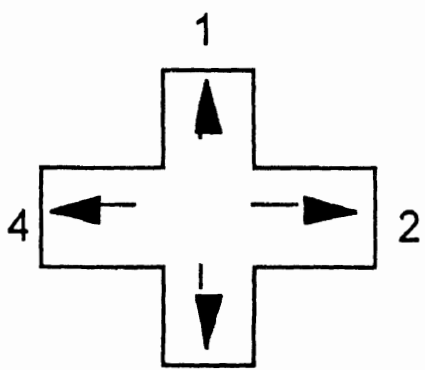

$3 \times$

Figure 34. Example of a hierarchical menu employing a single multiposition switch.

Guideline 14.1 - If a hierarchical menu system is used, place the commonly used functions as close to the top of the hierarchy as possible.

This shortens the sequence of actions to access them.

Guideline 14.2 - In designing hierarchical menus, the best structure trades off between depth and breadth.

Miller, and Landauer and Nachbar present data on user performance in tasks for various menu structures and equations for estimating the time to reach each menu item as a function of the menu design. ${ }^{[121,122,123]}$ Unfortunately, those equations are only valid for static selection from 
well known menu structures, not time sharing as occurs while driving. When recalibrated, those equations could be used to optimize menu design. Other important information on menu structures appears in Norman. ${ }^{[124]}$

Guideline 14.3 - Keep menu entry and menu navigation schemes the same throughout the interface.

This is an example of the application of principle 1, "be consistent." For menus, string entry and item selection should always be terminated in the same way, the same mechanism should always be used to move up and down the hierarchy, and keys for that purpose should always be in the same place on each screen. The importance of this guideline has been emphasized by the designers of the TravTek interface. 



\section{ENHANCEMENTS}

These guidelines are by no means complete. Clearly improvements can be made in the general auditory guidelines, the phone guidelines, and those associated with integration, topics that received less emphasis in the prototyping effort. However, because of the pressing need for these guidelines, the author would argue for releasing these guidelines as is (and doing so immediately), rather than continuing to improve them. While these gaps may be the subject of criticism, delays in release will result in missing several key windows of opportunity to affect product design, especially those related to navigation. There is no way to make up for those windows at a later date with improved guidelines.

There will also be a temptation to subject these documents to an extensive review by a wide variety of people and to add everything to the guidelines that anyone believes is missing. That type of review would be contrary to the tenets of the development approach employed for these guidelines-(1) develop guidelines from design decisions and (2) keep the guidelines short. A more effective approach would be to have designers of IVHS interfaces identify lessons learned from their efforts, and to incorporate those ideas into the guidelines. Feedback can also be obtained from application of the guidelines to products now being developed. A process to review suggestions should be implemented to assure that guidelines proposed are truly needed.

Subsequently, DOT should contract for the development of pre-production interfaces relating to topic areas where the guidelines are weak (e.g., hierarchical menu systems). Those projects should include funding research on unresolved interface design issues and developing additional guidelines. 



\section{REFERENCES}

1 Green, P. (1993). Human Factors of In-Vehicle Driver Information Systems: An Executive Summary (Technical Report UMTRI-93-18), Ann Arbor, MI: The University of Michigan Transportation Research Institute.

2 Green, P., Williams, M., Serafin, C., and Paelke, G. (1991. "Human Factors Research on Future Automotive Instrumentation: A Progress Report," Proceedings of the 35th Annual Meeting of the Human Factors Society, Santa Monica, The Human Factors Society, pp. 1120-1124.

3 Green, P. (1992). American Human Factors Research on In-Vehicle Navigation Systems (Technical Report UMTRI-92-47), Ann Arbor, MI: The University of Michigan Transportation Research Institute.

4 Brand, J.E. (1990). Attitudes Toward Advanced Automotive Display Systems: Feedback from Driver Focus Group Discussions (Technical Report UMTRI-90-22), Ann Arbor, MI: The University of Michigan Transportation Research Institute.

5 Green, P., and Brand, J. (1992). Future In-Car Information Systems: Input from Focus Groups (SAE paper 920614), Warrendale, PA: Society of Automotive Engineers.

6 Green, P., Serafin, C., Williams, M., and Paelke, G. (1991). "What Functions and Features Should Be in Driver Information Systems of the Year 2000?” (SAE paper 912792), Vehicle Navigation and Information Systems Conference (VNIS'91), Warrendale, PA: Society of Automotive Engineers, pp. 483-498.

7 Serafin, C., Williams, M., Paelke, G., and Green, P. (1991). Functions and Features of Future Driver Information Systems (Technical Report UMTRI-91-16), Ann Arbor, MI: The University of Michigan Transportation Research Institute.

8 Green, P., and Williams, M. (1992). "Perspective in Orientation/Navigation Displays: A Human Factors Test," Conference Record of Papers, the Third International Conference on Vehicle Navigation and Information Systems (VNIS'92) (IEEE Catalog \#92CH3198-9), Piscataway, NJ: Institute of Electrical and Electronics Engineers, pp. 221-226.

9 Williams, M., and Green, P. (1992). Development and Testing of Driver Interfaces for Navigation Displays (Technical Report UMTRI-92-21), Ann Arbor, MI: The University of Michigan Transportation Research Institute.

10 Paelke, G., Green, P., and Wen, C. (1993). Development and Testing of a Traffic Information System Driver Interface (Technical Report UMTRI-93-20), Ann Arbor, MI: The University of Michigan Transportation Research Institute. 
11 Serafin, C., Wen, C., Paelke, G., and Green, P. (1993). Development and Human Factors Tests of Car Telephones (Technical Report 93-17), Ann Arbor, MI: The University of Michigan Transportation Research Institute.

12 Hoekstra, E., Williams, M., and Green, P. (1993). Development and Driver Understanding of Hazard Warning and Location Symbols for IVSAWS (Technical Report UMTRI-93-16), Ann Arbor, MI: The University of Michigan Transportation Research Institute.

13 Williams, M., Hoekstra, E., and Green, P. (1993). Development and Evaluation of a Vehicle Monitor Driver Interface (Technical Report UMTRI-93-22), Ann Arbor, MI: The University of Michigan Transportation Research Institute.

14 Green, P., Hoekstra, E., Williams, M., Wen, C., and George, K. (1993). Examination of a Videotape-Based Method to Evaluate the Usability of Route Guidance and Traffic Information Systems (Technical Report UMTRI-93-31), Ann Arbor, MI: The University of Michigan Transportation Research Institute.

15 Geen, P., Hoekstra, E., Williams, M., George, K., and Wen, C. (1993). Initial Onthe-Road Tests of Driver Information System Interfaces: Route Guidance, Traffic Information, IVSAWS, and Vehicle Monitoring (Technical Report UMTRI-93-32), Ann Arbor, MI: The University of Michigan Transportation Research Institute.

16 Green, P., Hoekstra, E., and Williams, M. (1993). On-the-Road Tests of Driver Interfaces: Examination of a Route-Guidance System and a Car Phone (Technical Report UMTRI-93-35), Ann Arbor, MI: The University of Michigan Transportation Research Institute.

17 Green, P., Hoekstra, E., and Williams, M. (1993). On-the-Road Tests of Driver Interfaces: Examination of a Route-Guidance System and a Car Phone (Technical Report UMTRI-93-35), Ann Arbor, MI: The University of Michigan Transportation Research Institute.

18 Green, P. (1993). Measures and Methods Used to Assess the Safety and Usability of Driver Information Systems (Technical Report UMTRI-93-12), Ann Arobr, MI: The University of Michigan Transportation Research Institute.

19 Green, P. (1993). Suggested Procedures and Acceptance Limits for Assessing the Safety and Ease of Use of Driver Information Systems (Technical Report UMTRI-9313), Ann Arbor, MI: The University of Michigan Transportation Research Institute.

20 Levison, W.H., and Cramer, N. (1993). Description of the Integrated Driver Model (BBN Report 7840), Cambridge, MA: Bolt, Beranek and Newman. 
21 Levison, W.H. (1993). A Simulation Model for the Driver's Use of In-Vehicle Information Systems (TRB Paper 930935), paper presented at the Transportation Research Board Annual Meeting, Washington, DC, January 10 through 14.

22 United States Department of Defense (1989). Human Engineering Design Criteria for Military Systems, Equipment and Facilities (Military Standard MIL-STD-1472D), Philadelphia, PA: Naval Forms and Publications Center.

23 Sanders, M.S., and McCormick, E.J. (1993). Human Factors in Engineering and Design (7th Edition), New York, NY: McGraw-Hill.

24 ICE Ergonomics (1993). The Design of In-Vehicle Information Systems: Code of Practice and Design Guidelines, Loughborough, Leichestershire, England: Author.

25 Leiser, B., and Carr, D. (1991). Analysis of Input and Output Devices for In-Car Use (Deliverable Report GIDS/DIS1), The Netherlands: Traffic Research Centre, University of Groningen.

26 Apple Computer (1992). Macintosh Human Interface Guidelines, Reading, MA: Addison-Wesley.

27 Smith, S.L. and Mosier, J.N. (1986). Guidelines for Designing User Interface Software (Report 7 MTR-10090, ESD-TR-86-278), Bedford, MA: Mitre Corporation.

28 Carroll, J.M., Smith-Kerker, P.L., Ford, J.R. and Mazur-Rimetz, S.A. (1987-88). The Minimal Manual, Human Computer Interaction, 3,123-153.

29 American National Standards Institute (1988). American National Standard for Human Factors Engineering of Visual Display Terminal Workstations (standard ANSI/HFS 100-1988), Santa Monica, CA: The Human Factors Society.

30 Williams, M., Green, P., and Paelke, G. (1991). Further Development of Warnings for Automotive Lifts (Technical Report UMTRI-91-43), Ann Arbor, MI: The University of Michigan Transportation Research Institute.

31 IBM (1989). Systems Application Architecture, Common User Access, Advanced Interface Design Guide (Technical Report SC26-4582-0), Cary, NC: Author, December.

32 IBM (1989). Systems Application Architecture, Common User Access, Basic Interface Design Guide (Technical Report SC26-4583-0), Cary, NC: Author, December.

33 Polson, P.G., and Lewis, C.H. (1990). "Theory-Based Design for Easily Learned Interfaces," Human-Computer Interaction, 5, 191-220. 
34 Vossen, P.H., Sitter, S., and Ziegler, J.E. (1987). "An Empirical Validation of Cognitive Complexity Theory," in Bullinger, H.J. and Shackel, B., Human-Computer Interaction - INTERACT '87, Amsterdam, Netherlands: Elsevier Science, 71-75.

35 Bovair, S., Kieras, D.E., and Polson, P.G. (1990). "The Acquisition and Performance of Text-Editing Skill: A Cognitive Complexity Analysis," HumanComputer Interaction, 5, 1-48.

36 Turner, C.H., and Green, P. (1987). Human Factors Research on Secondary Controls: A Literature Review (Technical Report UMTRI-87-20), Ann Arobr, MI: The University of Michigan Transportation Research Institute.

37 Society of Automotive Engineers (1993). "Driver Hand Control Reach" (SAE J287, June 1988), in 1993 SAE Handbook, Warrendale, PA: Author.

38 Society of Automotive Engineers (1993). "Design Criteria-Driver Hand Controls Locations for Passenger Cars, Milti-Purpose Passenger Vehicles, and Trucks (10,000 GVW and Under)" (SAE J1138), in 1993 SAE Handbook, Warrendale, PA: Author.

39 Hallen, A. (1977). Comfortable Hand Control Reach of Passenger Car Drivers (SAE Paper 770245), Warrendale, PA: Society of Automotive Engineers.

40 Papazian, B. (1993). Management of Errors in Spoken-Language System Dialogues: A Literature Review (Technical Report BBN-7910), Cambridge, MA: BBN Systems and Technologies.

41 Slator, B.M., Anderson, M.P., and Conley, W. (1986). "Pygmalion-at the Interface," Communications of the ACM, 29, 599-604.

42 Halsted-Nussloch, R. (1989). "The Design of Phone-Based Interfaces for Consumers," CHI'89 Proceedings, New York, NY: Association for Computing Machinery, 347-352.

43 Leiser, R.G. (1989). "Exploiting Convergence to Improve Natural-Language Understanding," Interacting with Computers, 3, 284-298.

44 Ringle, M.D., and Halsted-Nussloch, R.H. (1989). "Shaping User-Input: A Strategy for Natural Language Dialog Design," Interacting with Computers, 3, 227-244.

45 Zoltan-Ford, E. (1991). "How to Get People to Say and Type What Computers Can Understand," International Journal of Man-Machine-Studies, 34, 527-547.

46 Frankish, C., and Noyes, J. (1990). "Sources of Human Error in Data Entry Tasks Using Speech Input," Human Factors, 32(6), 697-716. 
47 Schwab, E.C., Ball, C.A., and Lively, B.L. (in press). "Human Factors Contributions to the Development of a Speech Recognition Cellular Phone," in Bennett, Syrdal, and Greenspan (Eds.), Behavioral Aspects of Speech Technology, Amsterdam, The Netherlands: Elsevier.

48 Black, J.B., and Moran, T.P. (1981). "Learning and Remembering Command Names," Proceedings: Human Factors and Computer Systems, New York, NY: Association for Computing Machinery, 8-11.

49 Galer, M., Baines, A., and Simmonds, G. (1980). "Ergonomic Aspects of Electronic Dashboard Instrumentation," in D.J. Obourne, and J.A. Levis (Eds.), Human Factors in Transport Research (volume 1), London, U.K.: Academic.

50 Streeter, L.A., Vitello, D., and Wonsiewicz. (1985). "How to Tell People Where to Go: Comparing Navigational Aids,” International Journal of Man-Machine Studies, $22,549-562$.

51 Green, P., Goldstein, S., Zeltner, K., and Adams, S. (1988). Legibility of Text on Instrument Panels: A Literature Review (Technical Report UMTRI-88-34), Ann Arbor, MI: The University of Michigan Transportation Research Institute.

52 Smith, S.L., (1979). "Letter Size and Legibility," Human Factors, December, 21(6), 661-670.

53 Boreczky, J., Green, P., Bos, T., and Kerst, J. (1988). Effects of Size, Location, Contrast, Illumination, and Color on the Legibility of Numeric Speedometers (Technical Report UMTRI-88-36), Ann Arbor, MI: The University of Michigan Transportation Research Institute.

54 Cornog, D.Y., and Rose, F.C. (1967). Legibility of Alphanumeric Characters and Other Symbols 1I. A Reference Handbook (Miscellaneous Publication 262-2), Washington, D.C.: National Bureau of Standards.

55 Serafin, C., and Green, P. (1990). Driver Preferences for Instrument Panel Lighting Levels (Technical Report UMTRI-90-5), Ann Arbor, MI: The University of Michigan Transportation Research Institute.

56 Serafin, C., and Green, P. (1991). "Instrument Panel Lighting Levels Preferred by Drivers," Queinnec, Y. and Daniellou, F. (Eds.) Designing for Everyone and Everybody (Proceedings of the 11th Congress of the International Ergonomics Association), London, UK: Taylor and Francis, pp. 1456-1458.

57 Silverstein, L.D. (1987). Display Color Modeling and Algorithmic Color Selection, Cockpit Automation Technology Program, Phase II Software Development, Technical 
Background and Software Users Manual (Honeywell Publication H74-5410-00-00), Phoenix, AZ: Honeywell Systems and Research Center.

58 Silverstein, L.D., and Merrifield, R.M. (1985). The Development and Evaluation of Color Systems for Airborne Applications (Report DOT/FAA/PM-85-19, also listed as NADC-81-011-60), Washington, D.C.: U.S. Department of Transportation, Federal Aviation Administration.

59 Green, P. (1984). Driver Understanding of Fuel and Engine Gauges (SAE Paper 840314), Warrendale, PA: Society of Automotive Engineers (see also SAE Transactions, 93, 1985).

60 Landauer, T.K., Galotti, K.M., and Hartwell, S. (1983). Natural Command Names and Initial Learning: A Study of Text Editing Terms, Communications of the ACM, July, 26(7), 495-503.

61 Green, P. (1993). "Symbols for Controls and Displays," in Peacock, B. and Karwowski, W. (Eds.) Automotive Ergonomics, London, U.K.: Taylor and Francis, pp. 237-268.

62 International Standards Organization (1977). Road Vehicles - Passenger Cars-Location of Hand Controls, Indicators and Tell-Tales (International Standard 4040). Geneva, Switzerland: Author.

63 United States Department of Transportation (1989). Federal Motor Vehicle Safety Standard; Controls and Displays (Standard 101), Federal Register, March 9, 1987, Washington, D.C.: U.S. Department of Transportation, National Highway Traffic Safety Administration.

64 United States Department of Transportation (1989). Manual on Uniform Traffic Control Devices - 1988 edition (ANSI D6.1e-1989), Washington, D.C.:

Superintendent of Documents, U.S. Government Printing Office.

65 Ehrenreich, S.L. (1985). "Computer Abbreviations: Evidence and Synthesis," Human Factors, 27(2), 143-155.

66 Huchingson, R.D., and Dudek, C.L. (1983). "How to Abbreviate on Highway Signs," Transportation Research Record 904, National Academy of Sciences, Transportation Research Board, 1-4.

67 Nawrocki, L. (1979). Word Abbreviations in Man-Computer Communication Systems (ARI Working Paper MF-79-034, HF-74-04), Alexandria, VA: U.S. Army Research Institute. 
68 Galitz, W.O. (1985). Handbook of Screen Format Design (2nd ed.), Wellesley Hills, MA: QED Information Sciences.

69 Tullis, T.S. (1983). The Formatting of Alphanumeric Displays: A Review and Analysis, Human Factors, 25(6), 657-682.

70 Potter, R.C., Fidell, S.A., Myles, M.M., and Keast, D.N. (1977). Effectiveness of Audible Warning Devices on Emergency Vehicles (Report DOT-TSC-OST-77-38), Washington, D.C.: U.S. Department of Transportation.

71 Berson, B.L. (Jan, 1990). (Letter to the editor), Human Factors Society Bulletin, 33(1), p. 12, Santa Monica, CA: The Human Factors Society.

72 Boff, K.R., and Lincoln, J.E. (1988). Engineering Data Compendium: Human Perception and Performance, Wright-Patterson Air Force Base, OH: U.S. Air Force, Armstrong Aerospace Medical Research Laboratory, 2388-2389.

73 Boucek, G.P., Jr., Veitengrubber, J.E., and Smith, W.D. (May, 1977). Aircraft Alerting Systems Criteria Study. Volume II, Human Factors Guidelines for Aircraft Alerting Systems (FAA-RD-76-222-2), Washington, D.C.: Department of Transportation, Federal Aviation Administration.

74 Patterson, R.D. (1982). Guidelines for Auditory Warning Systems in Civil Aircraft (CAA Paper 82017), London, UK: Civil Aviation Authority.

75 Doll, T.J., and Folds, D.J. (1986). "Auditory Signals in Military Aircraft: Ergonomics Principles Versus Practice,” Applied Ergonomics, 17, 257,264.

76 Sorkin, R.D. (1987). "Design of Auditory and Tactile Displays," in Salvendy, G., (Ed.), Handbook of Human Factors, New York, NY: Wiley.

77 Patterson, R.D., and Milroy, R. (1980). Auditory Warnings on Civil Aircraft: The Learning and Retention of Warnings, MRC Applied Psychology Unit, Civil Aviation Authority contract 7D/S/0142.

78 Mellen, G. (1983). "Speech Technology for Avionic Computers," Proceedings of the IEEE 1983 National Aerospace and Electronics Conference, 1983, New York, NY: IEEE, 404-408.

79 Bertone, C.M. (1982), "Human Factors Considerations in the Development of a Voice Warning System for Helicopters," Behavioral Objectives in Aviation Automated Systems, Warrendale, PA: Society of Automotive Engineers, 133-142. 
80 Edman, T.R. (1982). "Human Factors Guidelines for the Use of Synthetic Speech Devices," Proceedings of the 26th Annual Meeting of the Human Factors Society, Santa Monica, CA: Human Factors Society, pp. 212-216.

81 Bucher, N.M., Karl, R.L., Voorhees, J.W., and Werner, E. (1984). "Alerting Prefixes for Speech Warning Messages," Proceedings of the IEEE 1984 National Aerospace and Electronics Conference, New York, NY: IEEE, pp. 924-931.

82 Simpson, C.A. (1980). Synthesized Voice Approach Callouts for Air Transport Operations (NASA Contractor Report CR 3300), Moffett Field, CA: NASA Ames Research Center.

83 Perez, W.A., Fleischman, R., Golembiewski, G., and Dennard, D. (1993). "TravTek Field Study Results to Date," Proceedings of the IVHS America 1993 Annual Meeting, Washington, D.C.

84 Bauer, T. (1992). personal communication.

85 Wierwille, W.W., Antin, J.F., Dingus, T.A., and Hulse, M.C. (1988). "Visual Attentional Demand of an In-Car Navigation Display," in Gale, A.G., Freeman, M.H., Haslegrave, C.M., Smith, P., and Taylor, S.P. (Eds.), Vision in Vehicles II, Amsterdam: Elsevier, 307-316.

86 Dingus, T.A., Antin, J.F., Hulse, M.C., and Wierwille, W.W. (1989). "Attentional Demand Requirements of an Automobile Moving-Map Navigation System," Transportation Research, 23A(4), 301-315.

87 Walker, J. Alicandri, E., Sedney, C. and Roberts, K. (1990). In-Vehicle Navigation Devices: Effects on the Safety of Driver Performance (FHWA/RD-90/053), McLean, VA: Federal Highway Administration, U.S. Department of Transportation.

88 Walker, J., Alicandri, E., Sedney, C., and Roberts, K. (1991). "In-Vehicle Navigation Devices: Effects on the Safety of Driver Performance," Vehicle Navigation and Information Systems (VNIS'91), New York, NY: Institute of Electrical and Electronics Engineers, pp. 499-525.

89 Walker, J., Alicandri, E., Sedney, C., and Roberts, K. (1992). "In-Vehicle Navigation Devices: Effects on the Safety of Driver Performance," Public Roads, 56(1), 9-22.

90 Rothery, R.W., Thompson, R.R., and Von Buseck, C.R. (1968). A Design for an Experimental Route Guidance System, Volume III: Driver Display Experimental Evaluation (Technical Report GMR-815-III), Warren, MI: General Motors Research Laboratories. 
91 Stilitz, I., and Yitzhaky, J. (1979). The Effect of Grid Size on Street Location Time in Maps, Applied Ergonomics, December, 10(4), 235-239.

92 Cross, K.D., and McGrath, J.J. (1977). A Study of Trip Planning and Map Use by American Motorists (Report 170-1, FHWA-WV-77-10), Charleston, VA: West Virginia Department of Highways.

93 Adeyemi, E.O. (1982). "The Effect of Map Orientation on Human Spatial Orientation Performance," The Cartographic Journal, June, 19(1), 2833.

94 Carpenter, J.T., Fleischman, R.N., Dingus, T.A., Szczublewski, F.E., Krage, M.K., and Means, L.G. (1991). "Human Factors Engineering of the TravTek Engineering of the TravTek Driver Interface," Conference Record of Papers at the 2nd Vehicle Navigation and Information Systems (VNIS '91) Conference, Dearborne, MI.

95 Streeter, L.A., and Vitello, D. (1986). "A Profile of Drivers' Map-Reading Abilities," Human Factors, 28(2), 223-239.

96 Paelke, G. (1992). "Development of a Traffic Information System Driver Interface," Proceedings of the IVHS-America 1992 Annual Meeting, Washington, D.C.: IVHSAmerica, pp. 793-802.

97 Stevens, S.S. (1975). Psychophysics, New York, NY: Wiley.

98 Baird, J.C., and Noma, E. (1978). Fundamentals of Scaling and Psychophysics, New York, NY: Wiley.

99 Davis, J.R. (1989). Back Seat Driver: Voice Assisted Automobile Navigation (Ph.D. dissertation), Cambridge, MA: Massachusetts Institute of Technology.

100 Gatling, F.P. (1975). Auditory Message Studies for Route Diversion (Report FHWARD-75-73), Washington, D.C.: U.S. Department of Transportation, Federal Highway Administration, June. (available from NTIS as PB 246-125/9).

101 Gatling, F.P. (1976). The Effect of Auditory and Visual Presentation of Navigational Messages on Message Retention (Report FHWA-RD-76-94), Washington, D.C.: U.S. Department of Transportation, Federal Highway Administration. (available from NTIS as PB 256 599/2).

102 Gatling, F.P. (1977). Further Studies of Auditory Messages (Report FHWA-RD-77130), Washington, D.C.: U.S. Department of Transportation, Federal Highway Administration, October. (available from NTIS as PB 279 858/5). 
103 Eberhard, J.W. (1968). "Driver Information Requirements and Acceptance Criteria," Highway Research Record \#265 (Route Guidance), Washington, D.C.: National Academy of Sciences, National Research Council, Highway Research Board, 19-30.

104 Eberhard, J.W., Jones, H.H., Kolsrud, G.S., and Schoppert, D. (undated). Driver Information Requirements and Acceptance Criteria for ERGS (unnumbered Technical report), McLean, VA: Serendipity, Inc.

105 Finnegan, P., and Green, P. (1990). The Time to Change Lanes: A Literature Review (Technical Report UMTRI-90-34), Ann Arbor, MI: The University of Michigan Transportation Research Institute.

106 Means, L.G., Fleischman, R.N., Carpenter, J.T., Szczublewski, F.E., Dingus, T.A., and Krage, M.K. "TravTek Auditory Interface," Transportation Research Record No. 1403. Operations and Safety. National Academy Press, Washington, D.C.

107 Dingus, T.A., Hulse, M.C., Krage, M.K., Szczublewski, F.E., and Berry, P. (1991). "A Usability Evaluation of Navigation and Information System "Pre-Drive" Functions" (SAE Paper 912794), Vehicle Navigation and Information Systems Conference Proceedings (NVIS'91), Warrendale, PA: Society of Automotive Engineers, pp. 527-536.

108 Paelke, G. (1993). "A Comparison of Route Guidance Destination Entry Methods," Proceedings of the Human Factors and Ergonomics Society 37th Annual Meeting, Santa Monica, CA: The Human Factors and Ergonomics Society, pp. 569-573.

109 Marics, M.A. (1990). How Do You Enter "D'AnziQuist" Using a Telephone Keypad?, Proceedings of the Human Factors Society 34th Annual Meeting, Santa Monica, CA: The Human Factors Society, 208-211.

110 Detweiler, M.C., and Schmacher, R.M., Jr., (1990). "Alphabetic Input on a Telephone Keypad," Proceedings of the Human Factors Society 34th Annual Meeting, Santa Monica, CA: The Human Factors Society, pp. 212-216.

111 Coleman, M.F., Loring, B.A., and Wiklund, M.E. (1991). "User Performance on Typing Tasks Involving Reduced-Size, Touch Screen Keyboards," Vehicle Navigation and Information Systems Conference Proceedings (VNIS'91), New York, NY: IEEE, pp. 534-549.

112 Dudek, C.L., Huchingson, R.D., Stockton, W.R., Koppa, R.J., Richards, S.H., and Mast, T.M. (1978). Human Factors Requirements for Real-Time Motorist Information Displays Volume 1 - Design Guide (Technical Report FHWA-RD-78-5), Washington, D.C.: Federal Highway Administration. 
113 Hoekstra, E., Williams, M., Green, P., and Paelke, G. (1992). Usability of Text, Graphic, and Video In-Car Traffic Information for Diversion Decisions (Technical Report UMTRI-92-40), Ann Arbor, MI: The University of Michigan Transportation Research Institute.

114 Hanson, B.L., and Bronell, C.E. (1979). "Human Factors Evaluation of Calling Procedures for the Advanced Mobile Phone System (AMPS)," IEEE Transactions on Vehicular Technology, May, VT-28(2), 126-131.

115 Walker, J.T. (1978). "Mobile Telephone Control Unit Design Guidelines for the Advanced Mobile Phone Service," IEEE Transactions on Vehicular Technology, VT 27(4), 276-281.

116 Serafin, C., Wen, C., Paelke, G., and Green, P. (1993). "Car Phone Usability: A Human Factors Test, "Proceedings of the Human Factors and Ergonomics Society 37th Annual Meeting, Santa Monica, CA: The Human Factors and Ergonomics Society, pp. 220-224.

117 Karnes, A.J. (1978). "A Study of the Effects of Mobile Telephone Use and Control Unit Design on Driving Performance," IEEE Transactions on Vehicular Technology, November, VT-27(4), 282-287.

118 Baber, C., and Wankling, J. (1992). "An Experimental Comparison of Text and Symbols for In-Car Reconfigurable Displays," Applied Ergonomics, 23(4), 255-262.

119 Green, P., and Burgess, W.T. (1980). Debugging a Symbol Set for Identifying Displays: Production and Screening Studies (Technical Report UM-HSRI-80-64), Ann Arbor, MI: The University of Michigan Transportation Research Institute.

120 Green, P. (1981). "Displays for Automotive Instrument Panels: Production and Rating of Symbols," HSRI Research Review, 12(1), 1-12.

121 Miller, D.P. (1980). Factors Affecting Item Acquisition Performance in Hierarchical Systems: Depth Vs. Breadth (unpublished Ph.D. dissertation), Columbus, OH: Ohio State University.

122 Miller, D.P. (1981). "The Depth/Breadth Tradeoff in Hierarchical Computer Menus," Proceedings of the Human Factors Society-25th Annual Meeting, Santa Monica, CA: The Human Factors Society, 296-300.

123 Landauer, T.K., and Nachbar, D.W. (1985). "Selection from Alphabethic and Numeric Menu Trees Using a Touch Screen: Breadth, Depth, and Width," CHI'85 Proceedings, New York, NY: Association for Computing Machinery, pp. 73-78.

124 Normal, K.L. (1991). The Psychology of Menu Selection, Norwood, NJ: Ablex. 
